\title{
I. Entstehung, Organisation, Zusammensetzung und Aufgaben der sowjetischen Partisanenbewegung in der Oblast' Baranoviči
}

\section{Einleitung}

Wie oben geschildert, unternahm die sowjetische Parteiführung frühzeitig Versuche, eine breite Partisanenbewegung in den besetzten Gebieten zu organisieren. Allerdings konnten sowjetische Stellen in den Territorien, die die Wehrmacht bereits in den ersten Kriegstagen eroberte, in dieser Hinsicht wenig unternehmen. Die Überraschung war zu groß und die Zeit zu knapp, so liegen keine Hinweise darauf vor, daß beispielsweise in der Oblast' Baranoviči Partisanengruppen oder -abteilungen zur Organisation und Durchführung des Partisanenkampfes zurückgelassen worden wären. Die Anfänge der sowjetischen Partisanenbewegung in der Oblast' gehen vielmehr auf spontane Aktivitäten von versprengten Rotarmisten oder von den deutschen Truppen überrollte sowjetische Aktivisten zurück, die deutsche Repressionen fürchteten.

Die ersten Partisanengruppen in der Oblast' Baranoviči bildeten sich im Sommer und Herbst 1941. Es handelte sich dabei um kleine "Überlebensgruppen" in den Rajons Radun', Ščučin und Vasiliški. Sie setzten sich aus vostočniki und okružency zusammen. Vostočniki waren Angehörige des sowjetischen Apparates, die nach 1939 aus der Sowjetunion in die besetzten Gebiete kamen und im Sommer 1941 von der Wehrmacht überrollt worden waren. Okružency waren versprengte Soldaten der Roten Armee aus den Schlachten des Sommers 1941, die nicht in Gefangenschaft geraten waren und sich im feindlichen Hinterland aufhielten. Die meisten von ihnen suchten Zuflucht in abgelegenen Dörfern und kleinen Siedlungen (chutory), wo sie sich als Landarbeiter verdingten. Die Gruppen waren klein und instabil im Hinblick auf ihre Zusammensetzung. Ihre Mitglieder schlossen sich zusammen, um der deutschen Verfolgung zu entgehen, und nicht um militärische Aktionen gegen die deutschen Besatzer zu führen.

Die Situation änderte sich im Winter 1941/1942, als deutsche Behörden die Registrierung aller Ortsfremden in der Oblast' anordneten. Diejenigen die sich meldeten, wurden ins Reich zur Zwangsarbeit verschickt oder in KZs inhaftiert. Die anderen, die den deutschen Behörden mißtrauten, gingen in die Wälder. So führten die Maßnahmen der deutschen Behörden dazu, daß sich im Frühjahr 1942 neue Partisanengruppen und -abteilungen bildeten, die bald die größten Waldgebiete der Oblast' - den Naliboki-Wald und den Lipčanskij-Wald - beherrschten. ${ }^{1}$ Diese

1 In einem Bericht der „Korweta“, einer Abteilung im Stab der Heimatarmee, die die Aktivi- 
Gruppen unterschieden sich von den „Überlebensgruppen“, die im Sommer 1941 entstanden waren, u.a. dadurch, daß sie sich vor allem aus ehemaligen Soldaten (okružency und entflohenen Kriegsgefangenen) zusammensetzten. Alle diese Gruppen operierten nicht einheitlich und hatten keinen Kontakt mit den zuständigen Stellen auf der sowjetischen Seite.

Im August 1942 bildete der Fallschirmspringer Vasilij Ščurbina (Deckname „Dima“) einen Sonderverband der Partisanenabteilungen, der die Oblasten Baranoviči, Minsk und Vilejka umfaßen sollte. Dieser Verband hatte die Aufgabe, in der Region die Aufklärungs- und Diversionstätigkeit zu koordinieren. Ščurbina gelang es, die meisten Gruppen, die in den Waldgebieten Lipčański und Naliboki operierten, seiner Führung zu unterstellen. Er sprach sich gegen die Bildung von großen Partisanenabteilungen aus und betrachtete es als seine Hauptaufgabe, Aufklärungs- und Diversionstätigkeit durchzuführen. Ščurbina kam jedoch bald ums Leben, und der Versuch, alle Partisanengruppen in einem Verband unter einheitlicher Führung zu vereinigen, scheiterte. Im Juli 1943 wurde dieser dann offiziell aufgelöst. ${ }^{2}$

Der im September 1942 gebildete Weißrussische Stab der Partisanenbewegung (BŠPD) bemühte sich von Anfang an, Verbindung mit den in der Oblast' Baranoviči operierenden Partisanenabteilungen aufzunehmen. Auch Anführer der einzelnen Abteilungen unternahmen ihrerseits Versuche, Kontakt mit den zuständigen Stellen auf der sowjetischen Seite herzustellen. Um dies zu erreichen, versuchten einige von ihnen, die Frontlinie zu überschreiten. Trotz der beiderseitigen Anstrengungen bestand lange Zeit keine reguläre Verbindung zwischen Abteilungen, die im NalibokiWald stationiert waren, und dem BŠPD. Folglich operierten die sowjetischen Partisanenabteilungen in der Oblast' unkoordiniert. Sie erhielten weder konkrete Anweisungen hinsichtlich ihrer Aufgaben noch Unterstützung seitens der zuständigen Stellen, die sich in den nicht besetzten Teilen der UdSSR befanden.

Im Frühjahr 1943 fiel in Moskau die Entscheidung, Partisanenführer und Parteifunktionäre in die Oblast' Baranoviči abzukommandieren. Dies geschah auf der Grundlage der Direktiven des V. Plenums des ZK der KP(b)B vom 27. und 28. Februar 1943. Im April 1943 traf General Major Vasilij Černyšev im Naliboki-Wald ein. Er trug den Decknamen „Platon“ und vereinigte in einer Person die Positionen des Sekretärs des Untergrundkomitees der KP(b)B für die Oblast' Baranoviči, des Bevollmächtigten des Zentralen Stabes der Partisanenbewegung (CŠPD) und des ZK der KP(b)B sowie des Befehlshabers des Partisanenverbandes Baranoviči. „Platon" wurde von anderen Parteifunktionären des Oblastkomitees begleitet. ${ }^{3}$

Nach der Ankunft teilte „Platon“ mit seinem Stab die Oblast' in Vereinigte Rajon-Zentren auf. Ein vereinigtes Rajonzentrum war eine Organisationsstufe zwi-

täten der Kommunisten verfolgte, für den Monat Oktober 1942 heißt es: „In der Gegend um Baranowicze befinden sich manche Dörfer und Gemeinden in den Händen von Partisanen. Starke Partisanenbewegung. " Archiwum Akt Nowych, Warschau (künftig: AAN), MF 423, Bl. 212.

2 Sonderverband der Partisanenabteilungen, in: Ëncyklapdyja historyi Belarusi, Minsk 1993, Bd. 1, S. 218.

3 Das Oblastkomitee Baranoviči im Untergrund, in: Belarus u Vjalikaj Ajčynnaj Vajne 1941-1945, S. 60. 
schen Oblast' und Rajon. Es gab sechs solcher Zentren in der Oblast' Baranoviči: Byten', Ivenec, Lida, Slonim, Stolbcy und Ščučin. Byten' und Ivenec wurden Ende 1943 aufgelöst. Die Vereinigten Rajon-Zentren wurden von Bevollmächtigten des $\mathrm{ZK}$ der $\mathrm{KP}(\mathrm{b}) \mathrm{B}$ und des $\mathrm{CŠPD}$ geleitet, die zugleich alle Partisanenabteilungen und -brigaden befehligten, welche auf dem jeweiligen Territorium operierten und die in vereinigten Rajon-Verbänden zusammengefaßt wurden. Die vereinigten Rajon-Verbände der Oblast' Baranoviči hatten Befehlsstäbe, deren Aufgabe darin bestand, militärischen Kampf, Diversions- und Sabotageaktivitäten, Aufklärung sowie Propaganda zu koordinieren und zu leiten.

Parallel zu diesen Strukturen entstanden Untergrundorgane der KP(b)B. Im Mai 1944 gab es in den 22 Rajons der Oblast' Baranoviči Partei- und Komsomol-Organisationen, die insgesamt 1568 Parteimitglieder und 3535 Komsomolzen zählten. ${ }^{4}$ Es ist jedoch anzumerken, daß die Untergrundorgane der Partei organisatorisch sehr schwach in ihren jeweiligen Operationsgebieten verankert waren. So hielten sich die meisten ihrer Mitglieder wie auch die Rajon-Sekretäre in Partisanenlagern auf.

General „Platon“ übernahm die Führung der bereits existierenden sowjetischen Partisanenabteilungen und -brigaden und begann zugleich, neue zu bilden. Anfang Juli 1944 soll der Verband von General „Platon“ und der Süd-Zone 24992 Partisanen gezählt haben. ${ }^{6}$ Hinzu kam der Verband Białystok des General Filip Kapusta mit mehreren Tausend Partisanen, die im Lipčanskij Wald ihre Basis hatten. Somit war die Oblast' Baranoviči im westlichen Weißrußland am dichtesten mit sowjetischen Partisanen durchsetzt. In der Oblast' Vilejka gab es zur gleichen Zeit 13012 sowjetische Partisanen, in Białystok 5079, in Brest 14899 und in Pinsk 8962.7

Über die ethnische Zusammensetzung der sowjetischen Partisanenbewegung in der Oblast' Baranoviči sind nur fragmentarische Erhebungen überliefert. Sicher ist jedoch, daß Weißrussen und Russen deutlich überwogen. Nach unvollständigen Angaben vom 1. Oktober 1943 - von insgesamt 62 wurden 48 Abteilungen berücksichtigt - befanden sich unter den 8795 Partisanen 5203 (59\%) Weißrussen, 2338 (26,5\%) Russen, 713 (8,1\%) Juden, 386 (4,4\%) Ukrainer, 34 (0,4\%) Polen und 122 $(1,6 \%)$ Angehörige anderer Nationalitäten. Aus den Einheimischen rekrutierten sich 5561 (63,2\%) Partisanen, 1224 (13,9\%) waren okružency, 1403 (15,9\%) entflohene Kriegsgefangene, 385 (4,3\%) waren durch das ZK der KP(b)B abkommandiert, für den Rest gibt es keine Angaben. Der Anteil der Frauen betrug 8,3\% (734). ${ }^{8}$

4 Aktennotiz von V. Černyšev über den Stand der Partisanenbewegung und des Partei- und Komsomoluntergrundes in den nördlichen Rajons der Oblast' Baranoviči zum 15. 5. 1944: NARB, f. 4p, op. 33a, d. 252, 1. 234.

5 Die Süd-Zone der Oblast' Baranoviči umfaßte die Rajons der Oblast', die südlich der Bahnlinie Minsk - Brest lagen. Der Partisanenverband der Süd-Zone wurde im Herbst 1943 gebildet und von Fedor Baranov befehligt. Anfang Juli 1944 zählte dieser Verband 2400 Partisanen.

6 Bericht des BŠPD über die Auflösung der Partisanenabteilungen und -brigaden in Weißrußland vom September 1944: NARB, f. 3500, op. 2, d. 1426, 1. 19.

7 Ebenda, 1. 20.

8 Bericht über die Zusammensetzung des Untergrundes und der Partisanenbewegung in der Oblast' Baranoviči nach dem Stand vom 1. 10. 1943, unvollständige Angaben: NARB, f. 1329, op. 1, d. 8, 11. 1-15. 
Nach der ebenfalls unvollständigen Zusammenstellung vom 1. Juli 1944 - von 22 wurden nur 15 Brigaden und eine selbständige Abteilung berücksichtigt - waren unter den 11193 Partisanen 6792 (60,7\%) Weißrussen, 2598 (23,2\%) Russen, 973 (8,7\%) Juden, $526(4,7 \%)$ Ukrainer, $143(1,3 \%)$ Polen und $161(1,4 \%)$ andere. Darunter befanden sich 7203 (64\%) Einheimische, 817 (7\%) okružency, 2944 (26\%) ehemalige Kriegsgefangene, Abkommandierte 69 (0,6\%), der Rest ohne Angaben. Der Anteil der Frauen betrug 10,4\% (1162). ${ }^{9}$

Nicht alle Partisanen schlossen sich ihren Abteilungen freiwillig an. Vielmehr sind Tausende von ihnen per Einberufungsbefehl ${ }^{10}$ oder auf mündliche Anordnung zwangsrekrutiert worden. Beispielsweise befahl am 25. Februar 1944 der Kommandeur des Verbandes des Vereinigten Rajonzentrums Ščučin, alle Männer der Jahrgänge 1918 bis 1925 zum Dienst in den Partisanenabteilungen zu rekrutieren. ${ }^{11} \mathrm{Die}$ Brigade „Frunze“, die im Winter 1942/43 formiert worden war, bestand überwiegend aus Partisanen, die rekrutiert worden waren. ${ }^{12}$

Es sei hierbei angemerkt, daß weißrussische Partisanen der Oblast' Baranoviči teilweise aus den östlichen Gebieten Weißrußlands stammten. Die Partisanen russischer Herkunft rekrutierten sich vor allem aus ehemaligen Soldaten der Roten Armee (okružency und entflohene Kriegsgefangene). ${ }^{13}$ Auffallend ist der niedrige Prozentsatz der Partisanen polnischer Herkunft, obwohl die Polen die zweitstärkste ethnische Gruppe in der Oblast' darstellten. Sie gehörten jedoch in der Regel der polnischen Untergrundbewegung an. ${ }^{14}$

Die ersten sowjetischen Partisanengruppen in der Oblast' Baranoviči waren keine regulären Abteilungen. Ihre Zusammensetzung fluktuierte stark, ihre Tätigkeit war unkoordiniert, Anführer wurden in Versammlungen gewählt. Ab Sommer 1942 wurde die Organisationsstruktur differenzierter. In den einzelnen Abteilungen schuf man die Stellen des Kommandeurs, Stabschefs und Kommissars. Im Herbst 1942 begann man, die einzelnen Abteilungen in Kompanien, Züge und Gruppen zu unterteilen. Mit der Zeit entstanden bei den Einheiten spezielle Gruppen für Logistik, Aufklärung, Nachrichten-, Sanitäts- und Abwehrdienst. Im Herbst 1942 wurde damit begonnen, die einzelnen Abteilungen zu Partisanenbrigaden zusammenzuschließen. Die Brigade als Organisationseinheit dominierte bald in der Oblast'.

Eine Brigade setzte sich aus drei bis neun Abteilungen zusammen und hatte keine fest vorgeschriebene Sollstärke. Die Brigaden zählten meist 300 bis 1000 Partisanen und nur manchmal über 1000. Die Brigaden waren in der Regel nicht zentral stationiert, sondern einzelne Abteilungen verfügten über eigene Lagerplätze. Die Verbin-

9 Bericht über die Zusammensetzung der Partisanenbrigaden und -abteilungen in der Oblast' Baranoviči nach dem Stand vom 1. 7. 1944: NARB, f. 1329, op. 1, d. 17, 11. 5-9.

10 Siehe Dokument 2 in diesem Kapitel.

11 Befehl Nr. 9 des Bevollmächtigten des ZK der KP(b)B und des BŠPD an Vereinigtes RajonZentrum Šččyn vom 25. 2. 1944: NARB, f. 1329, op. 1, d. 82, 1. 59.

12 Meldung über den Zustand der Brigade „Frunze“, Dubov, 3. 6. 1943: NARB, f. 1329, op. 1, d. $32,1.10$.

13 Zygmunt Boradyn, Niemen rzeka niezgody. Polsko-sowiecka wojna partyzancka na Nowogródczyźnie 1943-1944, Warszawa 1999, S. 28, 71-74.

14 Siehe Kapitel V. 
dung zwischen Abteilungen und Brigaden hielten Melder aufrecht, die sich zu Pferd oder zu Fuß fortbewegten.

$\mathrm{Ab}$ Sommer 1942 wirkte in den Brigaden und Abteilungen je eine Sonderabteilung (osobyj otdel, abgekürzt: OO), eine Zelle des NKVD und ab April 1943 des NKGB (Volkskommissariats für Staatssicherheit). ${ }^{15}$ Auf der Ebene des Vereinigten Rajonzentrums leitete der Beauftragte des Bevollmächtigten des ZK der KP(b)B und des BŠPD für operativ-tschekistische Angelegenheiten die Aktivitäten der Sonderabteilungen. Dieser war wiederum dem Oberst der Staatssicherheit Dmitrij Armjaninov, genannt „Donskoj“, unterstellt. „Donskoj“ unterstand direkt dem Volkskommissar der Staatssicherheit der BSSR Lavrentij Canava. ${ }^{16}$ Funktionäre der Staatssicherheit befehligten die NKVD - NKGB Sonderabteilungen, sie verfügten über separate Funkverbindungen mit ihren vorgesetzten Stellen und wurden mit Waffen, Munition sowie sonstiger Ausrüstung auf dem Luftweg gesondert beliefert.

Zu den Aufgaben der NKVD - NKGB Strukturen innerhalb der Partisanenbewegung gehörten: die Aufdeckung feindlicher Spione und Agenten, der Aufbau des Agentennetzes, die Bekämpfung von Fahnenflucht und Plünderungen, die Kontrolle der politischen Situation in den Abteilungen und im jeweiligen Operationsgebiet, die Durchführung von Verhaftungen und Ermittlungen, das Fällen und die Vollstreckung von Urteilen, die Anfertigung von Listen mit „antisowjetischen Elementen" sowie deren Verfolgung. ${ }^{17}$ Die Listen sollten dem sowjetischen Sicherheitsapparat nach dem Einmarsch der Roten Armee die systematische Eliminierung von „antisowjetischen Elementen“ ermöglichen. Auf den Gebieten, die von sowjetischen Partisanen kontrolliert wurden, spielten die Sonderabteilungen offen die Rolle der politischen Polizei, welche die nicht prosowjetische Zivilbevölkerung verfolgte.

In jeder Brigade und jeder Abteilung verfügte der stellvertretende Kommandeur für Aufklärungsangelegenheiten über einen Reiterzug bzw. eine Reitergruppe, dessen/deren Angehörige während des Vormarsches der Einheit das Terrain erkundeten. Eine wichtige Rolle beim Sammeln von Informationen spielten Agenten. Das Agentennetz des Verbandes Baranoviči zählte im Frühjahr 1944 etwa 2000 Agenten und Informanten. ${ }^{18}$

Der Partisanenverband Baranoviči wies im Jahre 1944 eine beachtliche Feuerstärke auf. Nach dem Stand vom Mai 1944 verfügten die 20 Brigaden und zwei selbständige Abteilungen des Verbandes mit 15101 Partisanen über 8689 Gewehre und 1115 automatische Gewehre, 609 leichte und 47 schwere Maschinengewehre, 1208 Maschinenpistolen und 2843 Pistolen und Revolver, 54 Granaten- und Minenwer-

15 Die Sonderabteilungen wurden ab Januar 1942 zunächst bei einzelnen Partisaneneinheiten gebildet; mehr dazu: Aleksej Popov: NKVD i partizanskoe dviženie. Moskau 2003, S. 138-159.

16 Lavrentij Canava (1900-1955), Volkskommissar der Staatssicherheit der BSSR, wurde im Jahre 1953 verhaftet und 1955 erschossen.

17 Richtlinien für die Tätigkeit der Sonderorgane im feindlichen Hinterland, ohne Datum: NARB, f. 3604, op.1, d.9, 1. 2.

$18 \mathrm{Vgl}$. Zygmunt Boradyn, Wydziały specjalne baranowickiego zgrupowania partyzantki sowieckiej przeciwko AK, in: Zbrodnie NKWD na ludności województw wschodnich RP, Koszalin 1995, S. 203. 
fer, zehn leichte Geschütze $45 \mathrm{~mm}$ und zwei Kanonen $76 \mathrm{~mm} .{ }^{19}$ Dies bedeutete aber zugleich, daß ein Teil der Partisanen - mindestens 524 - unbewaffnet war.

19 Angaben über Bewaffnung der Partisanenbrigaden und -abteilungen in der Oblast' Baranoviči nach dem Stand vom Mai 1944: NARB , f. 1329, op.1, d.17, 1l. 5-9. 


\title{
Dokumente
}

\author{
Dokument Nr. 1
}

\begin{abstract}
Anordnung über die Arbeit der Bevollmächtigten des ZK der KP(b) auf dem zeitweilig besetzten Territorium der BSSR" (zweite Jahreshälfte 1942)
\end{abstract}

\section{Streng gebeim}

\section{Anordnung}

Über die Arbeit der Bevollmächtigten des $Z K$ der KP(b) Belorußlands für Oblasten, Städte und Rajons auf dem zeitweilig okkupierten Territorium der BSSR

Zur Organisation des Kampfes des ganzen werktätigen Volkes von Belorußland gegen die deutschen Okkupanten, Erweiterung der Partisanenbewegung und Leitung der Kampftätigkeit der Partisanenabteilungen, Durchführung der politischen Parteiarbeit im gegnerischen Hinterland, Entfaltung der Diversions- und Aufklärungsarbeit in den Rajons, Städten und Oblasten der BSSR werden die Institutionen der Bevollmächtigten des ZK der KP(b) Belorußlands, des Oblastbevollmächtigten des ZK der $\mathrm{KP}(\mathrm{b}) \mathrm{B}$, des Stadtbevollmächtigten des $\mathrm{ZK}$ der $\mathrm{KP}(\mathrm{b}) \mathrm{B}$ und des Rajonbevollmächtigten des $\mathrm{ZK}$ der $\mathrm{KP}(\mathrm{b}) \mathrm{B}$ eingeführt.

Die Rechte und Pflichten der Bevollmächtigten des ZK der KP(b)B werden durch die vorliegende Anordnung festgelegt.

I. Der Oblastbevollmächtigte des ZK der KP(b) Belorußlands.

1. Der Oblastbevollmächtigte des ZK der $\mathrm{KP}(\mathrm{b})$ wird durch das $\mathrm{ZK}$ der $\mathrm{KP}(\mathrm{b}) \mathrm{Be}-$ lorußlands ernannt und löst im Namen des ZK der KP(b)B persönlich alle Fragen der Partisanenbewegung und der der illegalen Parteiarbeit auf dem ganzen Territorium der Oblaste. Seine Direktiven und Weisungen sind für alle in der Illegalität befindlichen Kommunisten und Komsomolzen und für die Kommandeurs- und Politkader der Partisanenbrigaden, -abteilungen, -diversions- und -aufklärungsgruppen auf dem Territorium der jeweiligen Oblast' bindend.

2. In seiner Arbeit ist der Bevollmächtigte des $\mathrm{ZK}$ der $\mathrm{KP}(\mathrm{b}) \mathrm{B}$ nur dem $\mathrm{ZK}$ der $\mathrm{KP}(\mathrm{b})$ Belorußlands rechenschaftspflichtig. Als Hilfe für den Bevollmächtigten werden 3-4 Gehilfen ernannt, darunter ein Komsomolfunktionär mit den Rechten eines Oblastbevollmächtigten des ZK des Leninschen Kommunistischen Jugendverbandes Belorußlands (LKSMB). Die gesamte Arbeit des Bevollmächtigten und seiner Gehilfen wird strengstens geheimgehalten.

3. Beim Bevollmächtigten des $\mathrm{ZK}$ der $\mathrm{KP}(\mathrm{b}) \mathrm{B}$ besteht eine illegale Druckerei und

In den Dokumenten wird nicht der heute übliche Name Weißrußland, sondern die in der betreffenden Zeit übliche Bezeichnung Belorußland (daher auch „B“ als Abkürzung für „Belorussisch“" usw.) gebraucht. - Anm. d. Übers. 
wird eine illegale Zeitung für die Oblast' herausgegeben. Zwecks Verbindung mit dem ZK der KP(b) Belorußlands und dem Zentralstab der Partisanenbewegung wird dem Bevollmächtigten des ZK der KP(b)B ein Funkgerät zugeteilt. Die Dislozierung des Bevollmächtigten des $\mathrm{ZK}$ der $\mathrm{KP}(\mathrm{b}) \mathrm{B}$ wird speziell, je nach der Situation in der Oblast', festgelegt.

4. Die Hauptaufgaben bei der Arbeit des Oblastbevollmächtigten des ZK der $\mathrm{KP}(\mathrm{b}) \mathrm{B}$ bestehen in Folgendem:

a) den Befehl Nr. 00189 des Volkskommissars für Verteidigung der Union der SSR, Genossen STALIN, „Über die Aufgaben der Partisanenbewegung“, unbedingt zu vollziehen; ${ }^{20}$

b) den Kampf des belorussischen Volkes gegen die deutschen Okkupanten auf dem vom Feind zeitweilig besetzten Territorium politisch zu leiten und der Partisanenbewegung den Charakter einer Bewegung des ganzen Volkes zu verleihen, damit die Partisanenbewegung Sache aller und eines jeden wird, der in die Klauen der deutschen Räuber gerät, und die breitesten Massen des Sowjetvolkes auf dem besetztenTerritorium umfaßt;

c) geheime Kampfreserven der Partisanenbewegung in allen Städten, Dörfern und Ortschaften auf dem zeitweilig okkupierten Territorium zu schaffen und aus ihnen die bestehenden Partisanenabteilungen aufzufüllen bzw. neue zusätzlich zu formieren;

d) die Kampftätigkeit der Partisanenbrigaden, -abteilungen, -diversions- und -aufklärungsgruppen zu leiten, ihre Tätigkeit darauf auszurichten, daß sie die Nachschubwege versperren, das gegnerische Hinterland, seine Stäbe, Militärgarnisonen und andere Kampfeinrichtungen zerstören, seine Lager und Kasernen in Brand stecken und sprengen, die Mannschaften des Gegners töten, Vertreter der deutschen Behörden gefangennehmen oder töten;

e) die Aufklärungsarbeit im Interesse der Roten Armee zu organisieren und zu leiten;

f) die Arbeit der Rajon- und Stadtbevollmächtigten des ZK der KP(b)B sowie der Parteizellen in den Partisanenabteilungen, Betrieben und Ortschaften zu leiten und die Tätigkeit des Parteiuntergrunds dort, wo er infolge der entstandenen Lage gestört wurde, wiederherzustellen;

g) die Partei- und Komsomolfunktionäre zur Arbeit als Rajon- und Stadtbevollmächtigte des $\mathrm{ZK}$ der $\mathrm{KP}(\mathrm{b}) \mathrm{B}$ sowie als Organisations- und Leitungskader der Partisanenabteilungen und -brigaden auszuwählen;

h) die politische Massenarbeit der Partei auf dem okkupierten Territorium zu leiten, Zeitungen, Flugblätter und andere Druckerzeugnisse herauszugeben sowie ihre Verbreitung zu organisieren;

i) das $\mathrm{ZK}$ der $\mathrm{KP}(\mathrm{b})$ Belorußlands über die Lage im gegnerischen Hinterland und über Maßnahmen, die der Bevollmächtigte des ZK der KP(b)B zur Erweiterung der Partisanenbewegung trifft, $\mathrm{zu}$ informieren.

II. Der Rajonbevollmächtigte des ZK der KP(b)B.

1. Der Rajonbevollmächtigte des ZK der KP(b)B wird vom ZK der KP(b)B ernannt und löst im Namen des ZK der KP(b)B persönlich alle Fragen, die mit der Partisa-

20 Abgedruckt in: Partizanskoe dviženie v gody Velikoj Otečestvennoj Vojny 1941-1945 gg. Dokumenty i materialy, Moskva 1999. 
nenbewegung und der politischen Öffentlichkeitsarbeit im gegnerischen Hinterland auf dem Territorium seines Rajons verbunden sind. In seiner Arbeit ist er dem Oblastbevollmächtigten des $\mathrm{ZK}$ der $\mathrm{KP}(\mathrm{b}) \mathrm{B}$ und dem $\mathrm{ZK}$ der $\mathrm{KP}(\mathrm{b}) \mathrm{B}$ unterstellt. Als Hilfe für den Bevollmächtigten werden 2-3 Gehilfen ernannt, darunter ein Komsomolfunktionär mit den Rechten des Bevollmächtigten des ZK des LKSMB für den jeweiligen Rajon.

2. Die Direktiven und Weisungen des Rajonbevollmächtigten des ZK der KP(b)B sind für alle Kommunisten und Komsomolzen des betreffenden Rajons und für die Kommandeurs- und Politkader der Partisanenabteilungen und -diversionsgruppen, die sich auf dem Territorium des jeweiligen Rajons befinden, bindend.

3. Die Hauptaufgaben in der Arbeit des Rajonbevollmächtigten des ZK der KP(b)B bestehen in Folgendem:

a) den Befehl Nr. 00189 des Volkskommissars für Verteidigung der Union der SSR, Genossen STALIN, „Über die Aufgaben der Partisanenbewegung“, unbedingt zu vollziehen;

b) die Kampftätigkeit der Partisanenabteilung und Diversionsgruppen, die sich im jeweiligen Rajon befinden, zu leiten;

c) die Arbeit an der Bildung bewährter Kampfreserven der Partisanenbewegung in den Ortschaften des Rajons sowie die praktische Tätigkeit zur Auffüllung der bestehenden bzw. Aufstellung neuer Partisanenabteilungen und -diversionsgruppen zu entfalten;

d) die Aufklärungsarbeit im Interesse der Roten Armee zu organisieren;

e) die illegalen Parteizellen in den Partisanenabteilungen und den Ortschaften und Betrieben zu leiten, neue Parteizellen zu bilden, die Aufnahme von Mitgliedern und Kandidaten der Partei zu bestätigen;

f) die parteipolitische Massenarbeit auf dem zeitweilig okkupierten Territorium zu entfalten, die Lügenpropaganda zu enthüllen und zum Hass und Erbitterung gegenüber den deutschen Besatzern zu erziehen;

g) die Verbreitung von illegalen Zeitungen, Flugblättern und anderen Druckerzeugnissen zu organisieren;

h) den Oblastbevollmächtigten des ZK der KP(b)B und unmittelbar das ZK der $K P(b) B$ über die Lage im Rajon und die eigene Tätigkeit zu informieren.

III. Der Stadtbevollmächtigte des ZK der KP(b)B.

1. Der Stadtbevollmächtigte des ZK der KP(b)B wird vom ZK der KP(b)B ernannt und löst im Namen des ZK der KP(b)B persönlich alle Fragen, die mit dem Kampf des Sowjetvolkes gegen die deutschen Okkupanten verbunden sind. Seine Direktiven und Weisungen sind für alle Kommunisten und Komsomolzen der jeweiligen Stadt bindend.

2. In seiner Arbeit ist er dem Oblastbevollmächtigten des $\mathrm{ZK}$ der $\mathrm{KP}(\mathrm{b}) \mathrm{B}$ und dem $\mathrm{ZK}$ der $\mathrm{KP}(\mathrm{b}) \mathrm{B}$ rechenschaftspflichtig. Als Hilfe für den Bevollmächtigten werden 2-3 Gehilfen ernannt, darunter ein Komsomolfunktionär. Beim Bevollmächtigten besteht eine illegale Druckerei für die Herausgabe von Flugblättern, Aufrufen und anderen Druckerzeugnissen. Zur Verbindung mit dem ZK der $\mathrm{KP}(\mathrm{b}) \mathrm{B}$ und dem Zentralstab der Partisanenbewegung wird dem Bevollmächtigten des ZK der $\mathrm{KP}(\mathrm{b}) \mathrm{B}$ ein Funkgerät zugeteilt.

3. Die Hauptaufgaben in der Arbeit des Stadtbevollmächtigten des ZK der KP(b)B bestehen in Folgendem: 
a) den Befehl Nr. 00189 des Volkskommissars für Verteidigung der Union der SSR, Genossen STALIN, „Über die Aufgaben der Partisanenbewegung“, unbedingt zu vollziehen;

b) die Aufklärungs- und Diversionsarbeit in der Stadt breit zu entfalten;

c) zur schonungsloser Ausrottung und Gefangennahme faschistischer Politiker, Generale, hoher Beamter sowie von Vaterlandsverrätern, die im Dienste des Feindes stehen, terroristische Gruppen zu bilden;

d) Leute auszuwählen und sie in die von den Deutschen eingerichteten örtlichen Verwaltungen und Behörden, in Betriebe, Lager und sonstige Objekte der deutscher Armee oder die der örtlichen Verwaltung einzuschleusen, damit sie eine verdeckte Aufklärungsarbeit leisten und Diversion verüben;

e) die Schaffung geprüfter Partisanenreserven, die alle ehrlichen Bürger und Bürgerinnen, die sich vom deutschen Joch befreien wollen, einschließen;

f) der Leitung der bestehenden illegalen Parteizellen und der Organisation neuer in den Betrieben, die von den Deutschen bei den Verwaltungen belassen worden sind sowie die Bestätigung der Aufnahme von Mitgliedern und Kandidaten der Partei; g) die parteipolitische Massenarbeit in der Stadt zu entfalten, die deutsche Lügenpropaganda zu enthüllen und zum $\mathrm{Haß}$ und zur Erbitterung gegenüber den deutschen Besatzern zu erziehen;

h) die Verbreitung von illegalen Zeitungen, Flugblättern und anderen Druckerzeugnissen zu organisieren;

i) den Oblastbevollmächtigten des $\mathrm{ZK}$ der $\mathrm{KP}(\mathrm{b}) \mathrm{B}$ und unmittelbar das $\mathrm{ZK}$ der $\mathrm{KP}(\mathrm{b}) \mathrm{B}$ zu informieren.

F. 4p, op. 33a, d. 215, 11. 26-29.

\section{Dokument Nr. 2}

\section{Befehl des Kommandeurs der Partisanenabteilung Denisenko über die Mobilmachung [September 1942].}

Befehl Nr. 322

Aufgrund der Befehle des Volkskommissars für Verteidigung, des Feldherrn und Führers der Völker der UdSSR, Leiters der bolschewistischen Partei und der Sowjetregierung Genossen STALIN!!!

\section{BEFEHLE ICH!!!}

Zum Entscheidungskampf gegen die faschistischen Hunde Hitlerdeutschlands, zur Verteidigung unserer Heimat sind folgende Genossen Bewohner des Dorfes Novoe Selo zu rekrutieren und in die Partisanenabteilungen aufzunehmen:

Sinica, Pavel Sacharovič,

Čeredoilo, Sergej Nikolaevič,

Keda, Vladimir Antonovič,

Keda, Nikolaj.

Im Falle der Weigerung der oben genannten Genossen, zu den Partisanen zu stoßen, oder im Falle ihrer Flucht aus der Abteilung sind sie als Verräter und Helfershelfer 
der deutschen Besatzer, als Vaterlandsverräter zu betrachten, wofür jeder von ihnen eine harte Bestrafung durch die Partisanenbewegung zu gewärtigen hat.

Jeder solche Mensch wird als Hitlerscher Hund erschossen werden.

Für vollständige Zerschlagung der deutschen Besatzer!!!

Tod den deutschen Okkupanten!!!

Es lebe unsere rubmreiche Heimat, ibre Freibeit, Abteilungskommandeur (Denisenko)

[...] September 1942

F. 3500, op. 4, d. 263, 1. 327 .

\section{Dokument Nr. 3}

\section{Protokoll der Befragung von Kovjazin, Vassilij Filipovič, vom 21. September 1942 \\ Protokoll der Befragung von Kovjazin, Vassilij Filipovič}

Vom 21. September 1942

Stadt Torpec

KOVJAZIN, V. F., geb. 1919 im Dorf Bol’šaja Vladimirovka, Beskargaiskij Rajon, Oblast' Pavlodar, Kasachische SSR, in einer Familie von Mittelbauern, Russe, parteilos, Mittelschulbildung, nicht vorbestraft, bis 1939 Lehrer der Mittelschule im Dorf Bol’šaja Vladimirovka (seinem Geburtsort), 1939 in die RKKA einberufen, Dienst als Fahrer im 40. Reserve-Artillerieregiment in der Stadt Puškin (bei Leningrad), ab Mai 1940 Dienst als Fahrer (sowie als Schreiber) im 311., mit dem Rotbannerorden ausgezeichneten Artillerieregiment (in der BSSR, an der sowjetisch-deutschen Grenze im Ort Derečin, Oblast' Baranoviči). Zu Beginn des Sowjetisch-Deutschen Krieges wurde unser Regiment zerschlagen, Anfang Juli 1941 wurde ich bei Minsk gefangen genommen, befand mich in der Stadt Minsk in einem Kriegsgefangenenlager, dann in Stolbcy, ebenfalls in einem Kriegsgefangenenlager; im August 1941 wurde ich, als die Deutschen die Ukrainer aus den Lagern entließen, unter dem Namen Resničenko, Vassilij Fedotovič, ebenfalls aus den Lagern entlassen und ins ehem. Landgut im Dorf Burdeviči (Mirskij Rajon, Oblast' Baranoviči) zur Arbeit geschickt, wo ich bis März 1942 als Landarbeiter beschäftigt war. Um diese Zeit gingen ich und eine Reihe anderer Genossen daran, uns Waffen zu beschaffen, in der Hoffnung, mit Frühjahrsbeginn als Partisanen in die Wälder zu fliehen.

Im April 1942 organisierte ich eine Partisanenabteilung, die im Oblast' Baranoviči, Rajon Djatly, operierte.

FRAGE: Berichten Sie ausführlich über die Organisation, Tätigkeit, Bewaffnung und Zusammensetzung Ihrer Partisanenabteilung.

ANTWORT: Wie ich schon erzählte, arbeitete ich von August 1941 bis März 1942 im ehemal. Landgut im Dorf Burdeviči, Mirskij Rajon, Oblast’ Baranoviči. Früher 
gehörte dieses Gut einem Pan Buglak, heute gehört es unmittelbar den deutschen Behörden. Das Gut wird vom Polen Niewirovski, Józef, verwaltet. Er war auch bei Pan Buglak Verwalter gewesen.

Aus den Kriegsgefangenenlagern an der [Eisenbahn]station Stolbcy kamen wir auf dieses Gut im Bestand von 5 Personen: Ich, V. F. Kovjazin, Vassilij Cicharev (sein richtiger Name war Vassilij Viktorov, geb. 1918 im Dorf Peski, bei Stadt Vjasniki, Oblast' Ivanovo), Andrej Petrovič Kovjazin, geb. 1918 (wir beide sind Landsleute, stammen aus demselben Dorf), Kyrill Zibrovskij, geb. 1921, Ukrainer, der fünfte war Pavlo (den Familiennamen kenne ich nicht, er wurde 1917-1918 geboren).

Drei von uns - ich, V. F. Kovjazin, Viktorov und A. P. Kovjazin - waren immer zusammen, hatten die gleiche Meinung, strebten danach, uns zu bewaffnen, und wollten, sobald der Sommer kam, in den Wald gehen. Bei den örtlichen Bauern im Dorf Burdeviči beschafften wir uns zwei Revolver und ein leichtes Maschinengewehr, Marke Degtjarjov, dieses letztere hatten wir in der Erde, unter dem Schnee vergraben. Das war im März 1942. Hier kam es zu Folgendem: Als wir die Revolver schon an uns genommen hatten, das Maschinengewehr aber noch nicht, bemerkte ein örtlicher Bauer aus dem Dorf Dolmatovščina (seinen Familiennamen kenne ich nicht), wie wir nachts mehrmals aus dem Dorf Burdeviči nach Dolmatovščina gingen und das Pan Ludwig (wohnhaft im Dorf Dolmatovščina) meldete. Wir durften aber nicht von Dorf zu Dorf gehen, nachts schon gar nicht.

Im Dorf Dolmatovščina besuchten wir den Kriegsgefangenen Boris Nikitin, 28 Jahre alt, aus der Umgebung von Moskau, wir berieten uns mit ihm und handelten im gleichen Sinne.

Pan Ludwig nahm einen Polizisten und den oben erwähnten Bauer mit, und sie kamen nach Burdeviči. Dort bestellten sie Viktorov (ihn kannten sie, er hatte eine Zeitlang bei Ludwig gewohnt) zu Niewirovski, um ihn auszufragen, warum jemand nachts hin- und hergeht usw. Danach fuhren Pan Ludwig und der Bauer den Viktorov in die Polizei, ins Dorf Šuchoviči, der Polizist aber blieb bei Niewirovski zurück. Als sie losfuhren, setzte ich mich zu ihnen, angeblich um Viktorov zu begleiten. Unterwegs tötete ich Pan Ludwig und den Bauern. Wir kehrten ins Dorf Burdeviči zurück, ich lief schnell in meine Wohnung, nahm Andrej Kovjazin mit, und wir fuhren zu Boris Nikitin nach Dolmatovščina. Wir begaben uns alle vier in den Rajon Djatly, zu den Gehöften Gomony (unweit des Nakryševskij-Dorfsowjets). Unser Ziel waren die Wälder bei Slonim. In den Gehöften Zasenja (ehemal. Nakryševskij-Dorfsowjet, Rajon Djatly, Oblast' Baranoviči) fanden wir Zuflucht bei den örtlichen Bauern, bei Semen Zasenja, 40 Jahre alt (vielleicht auch älter). Anfang April 1942 kamen zu uns Vikentij Martynkevič, etwa 30 Jahre alt, Šmuksta, 56 Jahre alt, und Il'ja Panasevič, 30 Jahre alt. Sie waren sämtlich Bauern aus dieser Gegend, mit ihnen kam auch Nikolaj Lukomec, geb. 1920, Ukrainer, er war aus einer Einkreisung ausgebrochen. Šmuksta (ehemaliger Sowjetfunktionär, mit dem Anrücken der Deutschen hielt er sich verborgen) und Lukomec verbargen sich im Dorf Dem'janovcy (bei Orlja). Über Panasevič und seinen Dorfgenossen Martynkevič ging bei der Polizei eine Anzeige ein, daß sie Leute bei sich verborgen hielten und daß Panasevič bewaffnet war. Panasevič und Martynkevič wurden verhaftet und in der Polizei entweder in Orlja oder in Djatly (genau erinnere ich mich nicht) eingesperrt. Sie konnten von dort fliehen, fanden Smukst und Lukomec und kamen mit ihnen zusammen zu uns. Zu uns kamen sie deshalb, weil wir, als wir in Richtung auf 
die Wälder bei Slonim gingen, im Gehöft Zasenja haltgemacht hatten, und in der Bevölkerung ging das Gerücht um, wir seien Fallschirmjäger, und so nannten wir uns auch. Auf diese Weise waren wir im April schon acht Mann stark, Panasevič und andere, die zu uns gestoßen waren, brachten ein Maschinengewehr, eine Degtjarev-MPi und einen Stutzen mit.

Ende April zählte unsere Gruppe schon an die 20 Mann. Sie bestand aus ehemaligen Eingekreisten und örtlichen Bauern. Zum Abteilungskommandeur wurde ich, Vassilij Kovjazin, zum Gehilfen Nikolaj Vachonin, 28 Jahre alt, gewählt. Wir operierten im Gebiet des Flusses Ščara, des Ortes Orlja, des Ortes Dzencel und zum Teil bei der Station Ružanka.

Ende Mai 1942, als unsere Abteilung bis zu 30 Mann stark war, wählten wir Valentin Bit'ko, 25 Jahre alt, Komsomol-Mitglied, Leutnant der RKKA, ehemaliger Eingekreister, zum Stabschef.

Zum 30. Juli 1942, d.h. an dem Tag, da ich, V. F. Kovjazin, und Andrej Petrovič Kovjazin die Abteilung verließen, um Verbindung mit der Roten Armee oder mit der Leitung der Partisanenbewegung herzustellen, zählte unsere Abteilung 50 Mann, darunter waren zwei Kommunisten: Vladimir Doroš, ehemaliger örtlicher NKVD-Mitarbeiter, und Petr Belickij, ehemaliger Eingekreister.

Als ich gegangen war, übernahm Nikolaj Vachonin statt meiner die Pflichten des Abteilungskommandeurs. Die Bevölkerung nannte unsere Abteilung manchmal "Čapaev-Leute“.

An Waffen hatte die Abteilung: 7 Degtjarev-Maschinenpistolen, 7 leichte Degtjarev-Maschinengewehre, ein überschweres MG, Kaliber 12,7 mm, und 40 russische Gewehre.

Davon nahmen wir 2 Degtjarev-MP's mit (eines davon wurde an Pučkov, einen Abteilungskommandeur der Brigade Malyšev, das andere an Gen. Marčenko übergeben). In dieser Zeit vernichtete unsere Abteilung in Začepiči (bei Orlja) einen deutschen LKW, dabei wurden 9 deutsche Soldaten, ein Polizist und ein Dolmetscher getötet. In Začepiči wurde das Sägewerk, das Eisenbahnschwellen produzierte, in Brand gesteckt. Außerdem wurden ein PKW vernichtet (verbrannt) und mit ihm zwei Ingenieure und ein sie begleitender Polizist. Diese Ingenieure waren gekommen, um das Werk wiederaufzubauen.

Im Ort Rožanki verbrannten wir alle Dossiers der Polizei und töteten den Polizeikommandanten und 5 Polizisten. Ebenda zerstörten wir eine Molkerei. Unterwegs töteten wir damals noch drei deutsche Soldaten.

Im Ort Dikuški wurde die Molkerei zerstört, außerdem töteten wir zwei Polizisten, die den Betrieb bewachten.

Bei Orlja, im Dorf Soroki, töteten wir den Vorsitzenden der BNS (Belorussische Nationale Selbstverteidigung, seinen Familiennamen kenne ich nicht) von Ščučino. Ferner trieben wir die Dorfverwaltungen in Nakryški und Mironščina auseinander. Außerdem agitierten wir die Bevölkerung, forderten sie auf, den Deutschen kein Vieh, keine anderen Lebensmittel zu liefern und nicht zur Arbeit nach Deutschland auszureisen.

FRAGE: Berichten Sie über die Einstellung der Bevölkerung zu den Deutschen. ANTWORT: In Ihrer Mehrheit ist die Bevölkerung gegen die Deutschen und wartet auf das Heranrücken von Einheiten der Roten Armee. Die negative Einstellung 
der Bevölkerung zu den Deutschen ist durch die barbarische Behandlung der Bevölkerung durch die Deutschen bedingt. Wenn die Bauern einen Deutschen z.B. nicht grüßen, schlagen die Deutschen mit Gummiknüppeln auf die Bauern ein. Die Deutschen haben bei den Bauern viele Hausdurchsuchungen gemacht, ihnen gute Sachen weggenommen, sich Getreide und Vieh angeeignet. Kühe dürfen nur jene behalten, die eine mehr als vierköpfige Familie haben. Die Deutschen gaben einen Befehl heraus, gemäß dem Bauern, die weniger als zwei Hektar Boden haben, nach Deutschland abzutransportieren sind. In den Augen der Deutschen sind solche Bauern Faulenzer. Die Deutschen erlauben den Bauern nur Getreidevorräte für ein Jahr zu behalten, und zwar ausgehend von $9 \mathrm{~kg}$ je arbeitsfähige Person für einen Monat, wobei die Kinder nicht mit inbegriffen sind, das übrige Getreide ist den Deutschen abzuliefern. Hierbei drohen sie: Sollte bei jemandem mehr als diese Getreidenorm gefunden werden, werden die Betreffenden erschossen.

FRAGE: Welche Partisanenabteilungen, die in Westbelorußland operieren, kennen Sie?

ANTWORT: Im Raum des Dorfes Malaja Volja am Fluß Ščara operiert die Abteilung von Boris (den Familiennamen kenne ich nicht), er ist Oberleutnant der RKKA, ihm fehlt der linke Arm, man nennt seine Abteilung die vom armlosen Boris, sie ist 50 Mann stark.

Unweit der Abteilung von Boris, beim Dorf Javorskaja Ruda, operiert die Abteilung von Filip (den Familiennamen kenne ich nicht), er ist Leutnant der RKKA, 18 Mann stark.

Im Raum der Station Doržec operiert eine Partisanengruppe, aber von ihr weiß ich nichts. Habe nur gehört, daß es beim Dorf Ozerany zu einem Gefecht kam, in dem ein Polizist getötet worden ist, der dann in Djatlovo begraben wurde. Wer sonst getötet wurde, weiß ich nicht.

In den Wäldern, im Raum Ljubno - Lida - Grodno, operieren ebenfalls Partisanen. Einzelheiten kenne ich nicht. Habe gehört, daß dort die Abteilungen von Gromov und Matrosov waren. Wer sie sind, weiß ich nicht.

FRAGE: Gibt es Möglichkeiten, die Abteilungen an Ort und Stelle zu bewaffnen? ANTWORT: Die Abteilungen können sich nur auf Kosten der Polizei und der deutschen Garnisonen bewaffnen. Doch dazu ist es notwendig, die Abteilungen vor allem mit Granatwerfern und Granaten zu versorgen. Außerdem ist es notwendig, die Abteilungen zu vereinigen, einen erfahrenen und angesehenen Leiter hinzuschicken, und dann kann man im Kampf gegen die Deutschen große Erfolge erzielen.

Sprengstoffe sind an Ort und Stelle nicht zu beschaffen.

Im Raum Velikaja Volja gibt es zwei Dörfer, das eine heißt Krupicy, das andere fällt mir im Moment nicht ein. In diesen Dörfern gibt es einen schweren Panzer mit einer 45-mm-Kanone und einen Kleinpanzer. Der Panzer und der Kleinpanzer befinden sich bei den Bauern. Man kann sie schnell einsetzen, wenn Kraftstoff und Akkumulatoren beschafft werden. Außerdem befinden sich am Fluß Ščara, beim Dorf Velikaja Volja, ein Panzerwagen und drei schwere Panzer mit 45-mm-Kanonen. Ebendort, in der Nähe, in den Sümpfen stehen weitere zwei, drei Panzer. All diese Waffen können schnell in Stand gesetzt werden, aber dazu sind Fachkräfte und eine Reihe von Ersatzmotoren nötig. Ebendort, beim Dorf Vel.Volja, befinden sich an der Ščara zwei Haubitzen, aber da fehlen Verschlußteile, eine Luftpumpe und mehrere Ölpumpen sowie Druckmesser. 
Auch sonst werden Werkzeuge benötigt.

FRAGE: Nennen Sie die Quartiere der deutschen Garnisonen.

ANTWORT: Mir ist bekannt, daß eine 27 Mann starke deutsche Garnison im Ort Orlja liegt. Dort befinden sich auch etwa 30 Polizisten.

Im Ort Dzencel liegt eine bis zu 50 Mann starke deutsche Garnison. Die dortige Polizei zählt bis zu 20 Mann.

Deutsche Garnisonen liegen auch in folgenden Orten: Station Dvožec, Station Novoel'naja, Stadt Slonim, Station Zel'va, Stadt Volkovysk, Stadt Baranoviči, die zahlenmäßig nicht sehr stark sind und ständig ausgewechselt werden. An diesen Orten befindet sich auch Polizei.

Im allgemeinen sind die Garnisonen in kleineren Orten bis zu 50, in den Städten bis zu 200 Mann stark.

Am Fluß Zel'vjanka, angefangen von der Eisenbahnstrecke Volkovysk - Slonim, einschließlich Mal'koviči, Novoselki, Daškovicy, verläuft die Grenze Ostpreußens. Wie die Grenze an anderen Orten verläuft, weiß ich nicht. An den genannten Abschnitten sind deutsche Grenzwachen untergebracht.

FRAGE: Geben Sie den Marschweg an, auf dem Sie sich ostwärts bewegten, um die Verbindung mit der Leitung der Partisanenbewegung herzustellen.

ANTWORT: Wir zogen am 30. Juli 1942 aus und gingen auf der Strecke des Gehöfts Zasenja - Srednie Nakryški - durch den Wald in Richtung Venzovec - zur Station Dvožec (südlich von Dvožec, im Wald, überquerten wir die Eisenbahn) und marschierten auf Požeče zu (hier überquerten wir im Wald eine Chaussee), weiter gingen wir auf Cirin zu (dort fuhren wir über die Brücke über den Fluß Serveč', fuhren durch Cirin hindurch, dort gab es keine Polizei), Dolmatovščina - Koževo Radun (hier setzten wir über den Fluß Uta über) - Pesočno (hier überquerten wir eine Chaussee)- Pšyluki (hier besteht im Wald die Abteilung des Politleiters Grigorij) - im Wald auf Nalibockaja Pušča zu - südlich vom Dorf Derevno - Dorf Kul' Volma (im Wald trafen wir den Abteilungskommandeur Serebrjakov, einen Hauptmann, er gehört zur Abteilung Nikitin) - Station Zaslavl' (die Station Zaslavl' passierten wir nördlicher, näher an Zaslavl', zwischen Ščerbany - Zaslavl') - Kamenec (wir gingen zwischen Kurneviči und Kamenec) - Trusoniči - Chozenčice - Myšice - Kremenec - Drygla - Chateviči - im Walde, westlich des Dorfes Sloboda Dediloviči - Zareč'e - Nivki (hier überquerten wir eine Chaussee) - Brod (hier überquerten wir den Fluß Berezina über eine Brücke) - Krajcy - Nivki (auf der Straße) - Fedorki - Kadlubišče (in Pyšno liegen die Deutschen) - Ort Dol'cy - Sloboda - durch den Wald nach Ugolki - Ostrovljany - Abteilung Malyšev und dann abteilungsweise nach Bor.

Meist gingen wir durch den Wald und kleine Ortschaften, wobei wir Eisenbahnstrecken und Chausseen nachts oder in der Morgendämmerung überquerten.

Aufgrund meiner Aussagen richtig niedergeschrieben, von mir durchgelesen

(Kovjazin)

Die Befragung und Niederschrift

vom Mitarbeiter der operativen Gruppe

des NKVD für die Oblast' Vitebsk

Leutnant der Staatssicherheit

(Kirilov)

F. 3500, op. 4, d. 251, 11. 22-26. 


\section{Dokument Nr. 4}

\section{Meldung des Gehilfen des Kommandeurs der 125. Partisanenabteilung „I. V. Stalin“ über die Partisanenabteilungen auf einem Teil des Territoriums der Oblast' Baranoviči in der zweiten Jahreshälfte von 1942}

\section{An die Politische Verwaltung der Roten Armee}

Habe zu melden, daß sich in den Wäldern auf dem Territorium von Slonim bis Minsk viele Partisanenabteilungen und einzelne Partisanengruppen befinden. Die Abteilungen sind 30-150 Mann, die Gruppen 3-10 Mann stark. Eine allgemeine Leitung der Partisanenbewegung besteht nicht. In der Leitung einzelner Abteilungen und Gruppen sind Leute, die nicht in der Lage sind, die vor der Partisanenbewegung stehenden Aufgaben zu erfüllen.

Politische Arbeit wird in den Abteilungen beinahe nicht geleistet. Die Verbindung mit der Bevölkerung ist schlecht, daher auch die fehlende Massenarbeit. Gegen die Beschaffung von Lebensmitteln, die Durchführung anderer Maßnahmen, die Deportation zur Arbeit nach Deutschland, die Organisation von Polizeirevieren und Selbstverteidigungsgruppen wird in vielen Rajons und Siedlungen nichts unternommen. Die Polizisten und Mitglieder der Selbstverteidigungsgruppen werden zur wichtigsten Stütze des Faschismus im Kampf gegen die Partisanen.

Die meisten Partisanenabteilungen ernähren, kleiden und bewaffnen sich auf Kosten der örtlichen Bevölkerung und nicht mit Beute aus den Kämpfen gegen den Faschismus. Das erweckt in der Bevölkerung Unzufriedenheit, sie sagt: „Der Deutsche nimmt einem alles weg, und auch den Partisanen muß man etwas geben." Bei der Beschaffung von Lebensmitteln und Kleidungsstücken treten bei einzelnen Partisanenabteilungen Erscheinungen von Marodieren und Rowdytum auf.

Sie veranstalten Durchsuchungen und lassen Gegenstände, die die Abteilung nicht benötigt, mitgehen, die sich dann einzelne Personen aneignen. Beispiel: Oberpolitleiter (Staršyj politruk) Murašov, Kommissar der Partisanenabteilung „I. V. Stalin“. Das Fehlen einer allgemeinen Leitung hemmt eine breite Entfaltung der Partisanenbewegung in diesen Niederlassungen. Jede Abteilung handelt für sich. Aufgrund unvollständiger Angaben weiß ich, daß sich in diesen Wäldern etwa 15 Partisanenabteilungen, insgesamt 1500-2000 Mann stark, und zahlreiche einzelne Gruppen befinden, und wenn diese unter einer einheitlichen Leitung vereinigt würden, würden die 3000-4000 Personen eine große Kraft darstellen. All diese Abteilungen haben keine allgemeinen Weisungen bezüglich der Winterperiode.

Ich bitte um die Erteilung entsprechender Weisungen über die Leitung, die Formulierung der Aufgabe für jede einzelne Abteilung und die materielle Sicherstellung der Erfüllung dieser Aufgaben. Sprengmittel, Munition und Waffen.

10. 11.42

Gehilfe des Kommandeurs

der 125. Partisanenabteilung „I. V. Stalin“ Oberpolitleiter

Burcev, Nikita Nikanorovič

F. 4p, op. 33a, d. 169, 1. 25. 


\title{
Dokument Nr. 5
}

\section{Aufzeichnungen des Partisanen Je. D. Rudko aus der Brigade Nikitin (Sommer - Herbst 1942)}

Aufzeichnungen

\author{
des Partisanen E. D. Rudko aus der Brigade Nikitin \\ Meine Autobiografie
}

Im März 1921 meldete ich mich freiwillig zur RKKA und diente bis Kriegsbeginn, genauer, bis zur Gefangenschaft, in ihren Reihen. Beim Kriegsausbruch war ich in der Stadt Nesviž, Oblast' Baranoviči, Westbelorußland, in der 36. Panzerdivision, in der ich den Posten des Inspektors und Leiters des Versorgungsdienstes der Division hatte. In den ersten Kriegstagen trat die Division ins Gefecht bei Baranoviči ein, ohne vollständig auf den Krieg vorbereitet zu sein: Sie hatte weder die materiellen Mittel in vollem Umfang bekommen noch den kompletten Mannschaftsbestand, so daß sie vom Feind schnell geschlagen wurde. Das letzte Gefecht für den Ausbruch aus der Einkreisung bei der Stadt Nesviž geschah am 28.-29. Juni 1941, und die Division wurde endgültig zerschlagen. Die einzelnen Gruppen von überlebenden Soldaten retteten sich, wie sie konnten. Ich als Leiter der zweiten Divisionsstaffel zog mich mit $11 \mathrm{Kraftfahrzeugen} \mathrm{und} \mathrm{etwa} 50$ mitfahrenden Soldaten nach Minsk und von dort nach Mogilev zurück. In Mogilev wurden die Kraftfahrzeuge auf Verfügung des Oblastkriegskommissariats einem Reserveregiment zugeteilt, während man die Soldaten und mich selbst an eine Leitstelle zur Versetzung in andere Einheiten überwies. Am 1. oder 2. Juli wurde die Leitstelle bei Alarm in die Stadt Čausy verlegt. In Čausy war ich etwa 10 Tage lang, dann wurde ich zusammen mit anderen Kommandeuren vom Vertreter der 21. Armee zum weiteren Dienen in dieser Armee ausgewählt. In der Armee wurde ich zum Leiter der Bekleidungs- und Versorgungsabteilung des Korps im Stab des 28. Schützenkorps ernannt und arbeitete bis zum 18. 9. $1941 \mathrm{im}$ Korps in diesem Amt. Die 2. Staffel des 28. Schützenkorps geriet zusammen mit dem Stab von zwei Staffeln anderer Korps, Divisionen und sogar der 5. und der 21. Armee in der Stadt Niratino, Oblast' Cernigovsk, in eine Einkreisung und dann in Gefangenschaft, und damit geriet auch ich am 18.9. 1941 in Gefangenschaft und wurde in die Stadt Kaunas in ein Kriegsgefangenenlager abtransportiert. Am 31.3. 1942 floh ich aus der Gefangenschaft und erreichte Ende April das Dorf Nikolaevka am Neman, Juratišskij Rajon, Westbelorußland. Mit aktiver Hilfe des Ältesten dieses Dorfes, Koleda (ehemal. Vorsitzender des Dorfsowjets), lebte ich im Wald in der Nähe von Nikolaevka, beschaffte mir ein Gewehr, sammelte (aufgrund von Gerüchten und Angaben einzelner Bürger) Nachrichten über die Operationsgebiete der Partisanen und begab mich am 14. 5. 1942 in den Naliboki-Wald, um eine Partisanenabteilung zu finden und mich in sie einzureihen. Unterwegs zu diesem Ziel begegnete ich beim Ort Naliboki einer 9 Mann starken Partisanengruppe, die mich als zehnten Mann aufnahm und nach der Überprüfung meiner Papiere zum Leiter dieser Gruppe wählte. Damals waren zwei Mitglieder dieser Gruppe unbewaffnet. Als Leiter der Gruppe stellte ich mir die Aufgabe, diese zwei Personen zu bewaffnen und uns einer großen Abteilung anzuschließen. Zu diesem Zweck beschloß ich, den ganzen Naliboki-Wald entlang zu gehen, und tat das. Im Wald, genauer: am Waldrand begegnete ich in einem Dorf (an 
den Namen erinnere ich mich nicht mehr) zwei Partisanen der Partisanenabteilung „I. V. Stalin“. Ich machte mich mit ihnen bekannt, charakterisierte meine Gruppe, teilte ihnen meine Ansicht zur räumlichen Verteilung der Partisanenbewegung in jedem Rajon mit (in jener Zeit gab es in Westbelorußland sehr viele kleine Gruppen von 20-40 Mann) und bat um ihre Hilfe, um über das Abteilungskommando meine Gruppe der Abteilung anzugliedern. Sie versprachen mir, mit dem Kommandeur und dem Kommissar der Abteilung zu sprechen und mir das Resultat mitzuteilen. $\mathrm{Zu}$ diesem Zweck wurde im Wald ein Treffpunkt vereinbart, wohin sie tatsächlich kamen und mir die Zustimmung der Abteilung übermittelten, zu ihnen zu stoßen. $\mathrm{Zu}$ dieser Zeit hatte ich meine zwei Leute bewaffnet und gliederte mich am 4.6. 1942 in die Abteilung „I. V. Stalin“ ein und wurde auf Befehl zum stellvertretenden Kommandeur des MG-Zugs ernannt. Der Leiter der Abteilung war Leutnant Smirnov, der Kommissar war Hauptmann Žukovec. Insgesamt war die Abteilung 200-250 Mann stark. Mit dieser Abteilung nahm ich im Juni 1942 (an das genaue Datum erinnere ich mich nicht) am Kampf um die Ortschaft Rubeževiči und den Ort Naliboki teil. Um den 29. Juni erhielt ich den Auftrag, mit 17 Fuhren aus dem Wald von Naliboki die Roggenvorräte der Abteilung in den Wald beim Dorf Rudnja - dem damaligen Quartier der Abteilung - zu transportieren. Auf dem Rückweg gerieten wir, als wir den Graben hinter dem Dorf Kletišče entlangfuhren, in einen deutschen Hinterhalt. Zwei Sicherungszüge liefen weg. Es blieben ich, der Kompanie- (Zugs-)Kommandeur Gen. Surkov, der erste Maschinengewehrführer seiner Kompanie mit dem MG und drei weitere Partisanen, einer von ihnen war Gen. Kalečic, an die beiden anderen Familiennamen erinnere ich mich nicht. Beim Rückzug konnten wir nur eine Fuhre mit einem Wildschwein retten. Es war sehr schwer, in die Abteilung „I. V. Stalin“ zurückzukehren, weil sie von den Deutschen eingekreist war. Kämpfend brachen sie aus der Einkreisung aus und suchten nach einem anderen Lagerort. Aber wohin sollten wir gehen? Das wußten wir nicht. Bei unserem Umherschweifen durch die Wälder auf der Suche nach der Abteilung stieBen wir, die genannten 10 Personen (vier weitere schlossen sich uns unterwegs an) auf die Abteilung Nikitin, und am 4.7. 1942 gliederte sich unsere ganze Gruppe in die Abteilung Nikitin ein, wo ich mich bis zum 18. 9. 1942, d.h. bis zur Entsendung an die Front, befand. Als ich in der Brigade war, beteiligte ich mich an keinen Gefechten, weil diese Brigade wegen fehlender Munition sich auf solche nicht einließ.

\section{Meine Bemerkungen - die Meinung über die Abteilung „I. V. Stalin“ und die Brigade Nikitin}

a) Abteilung „Stalin“.

Die Führung - der Stab - ist unbefriedigend. Der Abteilungskommandeur Leutnant Smirnov besitzt nur eine Kommandeurseigenschaft: Tapferkeit. Andere Kommandeurseigenschaften hat er nicht. Ist auch nicht um die Erfahrungen des Partisanenkampfes bereichert. Für einen Leutnant versteht er wenig von taktischen Fragen. Der Stabschef, ein Unterleutnant (an den Familiennamen erinnere ich mich nicht) ist in allen Fragen außerordentlich schwach. Beide haben bei den Partisanen keine Autorität. Die ganze - taktische und politische - Führung der Abteilung lag in den Händen des Kommissars Hauptmann Žukovec. Er war der einzige, der bei den Massen Autorität genoß. In Taktik und Politik war er gut beschlagen. Doch zu un- 
serem großen und allgemeinen Leidwesen war er in einem Kampf gegen die Deutschen gefallen, worauf sich die Leitung der Abteilung noch mehr verschlechterte. Die Abteilung selbst besteht zu 50 Prozent aus den ehemaligen Eingekreisten und Gefangenen und zu 50 Prozent aus den Einwohnern des Minsker- und des Dzeržinskij Rajons. Die Abteilung ist in hohem Maße kampffähig und patriotisch. Sie hat genügend Gewehre und Maschinengewehre, aber keine Maschinenpistolen und keine Munition (15-20 Patronen je Gewehr und 1-2 Trommelmagazine je MG), weshalb sie ungefähr seit Juli Gefechten mit dem Gegner ausweicht. Der Gegner kam dahinter, vertrieb die Abteilung aus dem Naliboki-Wald, folgt unablässig ihren Spuren und hat ihre beinahe vollständige Zersplitterung erreicht. Gerüchten zufolge hat sie sich in letzter Zeit mit der Abteilung von „Batja“ vereinigt, hat kein Funkgerät und steht mit Moskau folglich nicht in Verbindung.

Vor der Zersplitterung und der Vereinigung mit „Batja“ wurde die Abteilung aus einer Feldküche verpflegt. Als sie sich auf dem Territorium Westbelorußlands befand, beschafften sich die Leute ihre Lebensmittel zentral: bei den Familien von Polizisten, den Mühlen von Gutsbesitzern und aus Erbeutetem. Das ist ein positiver Aspekt der Abteilung, weil die Bauernschaft nicht betroffen ist.

b) Brigade Nikitin.

Der Stab - die Führung - ist stark, genießt bei den Massen Autorität. Die Abteilung ist 600-650 Mann stark. Zu 75-80\% besteht sie aus ehemaligen Eingekreisten und Gefangenen und zu 20-25\% aus örtlichen Einwohnern, hauptsächlich aus dem Minsker Rajon; die Abteilung, richtiger, die Brigade ist höchst kampffähig und patriotisch. Mit Gewehren und Maschinengewehren ausreichend bewaffnet, aber Maschinenpistolen und Munition fehlen (15-20 Patronen je Gewehr und 2-3 Magazine je Maschinengewehr), weshalb sie seit ungefähr Juli Gefechten mit dem Gegner ausweicht. Die Brigade hat Verbindung mit Moskau - dem NKVD - und bittet fortwährend um Munition. Erhalten hat sie Dutzende, wenn nicht Hunderte inhaltsmäBig unterschiedliche Antworten. Zum Beispiel: „Koordinaten melden“, „Landeplatz melden“, „Fracht 6 Fallschirme fertig“, „Warten“ usw., und erst am Anfang des dritten Monats seit Beginn solcher Funkgespräche erlebte die Brigade die Ankunft eines einzigen Flugzeuges, das zum allgemeinen Leidwesen Batterien, 6 Päckchen Tabak, Zeitungen und einige Kilo Hartbrot und Zwieback, aber keine Munition abwarf. Dieser Umstand erledigte die Brigade in moralischer Hinsicht endgültig, denn die Brigade verlor jede Hoffnung auf die Unterstützung mit Kampfmunition. Da die Brigade - die Führung - nicht untätig bleiben wollte, beschloß sie, im gesamten Bestand die Frontlinie zu überqueren, was sie auch tut. Nach Angaben einzelner Partisanen, die durch die Brigade Mel'nikov gingen, ist Nikitin mit seiner Brigade unterwegs in Richtung Frontlinie und hat schon Mel'nikovo erreicht, befindet sich also an der Westlichen Dvina. Meines Erachtens ist die Entscheidung der Brigade, zur Bewaffnung die Frontlinie zu überqueren, richtig. Ich bin sicher: Hätte der Volkskommissar für Verteidigung Genosse Stalin in all diesen bürokratischen Funkspruchverkehr mit einer NKVD-Abteilung (weiß nicht, welcher konkret) Einblick genommen, so hätte er gewisse Abteilungsleiter aus dem NKVD mit dem „Stalinschen Besen“" ausgekehrt, und dann hätte die Brigade die dringend benötigte Munition erhalten. 


\section{Bemerkungen über Abteilungen in Westbelorußland}

Auf dem Territorium Westbelorußlands befinden sich hunderttausende Partisanen, hauptsächlich ehemalige Kriegsgefangene und Eingekreiste; ihre Waffen haben sie aus den Wäldern und von der örtlichen Bevölkerung. Sie operieren meist in kleinen Gruppen mit einer Stärke von je 20-40 Mann, haben den Deutschen, besonders im Frühjahr und zu der Zeit, als noch Gminas (Gemeindeverwaltungen) bestanden, empfindliche Schläge versetzt. Doch war all das rein spontan, war Rache des Gefangenen für all das, was er bei den Deutschen gesehen und erlebt hatte. Jetzt aber sind sie alle so gut wie inaktiv: Die Munitionsvorräte sind erschöpft; sie stehen mit niemandem in Verbindung, sind zu $100 \%$ von der sowjetischen Wirklichkeit abgetrennt. Die Richtlinien von Partei und Regierung in der Frage der Partisanenbewegung sind ihnen unbekannt. Da sie nicht kämpfen, arten sie unvermeidlich zu einer zusätzlichen Last für die Bauern aus und bringen die Bauernschaft gegen die Partisanen insgesamt auf. Folglich schadet das der Partei und Regierung; konkret geschieht das folgendermaßen: Wenn die Deutschen nicht da sind, gehen die Partisanen ungehindert im Dorf hin und her, leisten keine Massenarbeit unter den Bauern, nehmen ihnen Kühe, Schafe, Brot und andere Lebensmittel weg. Sobald aber eine Strafabteilung auftaucht, fliehen die Partisanen, ohne Widerstand zu leisten, während die Bauern dann geprügelt und ihre Häuser in Brand gesteckt werden, weil sie die Partisanen unterhalten und verpflegt haben. Die Bauern sagen ohne Umschweife: „Zum Kuckuck mit solchen Partisanen, die mir das Letzte wegnehmen und mich nicht gegen die Deutschen verteidigen können. Ohne euch hätte der Deutsche mich nicht geprügelt und nicht mein Haus in Brand gesteckt.. "Das wäre erstens. Zweitens empören sich die Bauern über die Methode der Beschaffung der Lebensmittel, die so vor sich geht:

Eine Abteilung (Gruppe) bekommt von der Führung ein entsprechendes Dorf oder zwei Dörfer zugeteilt. Sie fährt nachts aus und nimmt in jedem Bauernhaus alles mit, was sie findet: Speck, Butter, saure Milch, Brot u. a. Lebensmittel. Deshalb verstecken die Bauern alles, was sie nur können. Nicht selten kommt es vor, daß solche „Partisanen“ nicht nur Lebensmittel an sich nehmen, sondern auch noch die Schränke und Truhen durchsuchen und Kleidung und Stiefel, ja sogar Luxusgegenstände - Toilettenwasser, Uhren u. a. Sachen - mitgehen lassen. Sie beschlagnahmen die Pferde und die Fuhren zum Lebensmitteltransport, versprechen, alles zurückzugeben, tun das jedoch faktisch selten. All das wird ohne Rücksicht auf die soziale und wirtschaftliche Lage der jeweiligen Familie getan. Nicht von ungefähr ist es so, daß, sobald die Partisanen in einem Dorf auftauchen, die auf dem Hof spielenden Kinder bei ihrem Anblick ins Haus laufen und schreien: „Mutter, Partisanen kommen!" Und die Mutter beeilt sich, alles, was sie besitzt, zu verstecken.

All das geschieht deshalb, weil die Partisanen in den Wäldern operieren, aber der Rajon selbst wird nicht kontrolliert, nicht gehalten, zentral geleitete Beschaffung nicht durchgeführt. Die Gutsherren und die Gmina-Verwaltungen sind zerstört, die Familien der Polizisten in der Hauptsache auseinandergejagt, und die Bauernschaft ist jetzt die einzige Quelle, um Lebensmittel zu beschaffen.

All dem ist hinzuzufügen, daß kleine (6-10 Mann starke) Gruppen von angeblichen Partisanen unterwegs sind, bei denen es sich in Wirklichkeit aber um Banden aus der örtlichen Bevölkerung handelt, die in den Dörfern nicht nur Lebensmittel und 
Kleindungsstücke, sondern sogar auch das Saatgut - Hafer, Lupine u.a. - rauben und auf diese Weise das Ansehen der Partisanen bei der Bauernschaft noch mehr erschüttern.

Schlußfolgerung: Notwendig sind Sofortmaßnahmen zum baldigen Zusammenschluß dieser kleinen Gruppen zu Abteilungen bzw. Brigaden und zu ihrer Versorgung mit Munition. Dann werden sie eine bedeutende, kampffähige Armee bilden, die fähig ist, die Rajons (das ganze gegnerische Hinterland) vom Feind zu säubern, sie zu kontrollieren, zentral geleitete Beschaffung durchzuführen und die Einberufungsjahrgänge zu rekrutieren. [...] $]^{21}$

Abschrift beglaubigt:

F. 4p, op. 33a , d. 169, 11. 53-55.

\section{Dokument Nr. 6}

\section{Meldung über den Zustand der Brigade „Frunze“ vom 3. Juni 1943}

\section{Streng gebeim \\ An den Chef des Belorussischen Stabs der Partisanenberwegung Gen. Kalinin. Meldung}

Gemäß Ihrem Funkspruch habe ich über die Frunze-Brigade Folgendes zu melden: In die Brigade wurde Major Vasilevič entsandt, der feststellte, daß die Brigade per 1. 2. 1943650 bewaffnete Kämpfer zählte. Die Brigade wurde in ihrer Mehrheit aus der örtlichen Bevölkerung des Dzeržinskij Rajons im Zuge der Mobilmachung formiert. Die meisten sind junge Leute, die nicht in der Roten Armee gedient haben. Die Führung der Brigade stellte der Abteilung keine Gefechtsaufgaben, führte keine einzige Kampfoperation durch, beschäftigte sich nicht mit der Ausbildung und dem Zusammenschluß der Brigade und der Abteilungen. In der Brigade und den Abteilungen gab es keine Dispziplin, herrschten Trinkerei, Marodieren und rechtswidrige Erschießungen. Die Bevölkerung sprach von der Frunze-Brigade als von Marodeuren und Banditen.

Infolgedessen zerfiel die Brigade gleich bei der ersten Begegnung mit einer Strafabteilung am 1.2. 1943 und verlor alle Maschinengewehre und 2 Kanonen.

Die Leitung erteilte die Anordnung, die Brigade bis zum Frühjahrsanfang in kleine Gruppen von je 10-15 Mann aufzulösen. Ein Teil der ehrlichen Partisanen bildete kleine selbständige Gruppen; diese Leute wollten sich nicht der Brigadenführung unterordnen. Einige wenige kehrten in ihre Häuser zurück und leben gegenwärtig dort. Rd. 70-100 Personen (genaue Zahl läßt sich schwer feststellen) ergaben sich der Polizei in der Stadt Dzeržinsk und fuhren nach Deutschland. Ein Teil der Partisanen schloß sich anderen Brigaden und Abteilungen an. Weitere kleine Gruppen halten sich in den Wäldern versteckt und leben für sich, lassen sich schwer finden. All diese Gruppen führten keine Kampfhandlungen durch, vielmehr gaben sie sich auch die Brigadenführung - der Trunksucht und Plünderungen hin. Wegen der

21 Gekürzt: Lage in Litauen. 
Trunksucht und der gesetzwidrigen Erschießung des Gen. Kovalev, Kommissar der Brigade „Budennyj“, wurde der Stabschef abgesetzt und wird zur Verantwortung gezogen.

Ich habe folgende Arbeit geleistet: Eine Gruppe von 24 Partisanen und Partisaninnen wurde zur Stalin-Brigade entsandt. Aus den übrigen wurden 4 Abteilungen aufgestellt, die nunmehr der Führung der Frunze-Brigade unterstellt sind.

$\begin{array}{lcll}\text { Suvorov-Abteilung } & 52 \text { Personen } & \text { Abteilungskommandeur } & \text { Kušnir } \\ \text { Dzeržinskij-Abteilung } & 41 \text { Personen } & \begin{array}{l}\text { Abteilungskommandeur } \\ \text { Kommissar }\end{array} & \begin{array}{l}\text { Žerdev } \\ \text { Nasonov }\end{array} \\ \text { Kutuzov-Abteilung } & 47 \text { Personen } & \begin{array}{l}\text { Abteilungskommandeur } \\ \text { Kommissar }\end{array} & \begin{array}{l}\text { Golcev } \\ \text { Sumeev }\end{array} \\ \text { Frunze-Abteilung } & 57 \text { Personen } & \begin{array}{l}\text { Abteilungskommandeur } \\ \text { Kommissar }\end{array} & \begin{array}{l}\text { Degterev } \\ \text { Cygankov }\end{array}\end{array}$

In den Abteilungen wurden Partei- und Komsomolgruppen gebildet und Versammlungen zur Frage des Beschlusses des Plenums des ZK der KP(b)B über die Partisanenbewegung in Belorußland durchgeführt.

Es ist unerläßlich, den Hauptmann Serebrjakov und den Bataillonskommissar Vaučik von den Leitungsposten in der Frunze-Brigade abzusetzen, weil sie ihre Autorität bei den Mannschaften verloren haben und unfähig sind, die Brigade und die $\mathrm{Ab}$ teilungen zu führen und auf den Kampf gegen den Faschismus auszurichten. Es wäre wünschenswert, Sie an Ihren Standort zu entsenden. Warte auf Ihre Weisungen zu diesen Fragen.

Bevollmächtigter des ZK der KP(b)B und des Belorussischen Stabs der Partisanenbewegung für das Ivenecker-Zentrum für mehrere Rajons 3. Juni 1943

(Dubov)

F. 1329, op. 1, d. 32, 1. 10.

\author{
Dokument Nr. 7 \\ Meldung des Kommandeurs der Partisanenbrigade „Pervomajskaja“ \\ Hauptmann Kovalev \\ An den Bevollmächtigten des $Z K$ der $K P(b) B$ \\ und Vertreter des Generalstabs der RKKA \\ Meldung
}

Unterwegs, bei der Prüfung der Operationen der Abteilungen begegnete ich einer Abteilung, die sich „Luftlandesoldaten“ von Oberstleutnant Znamenskij nannte. Nach der Bekanntschaft mit dem Kommandeur und dem Kommissar der Abteilung schlugen wir ihnen vor, sich bei Ihnen zur Berichterstattung zu melden. Auf diesen Vorschlag antwortete der Abteilungskommandeur M. L. Bočkin: „Ich weiß nicht, wer Platon ist. Woher kommt er, und wo war er, als wir uns hier eingearbeitet und 
gekämpft haben? Vielleicht ist er ein Spion", usw. Ich mußte den Gen. Jaročkin und den Kommissar, der ihn unterstützte, scharf zurechtweisen und ihnen die ultimative Forderung stellen, sich binnen zehn Tagen bei Ihnen zu melden.

Bei der Prüfung erwies sich, daß von den Luftlandesoldaten nur drei Personen übriggeblieben waren. Die übrigen stammen aus den nahen Ortschaften und aus Ostbelorußland. Sie stören nur unsere Abteilungen bei ihrem Vorgehen. Zum Beispiel: Die Abteilungen bewaffnen die örtlichen Einwohner, die mit den Partisanen zusammenarbeiten, und stellen ihnen spezielle Papiere aus. Wenn die "Luftlandesoldaten“ davon erfahren, nehmen sie ihnen die Waffen, bei Gelegenheit auch das Pferd oder Lebensmittel weg. In letzter Zeit führen sie keine Kampfoperationen durch, haben die Abteilung als Kosaken eingekleidet und führen eine Jungpionierfahne mit. Sie erklären, einen Sonderauftrag zu haben, und wollen sich niemandem unterordnen. In ihrem Auftrag machte der Kommissar der Brigade, Hauptmann Gen. Deev, die Frunze-Abteilung aus. Er sprach mit dem Abteilungskommandeur, der sich Bataillonkommissar nennt. Er redet ähnlich wie die "Landesoldaten“ und will sich der Kavallerieabteilung von „Mitka“ anschließen.

Als ein Verräter aus dem Partisanenlager zu den Deutschen floh und ein Abteilungskommandeur lebend in Gefangenschaft geriet, wurden der Standort des Stabs der Brigade und des Lazaretts entdeckt, umso mehr als in der Nähe ein Judenlager des Ivenecker vereinigten Rajonzentrums liegt, dessen Leute zum Partisanenlager in Fuhren kommen, die von örtlichen Bauern gelenkt werden.

In Anbetracht des oben Dargelegten bin ich gezwungen, nach einem neuen ständigen, von anderen Abteilungen genügend entfernten Quartier zu suchen.

Der Brigadenkommissar Hauptmann Deev berichtete mir, daß P. I. Smirnov zum Stabschef der Brigade ernannt wurde, in der Hauptmann Siničkin Brigadekommandeur ist. Meines Erachtens wurde Gen. Smirnov von Hauptmann Siničkin gewählt, weil er eine Zeitlang sein Adjutant war. Er zog jedoch einige Besonderheiten von Gen. Smirnov nicht in Betracht, aufgrund derer sich Gen. Smirnov für den Posten des Stabschefs in keiner Weise eignet.

Ich halte es nicht für zweckmäßig, ihn gegenwärtig von der Aufklärungsarbeit, die er gern macht, zu entfernen; zudem hat er im Rajon Kontakte hergestellt. Sein Fehlen würde die erst begonnene und sich gut anlassende Arbeit nur zerstören. Aufgrund des oben Dargelegten bitte ich, Ihren Befehl über die Ernennung von Gen. Smirnov aufzuheben. Ich empfehle, einen echten Stabsaufklärer einzusetzen, der diese Arbeit ausgezeichnet kennt. Nach unserer Ankunft hatten wir alle Angaben von ihm bekommen. [...] Als ich bei Ihnen war, wollte ich darum bitten, ihn in meine Brigade aufnehmen zu dürfen, wagte es jedoch nicht. Es handelt sich um den Kommissar der Vorošilov-Abteilung Nikolaj L. Ein kampferprobter und mutiger Mensch, hat viele Kampfoperationen durchgeführt, genießt hohes Ansehen nicht nur in seiner Abteilung, sondern auch in der ganzen Lenin-Brigade. Er hat viele Differenzen mit B. Bulat. Gen. Smirnov hat in den Abteilungen der Lenin-Brigade keine Autorität. Bitte mich von Ihrem Beschluß in Kenntnis zu setzen. Auch bitte ich ausdrücklich darum, zu uns den Kommissar der Vorošilov-Abteilung zu entsenden. Da wir in Baranoviči Kontakte haben, können wir eine Operation durchführen, dazu brauchten wir Gifte: je ca. 1 kg Zyankali, Kali, Arsen, Strychnin sowie Holzspiritus. Im Operationsraum der Abteilungen unserer Brigade halten sich viele jüdische Familien versteckt, und zwar sowohl örtliche Juden als auch solche, die aus 
Baranoviči u. a. Orten geflohen sind. Ich erteilte allen Abteilungen Weisung, diesen Familien zu helfen.

Kommandeur der Partisanenbrigade

„Pervomajskaja“ Hauptmann

19.6.1943

(Kovalev)

F. 3500 , op. 4 , d. $250,1.8$.

Dokument Nr. 8

\title{
Meldung über den Zustand des Untergrunds und der Partisanenbewegung in der Oblast' Baranoviči per 1. Oktober 1943
}

\author{
An den Sekretär des $Z K$ der KP(b) Belorußlands \\ Gen. Ponomarenko \\ vom illegalen Oblastkomitee Baranoviči \\ $\operatorname{der} K P(b)$ Belorußlands
}

\section{Meldung \\ Über die Partisanenbervegung und den Parteiuntergrund der Oblast' Baranoviči, Stand 1. Oktober 1943}

Das Untergrund-Oblastkomitee Baranoviči der KP(b)B nahm seine Arbeit im März 1943 auf. Die durch das ZK der KP(b)B übergebene Technik - wie die Druckerei und Funkgeräte - blieb auf dem Weg zum Bestimmungsort (ab Gomel) vollständig erhalten und wird verwendet. Seine Hauptaufgaben sah das Oblastkomitee der $\mathrm{KP}(\mathrm{b}) \mathrm{B}$ darin, mit den Abteilungen Verbindung aufzunehmen, die Partisanenbewegung zu erweitern, neue Abteilungen und Gruppen aufzustellen, die politische Leitung der Partisanenbewegung zu verstärken, die Rolle der Parteiorganisationen zu erhöhen, Untergrund-Parteiorgane zu schaffen und die Gefechtstätigkeit der Abteilungen entscheidend zu aktivieren.

Gegenwärtig hat das Oblastkomitee der KP(b)B alle Rajons der Oblast' voll erfaßt (Verbindung mit den Abteilungen aufgenommen und mehrere Maßnahmen zur Verstärkung der Partisanenbewegung getroffen); eine Ausnahme bilden die Rajons Nesviž, Kleck und Ljachoviči, in die eine verdoppelte Verbindungsgruppe entsandt wurde, die Kontakte mit den dort arbeitenden Rajonparteikomitees und Partisanenabteilungen herzustellen hatte. [... $]^{22}$

In den Rajons Ljachoviči, Kleck und Byten' operieren mehrere Partisanenabteilungen, die Verbindung mit ihnen wird angebahnt. Die Reserven der Abteilungen und Brigaden zählen über 10000 Personen.

Seit das Oblastkomitee der KP(b)B seine Arbeit aufgenommen hat, wurden 3 neue Brigaden - die Kirov-, die Pervomajskaja- und die Dzeržinskij-Brigade - sowie 26 neue Partisanenabteilungen aufgestellt. Das sind: die Kutuzov-, die Aleksandr-

22 Gekürzt: Tabelle: Dislozierung und Stärke der Abteilungen und Brigaden in der Oblast'. 
Nevskij-, die Parchomenko-Abteilung (Stalin-Brigade), die Abteilung „Za Sovetskuju Rodinu“, die Ponomarenko-Abteilung und die Abteilung Nr. 6 (Čkalov-Brigade), die 2. Komsomol-Abteilung (Žukov-Brigade), die Suvorov-, die KotovskijAbteilung, die Abteilungen „Mstitel”“ und „Groznyj“ (Pervomajskaja-Brigade), die Abteilungen „Baltijcy“, „Nepobedimyj“, die Lenin-Abteilung (Lenin-Brigade), die Ščors-, die Kotovskij-Abteilung (Rajon Novogrudok), die Frunze-, die MolotovAbteilung (Rajon Kareliči), die Dzeržinskij-Abteilung (Rajon Byten'), die Abteilung Zorin, die Abteilung Ždanov, die Vorošilov-, die Kotovskij-Abteilung (Frunze-Brigade), die Komsomol-, die Ponomarenko-, die Ryžak-Abteilung (Stalin-Brigade).

Die Frunze-Brigade, die im Februar 1943 bei Kampfhandlungen mit Straftrupps zerfallen war, wurde wiederhergestellt und gesammelt.

Seit dem Frühjahr 1943 versuchten die Deutschen, auf allerlei Umwegen, durch Betrug, Provokationen und Razzien auf dem Territorium der Oblast' ihre „Totalmobilmachung“ durchzuführen, aber keiner ihrer Tricks brachte den Hitlerleuten die erwarteten Resultate. $\mathrm{Zu}$ den Sammelstellen kamen einige wenige Leute, während die Bevölkerung der Dörfer samt und sonders in die Wälder ging und geht. Im Juli und August unternahmen die Deutschen unter Einsatz zahlreicher Sonderkommandos des Generalkommissars von Belorußland, Kube, eine groß angelegte Strafexpedition gegen die Partisanen des Naliboki-Wald, Rajon Ivenec, und vieler anderer Rajons der Oblast'; zugleich versuchten sie, von SS-Truppen unterstützt, die Bewohner zu fangen und das Vieh an sich zu bringen. In einigen Gegenden ist ihnen das gelungen, aber auf den Straßen zu den Städten L.ida, Stolbcy und Zaslavl' sind die Bewohner in ihrer Mehrheit weggelaufen und halten sich jetzt in den Wäldern versteckt. Im Naliboki-Wald (Rajon Ivenec) und anderen Wäldern leben gegenwärtig ganze Dörfer familienweise in Erdhütten. In der belorussischen Bevölkerung gibt es eine starke Tendenz, sich den Partisanen anzuschließen. Viele nehmen wir auf, wobei wir Waffen beschaffen müssen, die anderen werden als Reserve in Gruppen organisiert, wir ernennen die Kommandeure, und die Abteilungen erteilen ihnen einzelne Aufträge: Aufschüttung von Sperren, Inbrandsetzung und Demontage von Brücken, Störung der Verbindungslinien, Aufklärung u.a.

Nach vorläufigen Angaben halten sich in den Wäldern der Naliboki-Pušča über 2000 Personen versteckt. Negativ wirkt sich die Tatsache aus, daß wir wenig Waffen haben, selbst in einigen Abteilungen gibt es noch Unbewaffnete. Die Bewohner, besonders die Belorussen, halten zu den Partisanen, und dies trotz eines beispiellosen Terrors (der Hinweis mag genügen, daß die Deutschen im Juli und August 1943 bis zu 4000 Kinder, Frauen und alte Leute getötet und über 200 Dörfer verbrannt haben), helfen ihnen auf jede Weise, versorgen sie freiwillig mit Getreide, Vieh u.a. und sagen hierbei: „Nehmt das, ihr sollt euch gut verpflegen, sonst kommt der verfluchte Deutsche und frißt uns alles weg."

Das Oblastkomitee hat 7 neue Gruppen von Organisatoren gebildet, die sich durch Heranziehung der örtlichen Bevölkerung zu Abteilungen entwickeln sollen.

Die Abteilungen und Brigaden haben große Reserven an Partisanenkräften (über 10000 Personen), die wir jederzeit einsetzen können.

Im Frühjahr und Sommer 1943 haben sich die Partisanenabteilungen bedeutend verstärkt. Während 26 neue Abteilungen entstanden, sind zugleich die alten Abteilungen bis auf 2500 Personen, davon einige auf das Doppelte bis Dreifache ange- 
wachsen. Jetzt, nach der Blockade, werden die Abteilungen durch örtliche Bewohner verstärkt.

Es sei hervorgehoben, daß die Belorussen den Partisanen positiv gegenüberstehen und sich den Abteilungen anschließen, während sich viele Polen negativ zu den Partisanen verhalten und ihnen sogar feindlich gesinnt sind. Es ist eine Reihe von Fällen bekannt, in denen Polen in den Dörfern kleine Partisanengruppen bei der Ausführung von Aufträgen ermordet haben. Sie benachrichtigen die Deutschen über die Bewegungen der Partisanen. Die katholischen Belorussen schwanken und verhalten sich reserviert, einerseits sympathisieren sie mit den Partisanen, aber ein Teil von ihnen arbeitet mit den Polen zusammen. Unter solchen Leuten leisten wir die entsprechende Arbeit. [...]

\section{Untergrund-Parteiorganisationen}

Große Aufmerksamkeit schenkt das Oblastkomitee der $\mathrm{KP}(\mathrm{b}) \mathrm{B}$ der Schaffung eines Netzes von Untergrund-Rajonkomitees der $\mathrm{KP}(\mathrm{b}) \mathrm{B}$ und von Parteigrundorganisationen und der Organisation seiner Arbeit. Gegenwärtig gibt es in den 26 Rajons der Oblast' 20 illegale Rajonkomitees der KP(b)B und Bevollmächtigte des Oblastkomitees der $\mathrm{KP}(\mathrm{b}) \mathrm{B}$ für die einzelnen Rajons. Es bestehen und funktionieren folgende Vereinigte Rajonzentren der Partei: Šcučin, Lida, Stolbcy, Ivenec, Slonim; sie sind gleichzeitig operative Führungszentren für die Partisanenabteilungen und -brigaden. $[\ldots]^{23}$

F. 1329, op. 1, d. 8, 11. 1-9, 15 .

\section{Dokument Nr. 9}

\section{Erläuterungs-Meldung zum Jahresbericht über die Kampf- und Subversionstätigkeit der Lenin-Partisanenbrigade seit ihrer Organisation bis zum 1. Dezember 1943}

Streng gebeim

Die Lenin-Partisanenbrigade wurde als mächtiger, völlig in sich geschlossener Truppenverband im gegnerischen Hinterland im Dezember 1942 organisiert.

Vor der Organisation der Lenin-Brigade operierten im Lipičanskij-Wald und den Duborovskij-Wäldern die Partisanenabteilungen „Pobeda“ (Sieg), „Bor'ba“ (Kampf) und die Vorošilov-Abteilung vereinzelt, ohne im Kampf Verbindung miteinander aufzunehmen.

Auf der Grundlage der Aktionen dieser Abteilungen wurde Anfang Dezember 1942 der Stab für die Führung des gesamten Partisanenkampfes im Lipičanskij-Wald gebildet.

Zum Brigadekommandeur wurde Hauptmann Fedor Michailovič Siničkin, zum Stabschef Oberleutnant Boris Adamovič Bulat, zum Chef Aufklärung der Brigade Oberleutnant Nikolaj Nikolaevič Poceluev ernannt. Erst eine geraume Zeit nach der Organisation der Brigade wurde Bataillonskommissar Grigorij Vasil'evič Maka-

23 Gekürzt: Tabelle: Rajonkomitees der KP(b)B und ihre Zusammensetzung, Angaben über polnischen Untergrund und Stimmung in der Bevölkerung. 
rov zum Kommissar der Brigade ernannt. Das war der Anfang einer zentralen militärischen und politischen Führung der Abteilungen. Es wurde die Verbindung mit dem in den Naliboki-Wald dislozierten OSPO aufgenommen. Außerdem wurden Partisanen mit einer Meldung nach Moskau entsandt; sie mußten die Frontlinie überqueren, um die Verbindung mit der Heimat herzustellen. Diese Aufgaben wurden vollständig erfüllt, die Verbindung mit der Heimat - dem „Großen Festland“ besteht.

Voller Haß gegen den Feind, der unsere angestammten Lande zeitweilig besetzt hat, beschloß die Leitung, alle Partisanenabteilungen und -gruppen, die im Raum der Brigade agierten, zu vereinigen und sich zu unterstellen, um überall im gegnerischen Hinterland mächtigere Schläge führen zu können.

Im Januar 1943 wurde der Brigade die Pervomajskaja-Abteilung angegliedert, die im Raum Gorodišče - Kareliči und Molčad' - Dvorec operierte. Ihr folgten die Abteilung „Oktjabr" , die im Rajon Novogrudok vorging, und die im Raum der Stadt Lida operierende Abteilung „Iskra“.

Dank dieser Organisationsarbeit zählte die Brigade im Mai 1943 schon 2150 Partisanen, die gut organisiert und mit Kanonen, Maschinengewehren, Maschinenpistolen und Gewehren bewaffnet waren. Die Stärke der zur Brigade gehörenden Abteilungen und der in der örtlichen Bevölkerung verbreitete Wunsch in die Partisanenabteilungen einzutreten, machte es erforderlich, neue Abteilungen zu organisieren, und 1943 wurden sie aufgestellt: im Mai die Abteilungen „Baltiec“ und „Nepobedimyj“, im Juli die Lenin- und im August die Kalinin-Abteilung.

Im Juni 1943 stellte die Lenin-Brigade einen mächtigen Truppenverband dar: 8 große, gut bewaffnete, allerdings 20 , ja bisweilen $100 \mathrm{~km}$ weit auseinander liegende Abteilungen. Von der Führung besonders weit entfernt waren die „Pervomajskaja“-, die „Oktjabr" - und die „Iskra“-Abteilung. Diese Entfernung der Abteilungen vom Brigadekommando tat ihrer Gefechtstätigkeit Abbruch, minderte die Qualität der politischen Arbeit unter den Partisanen und verlangsamte das Wachstum der Partisanenbewegung.

Zur Annäherung des Brigadekommandos an die Abteilungen erteilte Gen. Stepan Petrovič Šupenja, Bevollmächtigter des ZK der KP(b)B für das Vereinigte Rajonzentrum Ščučin, am 23. Mai 1943 den Befehl, die Pervomajskaja-Abteilung aus der Lenin-Brigade auszugliedern und eine Pervomajskaja-Brigade aufzustellen, wozu die Kompanien von Boris Groznyj, Ivan Čumačenko, Michail Strel'kov und Nikolaj Markov zu selbständigen Partisanenabteilungen im Rahmen der PervomajskajaBrigade entwickelt wurden.

Im Zuge der weiteren Festigung der Abteilungen und der Brigade erteilte der Bevollmächtigte des ZK der KP(b)B Gen. Šupenja am 21.7.43 den Befehl, die Abteilungen „Oktjabr"“, „Baltiec“, „Iskra“ und die Vorošilov-Abteilung aus der LeninBrigade auszugliedern, und organisierte so eine zweite Partisanenbrigade, die aus der Lenin-Brigade hervorgegangen war und den Namen Kirov-Brigade erhielt.

Infolge der Teilung bestand die Lenin-Brigade im Juli 1943 aus zwei Abteilungen: „Bor'ba“ und „Pobeda“, während die dritte Abteilung, die „Nepobedimyj“, die nur 24 Partisanen zählte, sich entwickeln sollte. Die vierte, die Lenin-Abteilung, entstand durch Zusammenlegung der Abteilungen „Bor'ba“ und „Pobeda“. Anfang Juli zählte die Brigade somit nicht mehr 2150, sondern nur noch 785 aktive Partisanen und Partisaninnen, die Kommandeure mitgerechnet. 
Das Brigadekommando sah sich neuen Aufgaben gegenüber:

a) die Kampftätigkeit der Lenin-Brigade nicht zu vermindern, sondern im Gegenteil zu verstärken;

b) die zahlenmäßige Stärke der Brigade durch Neuaufnahmen zu erhöhen;

c) die neu aufgenommenen Partisanen militärisch auszubilden und zu bewaffnen;

d) im Rahmen ihrer Kampftätigkeit die Subversionsarbeit auf den Straßen des Feindes zu verstärken und Hinterhalte gegen den Feind anzulegen.

Die Kampf- und politische Tätigkeit der Brigade im Sommer und Herbst zusammenfassend, kann gesagt werden, daß die Führung der Brigade und der Abteilungen diese Aufgabe ganz gut bewältigt hat.

1. Per 1. Dezember 1943 zählt die Lenin-Brigade 1105 aktive Partisanen und Partisaninnen sowie Leitungs- und Politkader. Mehr als 50\% des gesamten Mannschaftsbestands machen Belorussen aus, die aus den Dörfern um die Pušča in die Abteilung gekommen sind. Die ganze Mannschaft ist ohne jede Hilfe von außen mit Gewehren, Maschinengewehren und -pistolen bewaffnet worden. In allen vier Abteilungen wurden Partei- und Komsomolorganisationen gebildet, die regelmäßige politische Arbeit unter den Partisanen und der Zivilbevölkerung leisten. Im Sommer sind die Parteiorganisationen in der Brigade bedeutend gewachsen. 48 Personen sind Kandidaten der Partei geworden, 4 Kandidaten als Mitglieder in die KPdSU(b) aufgenommen worden. Die Parteiorganisation der Brigade zählt insgesamt 96 Kommunisten, davon 25 Mitglieder und 71 Kandidaten der KPdSU(b). Der Anteil der Parteimitglieder beträgt 8,5\% des gesamten Brigadebestandes. Die Parteiorganisationen der Abteilungen führen regelmäßig Parteiversammlungen mit den Bauern in den Dörfern durch, bei denen sie Fragen der Offensive der Roten Armee an der Front, den Bericht von Gen. Stalin zum 26. Jahrestag der Sozialistischen Oktoberrevolution, den Befehl von Gen. Stalin zum 1. Mai und den zum 26. Jahrestag erörtern. Es finden Aussprachen zu Zeitungsmaterialien des Oblastkomitees Baranoviči der $\mathrm{KPdSU}(\mathrm{b})$ und des Vereinigten Rajonzentrums Šččin statt.

Politisch festgefügt und stark sind die Komsomolorganisationen der Lenin-Brigade. Diese zählt 6 Komsomolgrundzellen, die organisatorisch, militärisch und politisch erstarkt sind. In jeder Abteilung wurde ein Komsomolkomitee gewählt. An der Spitze steht jeweils der Sekretär des Komsomolkomitees, der seine Pflichten als Partisan weiter erfüllt. Insgesamt zählt die Komsomolorganisation der Brigade 234 Komsomolzen. Sie sind tatsächlich nicht nur ein Beispiel für die parteilose Jugend, sondern auch in der Jugend der Abteilungen führend und haben erreicht, daß ihre Organisationen politisch und als Kampfkraft Ansehen genießen. Das bestätigt die Tatsache, daß von den durch die Brigade im Oktober und November 1943 zum Entgleisen gebrachten 30 Zügen 20 Züge auf die Diversionsgruppen der Komsomolzen entfallen.

2. Kurz gesagt ist die Kampftätigkeit der Brigade dadurch charakterisiert, daß alle Abteilungen im letzten Halbjahr hauptsächlich zur Diversionsarbeit und zur Anlegung von Kampfhinterhalten gegen sich bewegende Truppen des Gegners übergegangen sind.

Von Januar bis incl. Dezember 1943 brachten die Abteilungen „Pobeda“, „Bor'ba“, „Nepobedimyj“ und die Lenin-Abteilung 91 gegnerische Züge zum Entgleisen, hierbei zerstörten sie 89 Lokomotiven, 771 Waggons, 22 Loren und 14 Tanks mit Brennstoff. Unter den gesprengten Zügen waren Ausrüstungstransporte des Geg- 
ners (Panzer, Flugzeuge, Artillerie, Soldatenausrüstung usw.) und Truppentransporte zur und von der Front. Durch Sprengung und Entgleisung dieser Züge erlitt der Gegner große Mannschaftsverluste. Nach den vorliegenden Nachrichten und Aufklärungsangaben fanden bei den Entgleisungen 1728 Hitlerleute den Tod.

Neben der Sprengung von Eisenbahnzügen orientieren das Brigadekommando und die Führung der Abteilungen die Partisanen darauf, Eisenbahnbrücken zu sprengen, denn die Brigade verfügt über gut ausgebildete Sprengmeister, die solche Aufträge immer sehr gern ausführen. In dieser Zeit hat die Brigade 28 Eisenbahn-Stahlbetonbrücken gesprengt. Durch diese Explosionen wurde jedesmal eine ganze Bahnstrecke völlig lahmgelegt.

Wegen der beständig arbeitenden Sprengtrupps muß der Feind die Bahnstrecken Lida - Baranoviči und Baranoviči - Volkovysk sowie die betreffenden Brücken unter starker militärischer Bewachung halten. Wir haben dem Feind auf den Eisenbahnen in seinem Hinterland ein Schneckentempo aufgezwungen, das ihn an normaler Munitionsversorgung der deutschen Front hindert.

Auf den Chausseen wurden an strategischen Punkten 4 Stahlbeton- und 49 Holzbrücken gesprengt und zerstört.

An den Chausseen und Eisenbahnstrecken wurden 106,9 km Fernmeldeverbindungen des Gegners zerstört, zum Teil verbrannt und 106 Verbindungsmasten gefällt. An einigen Strecken wie z.B. Derečin - Slonim legt der Feind seit einem Jahr die Drahtverbindung an und stellt Masten auf, kommt jedoch nie dazu, diese Verbindung zu benutzen. Der Feind stellt die Verbindung wieder her, und nachts kommen die Partisanen der Abteilung „Pobeda“ und zerstören das Wiederhergestellte.

Neben der Diversionsarbeit an den Verbindungslinien des Gegners hat die LeninBrigade Fabriken und Werke im gegnerischen Hinterland gesprengt und zerstört. Im Frühjahr 1943 sprengte eine Gruppe des Unterpolitleiters Gen. Šubin das 1. staatliche polnische Zementwerk in der Ortschaft Ros.

Die Gruppe von Prokop Gerasimčik verbrannte und zerstörte die Papierfabrik „Albertin" in Slonim, vernichtete die Ziegelei Nr. 1, eine Stärkefabrik, 4 Sägemühlen, 3 Brennereien, eine Teerbrennerei sowie 22 Molkereien. Ferner wurden 57 für die Unterbringung deutscher Garnisonen bestimmte gemauerte Gebäude zerstört bzw. verbrannt.

Die Brigade leistete all diese Diversions- und Sabotagearbeit ohne jede Hilfe vom „Festland“. Der Sprengstoff wurde aus alten Geschossen und Blindgängern gewonnen, die wir in den Wäldern fanden. Doch muß ohne Umschweife gesagt werden, daß unsere inneren Reserven bei der Sprengstoffbeschaffung jetzt ganz gering sind. Ohne Hilfe der Heimat wird unsere Arbeit künftig vielleicht schwächer.

Im Auftrag des Staates führte die Brigade mit ihren Kräften im August einen Schienenkrieg gegen die Eisenbahnen des Gegners durch. Alle Partisanen, die zuvor entsprechend unterwiesen worden waren, nahmen an diesem Krieg teil. Zur Durchführung einer dermaßen wichtigen Arbeit wurden jeder Abteilung Eisenbahnzonen zugeteilt, jede Abteilung teilte ihre Zone unter den Kompanien, jede Kompanie unter den Zügen auf. Am 18. August nahmen die Leute ihre Ausgangsstellung ein, und in der Nacht zum 19. August wurden 489 Sprengungen vorgenommen. In nur einer Nacht flogen an den vom Feind besetzten Bahnstrecken 489 Gleise in die Luft.

Die massierten Detonationen jener Nacht zwangen den Feind in seine Unterstände, so daß er keinen einzigen Schuß auf unsere Partisanen abgeben konnte. Der Zugver- 
kehr an den Strecken Volkovysk - Lida, Volkovysk - Baranoviči, Lida - Baranoviči wurde für drei Tage und Nächte lahmgelegt. Der Feind mußte Abstellgleise abbauen und Gleise in einer Länge von $28 \mathrm{~km}$ auswechseln; mancherorts waren die Gleise zerstört.

\section{Offene Kämpfe und Hinterhalte gegen den Feind}

Die Diversion der Partisanen der Lenin-Brigade war nicht die einzige Form des Kampfes gegen den Feind.

Viel Zeit widmeten unsere Partisanen Gefechten und Hinterhalten gegen den Feind. Zwischen Dezember 1942 und Dezember 1943 wurden von den Abteilungen „Bor'ba“, „Pobeda“, Nepobedimyj" und der Lenin-Abteilung dem Feind 178 Gefechte geliefert und Hinterhalte gegen ihn gelegt.

In den offenen Gefechten gegen den Feind, hauptsächlich bei Razzien, und bei der Zerschlagung deutscher Polizeireviere sowie in den Kämpfen aus dem Hinterhalt wurden nach Dokumenten in den Akten der Brigade 3310 hitlerische Soldaten und Offiziere getötet, 231 verwundet, 19 gefangengenommen und erschossen.

Es wurden 2 Kleinkampfwagen angeschossen und vernichtet, ein gepanzertes Fahrzeug zerstört, ein Flugzeug verbrannt, $71 \mathrm{Kraftfahrzeuge,} \mathrm{ein} \mathrm{Krad,} 5$ Traktoren mit Anhängern vernichtet, 27 deutsche Gemeindeverwaltungen und 20 Polizeireviere zerstört.

Besonders stark waren die Kämpfe bei Razzien, bei der Zerschlagung der Polizeigarnison in Ruda Javorskaja und beim Angriff auf die Ortschaft Derečin. In diesen Gefechten zeigten die Partisanen der Lenin-Brigade ihre Kampfkraft, ihre Fähigkeit, den Feind zu schlagen, und festigten unter den örtlichen Bauern und Stadteinwohnern ihr Ansehen als Kämpfer.

\section{Verluste der Lenin-Brigade und medizinische Hilfe}

Die medizinische Hilfe und die Sanitätsbetreuung der Abteilungen und Partisanen sind in der Brigade ähnlich wie in der Roten Armee organisiert. Die Brigade hat einen Sanitätschef, er leitet die gesamte medizinische Arbeit in den Abteilungen. Beim Stab der Brigade besteht ein stätionäres Lazarett, das alle nach dem Stellenplan vorgesehenen Ärzte und Sanitäter hat. Jede Abteilung hat einen Abteilungsarzt, jede Kompanie ihren Kompaniefeldscher.

In allen Kämpfen und bei Razzien vom Dezember 1942 bis zum 1. Dezember 1943 verlor die Lenin-Brigade 134 Partisanen, 5 Personen gelten als vermißt, die Zahl der Verwundeten betrug in diesem Zeitraum 129.

Alle Verwundeten kommen ins Brigadelazarett. Dort wurden 171 Verwundete sowie 112 Patienten mit unterschiedlichen Erkrankungen, hauptsächlich Erkältungen, behandelt. Die Medikamente für die Behandlung der Verwundeten und Kranken stammen aus verschiedenen Quellen, darunter aus deutschen Einrichtungen, wozu uns unsere Leute verhalfen. In den letzten Monaten mangelt es dem Lazarett an den nötigen Medikamenten, und es ist völlig unmöglich, sie zu beschaffen; wir brauchen diesbezügliche Hilfe seitens übergeordneter Leitungsorgane.

\section{Die Aufklärungstätigkeit der Brigade}

Die Brigade hat zwei Richtungen in ihrer Aufklärungstätigkeit: Es gibt die Truppenaufklärung, die aus den bei den Abteilungen und der Brigade aufgestellten Ka- 
valleriezügen besteht, und einen Geheimdienst, der über illegale antifaschistische Komitees und geheime Informanten, die in deutschen Einrichtungen tätig sind und frei in den Dörfern leben, organisiert ist. Die Leiter der Aufklärung sind Nikolaj Nikolaevič Poceluev und der Leiter der Sonderabteilung der Brigade Vladimir Adamovič Doroš.

Die Kavallerieaufklärung setzt sich aus 15 berittenen Aufklärern bei jeder Abteilung und 15 Reitern der Brigade zusammen. Die Operationszonen der Aufklärung sind für jede einzelne Abteilung festgelegt. Unter den Aufklärern sind die Tätigkeitszonen paarweise verteilt. Die Truppenaufklärung kontrolliert die örtlichen Polizeigarnisonen, beobachtet die Verlegung der gegnerischen Kräfte, paßt auf fremde Personen auf, die in den Stationierungsräumen der Partisanenabteilungen auftauchen, sammelt Informationen über einzelne Ortschaften und sorgt für Ordnung in den Dörfern, die zur Partisanenbewegung loyal stehen.

Der Geheimdienst besteht aus heimlich angeworbenen Informanten, die an verschiedenen Orten tätig sind. Sie gehören den Kampfabteilungen nicht an, dennoch gelten alle unsere Geheimaufklärer als in unserem Dienst befindlich und haben von uns ausgestellte Papiere. Die Zahl solcher Aufklärer, die außerhalb der Brigade, aber für die Brigade arbeiten, erreicht 61.

Dank ihnen erhalten wir wertvolle Nachrichten über die Eisenbahnen, die Verlegung der Truppen, die Ergebnisse unserer Diversion im Bahntransport, über Personen, die in deutschen Einrichtungen tätig sind, Handlungen und Absichten des Gegners und der Weißpolen. Dank der Tätigkeit unserer Informanten säubern wir die Gebiete um die Pušča von deutschen und polnischen Spionen.

Aufgrund der Materialien unserer Aufklärer wurden 55 deutsche Informanten und Spione getötet. Über unsere Aufklärer prüfen wir Leute aus der örtlichen ländlichen und städtischen Bevölkerung, die in unsere Abteilungen eintreten. Der Geheimdienst wird von speziell ausgebildeten Leuten geleitet. Sie stehen im Dienst der Kavallerieaufklärung und bereiten regelmäßig die Rajons, um Materialien zu sammeln. Mithilfe des Geheimdienstes konnten wir mehrere Diversionsakte in der Polizeigarnison der Stadt Djatlov verüben, ferner sprengten wir mit einer heimlich gelegten Mine ein deutsches Panzerfahrzeug. Wir sprengten auch die Dampfkessel in einer Sägemühle von Slonim und mittels eines unserer Agenten die Ausrüstung im Kraftwerk von Slonim und verbrannten die Werkbänke in einer Sägemühle. Diese Arbeit leisten wir zum ersten Mal. Nach Maßgabe dessen, wie uns die Minen geliefert werden, kann sie erweitert werden. Dazu bestehen viele Möglichkeiten.

\section{Kurze Charakteristik der Entstehung, Erstarkung und Kampftätigkeit der Abteilungen der Lenin-Brigade}

1. Die Abteilung „Pobeda“ zählt 460 Partisanen, Partisaninnen, Kommandeure und Politleiter. Ihr Stützpunkt ist der Rajon Derečin, Oblast' Baranoviči. Bewaffnung der Abteilung: 304 Gewehre, 47 Scharfschützengewehre, 45 leichte Maschinengewehre, ein schweres Maschinengewehr, 2 Degtjarev-Maschinenpistolen, 1 Kompaniegranatwerfer, eine 45-mm-Kanone, außerdem 119 Revolver und Pistolen an persönlichen Waffen.

Die Parteiorganisation der Abteilung zählt 7 Miglieder und 21 Kandidaten der KPdSU(b), die Komsomolorganisation besteht aus 82 Mitgliedern.

Der Abteilungskommandeur ist Pavel Ivanovič Bulak, der Abteilungskommissar 
Grigorij Grigor'evič Ivlev. Die Abteilung ist vier Partisanen-Kampfkompanien stark, an deren Spitze jeweils Kompaniechefs und -politleiter stehen. Jede Kompanie hat vier Züge, jeder Zug zwei Gruppen. Der Kommandeursbestand der Abteilung ist vollzählig.

Die Formierung der Abteilung „Pobeda“ begann im Mai 1942 in den DuborovskieWäldern, die Angehörigen waren Belorussen, die in den Sowjetorganen tätig gewesen waren, und Russen, die aus der Gefangenschaft geflohen waren und zeitweilig, nach dem Abzug der Roten Armee, den Bauern bei ihren Arbeiten halfen. Die Abteilung wuchs durch Neuaufnahmen hauptsächlich im Juni bis August 1942, das maximale Wachstum der Abteilung war im März und April 1943 zu verzeichnen. Im Juni 1943 zählte die Abteilung bereits an die 350 Personen.

Im Juni wurden 70 Partisanen der Abteilung „Pobeda“ zur Aufstellung der neuen Lenin-Abteilung versetzt, aber bis Dezember 1943 ist die Abteilung erneut auf die Stärke von 460 Mann angewachsen und hat sich dank der Hilfe der örtlichen Bevölkerung bewaffnet.

Ihrem Kampf nach ist die Abteilung „Pobeda“ die aktivste in der Brigade. In der Zeit ihrer Tätigkeit wurden 34 Militärzüge zum Entgleisen gebracht, 358 Mannschaftswaggons und Technik des Gegners zerstört, 103 Gefechte geführt und Hinterhalte gegen den Feind gelegt, 20 Eisenbahnbrücken gesprengt und 18 Chausseebrücken verbrannt.

Die Abteilung hat in den Kämpfen viele Waffen erbeutet.

2. Die Abteilung „Bor’ba“ zählt 224 Partisanen, Kommandeure und Politleiter. Ihr Stützpunkt ist der Rajon Djatlovo, Oblast' Baranoviči. Bewaffnung: 163 Gewehre, 21 Scharfschützengewehre, 16 leichte Maschinengewehre, 9 Degtjarev-Maschinenpistolen, 1 überschweres Maschinengewehr, 1 DS-Maschinengewehr, $145-\mathrm{mm}-\mathrm{Ka}$ none, außerdem an persönlichen Waffen 33 Revolver und Pistolen.

Die Parteiorganisation der Abteilung zählt 7 Mitglieder und 28 Kandidaten der KPdSU(b). Die Komsomolorganisation besteht aus 77 Mitgliedern. Der Abteilungskommandeur ist Leutnant Sergej Petrovič Smirnov, der Abteilungskommissar Andrej Kovjazin. Beim Abteilungsstab besteht ein Aufklärungszug. Die Abteilung hat 3 Partisanenschützenkompanien, jede Kompanie hat Züge, jeder Zug zwei Gruppen. Die Kommandeure werden nicht gewählt, sondern ernannt. An der Spitze der Kompanien stehen die Kompaniechefs und -politleiter. Der Kommandeursbestand der Abteilung ist vollzählig.

Ihren Kampfeigenschaften nach steht die Abteilung „Pobeda“ an zweiter Stelle in der Lenin-Brigade. Von Dezember 1942 bis incl. Dezember 1943 brachte die Abteilung 37 Militärzüge zum Entgleisen, wobei 31 Lokomotiven, 245 Waggons mit diversem Kriegsmaterial, ferner 11 Loren mit Panzern zerstört, mehrere Züge mit Mannschaften des Gegners zum Entgleisen gebracht und hierbei 687 Hitlerleute getötet wurden. Vier Eisenbahnbrücken wurden gesprengt, 28 Chausseebrücken niedergebrannt und zerstört. Von der Abteilung wurden 48 Gefechte geführt und Hinterhalte gelegt, hierbei 391 Hitlerleute vernichtet.

Die Abteilung "Bor'ba“ ist eine kampffähige, geschlossene Abteilung. Der Kommandeur und der Kommissar der Abteilung verstehen ihre Aufgaben, sind diszipliniert, moralisch fest, der Sache unserer Partei und unserer sozialistischen Heimat ergeben.

Die Abteilung „Bor’ba“ wurde im Mai 1942 organisiert. 
3. Die Lenin-Abteilung zählt 189 Partisanen, Kommandeure und Politleiter. Ihr Stützpunkt ist der Kozlovskij Rajon, Oblast' Baranoviči. Bewaffnung: $118 \mathrm{Ge}-$ wehre, 20 Scharfschützengewehre, 15 leichte Maschinengewehre, ein schweres Maschinengewehr, 11 Degtjarev-Maschinenpistolen, eine 122-mm-Kanone, außerdem an persönlichen Waffen 33 Revolver und Pistolen.

Die Abteilung entstand im Juli 1943, der Abteilungskommandeur ist Leutnant Valentin Stepanovič Bit'ko, der Kommissar Gabdulachmat Gabdulvakilov. Seit ihrer Entstehung brachte die Abteilung 8 Eisenbahnzüge zum Entgleisen, davon zwei Mannschaftstransporte, wobei 275 hitlerische Soldaten und Offiziere den Tod fanden.

Von der Abteilung wurden 23 Gefechte durchgeführt und Hinterhalte gegen den Feind gelegt. In den Kämpfen wurden 85 Hitlerleute getötet und weitere 77 verwundet, $17 \mathrm{Kraftfahrzeuge,} \mathrm{ein} \mathrm{Kleinkampfwagen} \mathrm{und} \mathrm{ein} \mathrm{Traktor} \mathrm{mit} \mathrm{Anhänger}$ zerstört. Als Kampfeinheit ist die Abteilung fest geschlossen.

4. Die Abteilung „Nepobedimyj“ "zählt 130 Partisanen, Kommandeure und Politleiter. Bewaffnung: 95 Gewehre, 4 Maschinengewehre, 5 Degtjarev-Maschinenpistolen, außerdem an persönlichen Waffen 11 Revolver und Pistolen.

Die Abteilung wurde im Mai 1943 organisiert. Ursprünglich 24 Mann stark, wuchs sie durch Neuaufnahmen aus der Stadt Slonim und der örtlichen Bevölkerung. In dieser Zeit hat die Abteilung 12 Eisenbahnzüge zum Entgleisen gebracht, die Papierfabrik in Slonim verbrannt und die Ausrüstung im Kraftwerk von Slonim gesprengt.

Über die Stadt Slonim versorgt die Abteilung die Brigade mit wertvollen Aufklärungsangaben über den Gegner.

Der Abteilungskommandeur ist Prokop Gerasimčik, der Abteilungskommissar ist Politleiter Stepan Kosterenko.

Als Kampfeinheit ist die Abteilung fest geschlossen.

Für die Kampf- und Diversionstätigkeit haben die Führung der Abteilungen und das Brigadekommando 123 Partisanen, die sich in den Kämpfen für die Heimat, die Festigung der militärischen Disziplin ausgezeichnet haben, für Regierungsauszeichnungen und 45 Personen für gute Leitung der Einheiten zur Beförderung zu mittleren und höheren Kommandeuren vorgeschlagen.

Kommandeur der Lenin-Brigade

Bataillonskommissar

(Makarov)

Stabschef der Lenin-Brigade

Unterpolitleiter

(Šubin)

F. 3500, op. 4, d. 2, 11. 68-74. 


\section{Dokument Nr. 10}

\section{Befehl Nr. 0064 des Bevollmächtigten des Zentralstabes der Partisanen- bewegung für die Oblast' Baranoviči vom 23. Dezember 1943 über die Aufstellung der Čapaev-Brigade}

Streng geheim

Expl. Nr......

\section{Befehl}

des Bevollmächtigten des Zentralstabes der Partisanenbewegung beim Hauptquartier des Oberkommandos und des $Z K \operatorname{der} K P(b) B$ für die Oblast' Baranoviči

23. Dezember 1943 Nr. 0064 Pušča N.

1. Zwecks Erweiterung der Partisanenbewegung und besserer Manövrierfähigkeit und Kontrolle sind die Čapaev- und die Parchomenko-Abteilung aus der StalinBrigade auszugliedern und zu einer Brigade zu entfalten. Sie wird nach Čapaev benannt.

2. Ich ernenne:

Grigorij Leonidovič Kudrin zum Brigadekommandeur, Pavel Aleksandrovič Sklemin zum Brigadekommissar, Aleksej Vasil'evič Sautin zum Stabschef der Brigade,

Aleksej Iosifovič Bus'ko zum Leiter der Sonderabteilung der Brigade i. V., Nikolaj Vasil'evič Pavlov zum Stellvertreter des Brigadekommissars für den Komsomol.

3. In die Brigade sind einzugliedern: die Čapaev-Abteilung, die neu organisierte Furmanov-, die Parchomenko- und die (unbewaffnete) Reserveabteilung.

4. Als Kommandeur der Čapaev-Abteilung bestätige ich Boris Alekseevič Borovikov, als Abeilungskommissar Pavel Stanislavovič Kočatkov.

Als Kommandeur der Furmanov-Abteilung bestätige ich Nikolaj Grigor'evič Gučinskij, als Abteilungskommissar Petr Prokof'evič Danilovi. V.

Als Kommandeur der Parchomenko-Abteilung bestätige ich Michail Filipovič Sergeev,

als Abteilungskommissar Stepan Petrovič Ošerov.

5. Das Brigadekommando hat der Reserveabteilung einen bewaffneten Begleitschutz zu stellen und unbewaffnete Partisanen weitgehend zur Aufklärung, Brükkenbeschädigung, Störung von Fernmeldeverbindungen u. a. heranzuziehen.

6. Als den Operationsraum der Brigade setze ich fest: Voložin, Višnevo und die Dörfer des Juratišskij Rajons nördlich der Straße Bakšty - Iv'e. Bis zur Verlegung in den neuen Raum sind die politische Arbeit und die wirtschaftlichen Operationen im Operationsraum der Čapaev-Abteilung (Rajon Ivenec) durchzuführen.

7. Der neu organisierten Brigade stelle ich folgende Aufgaben: entschieden die Arbeit der Waffenbeschaffung zu verstärken; die zahlenmäßige Stärke der Abteilungen durch Aufnahme örtlicher Bewohner zu erhöhen; ununterbrochene Schläge gegen die Bahnstrecke Lida - Molodečno durchzuführen, dazu Militärzüge, die Gleise und Bahnanlagen zu sprengen; in der Winterzeit mindestens 40 Militärzüge zum Entgleisen zu bringen; die Chausseen Voložin - Gorod'ki und Voložin - Lida systematisch zu verminen, die Strecke zu kontrollieren, die Mannschaften und die Tech- 
nik des Feindes aus Hinterhalten zu vernichten; Aufklärung für die Rote Armee durchzuführen; Landesverräter zu töten.

8. In Bezug auf die operative Führung unterstelle ich die Brigade dem Oblastzentrum. Die Parteiorganisationen der Brigade gehören zum Rajonkomitee Voložin $\operatorname{der} \mathrm{KP}(\mathrm{b}) \mathrm{B}$.

Bevollmächtigter des Zentralstabes

der Partisanenbewegung beim Hauptquartier

des Oberkommandos und des ZK der KP(b)B

für die Oblast' Baranoviči

Generalmajor

(Platon)

Angefertigt in 4 Expl.

Expl. Nr. 1 - zu den Akten.

Expl. Nr. 2 - an die Čapaev-Brigade.

Expl. Nr. 3 - an die Stalin-Brigade.

Expl. Nr. 4 - an Dubov.

F. 1329, op. 1, d. 29, 1. 138.

\section{Dokument Nr. 11}

\section{Befehl Nr. 0065 des Bevollmächtigten des Zentralstabes der Partisanen- bewegung für die Oblast' Baranoviči vom 28. Dezember 1943 über die Aufstellung der Ponomarenko-Brigade}

Streng gebeim Expl. Nr......

\section{Befehl}

des Bevollmächtigten des Zentralstabes der Partisanenbewegung beim Hauptquartier des Oberkommandos und des $Z K \operatorname{der} K P(b) B$

$$
\text { für die Oblast' Baranoviči }
$$

\section{Dezember 1943}

Nr. 0065

Pušča N.

5. Zur Dezentralisierung der Stalin-Brigade, besserer Kontrolle, Manövrierfähigkeit und Verstärkung der Partisanenbewegung sind aus der Stalin-Brigade die Ponomarenko- und die Budennyj-Abteilung auszugliedern und zu einer Brigade zu entfalten. Diese ist nach Ponomarenko $z u$ benennen.

6. Ich ernenne den Gen. Semen Grigor'evič Ganzenko zum Brigadekommandeur, den Gen. Georgij Vasil'evič Budaj zum Kommissar, den Gen. V. Zykov zum Stabschef der Brigade, den Gen. Dmitrij Stepanovič Sadovskij zum Chef der Sonderabteilung der Brigade, den Gen. Bojko zum Stellvertreter des Kommissars für den Komsomol.

7. In die Brigade sind folgende Abteilungen einzugliedern:

a) die Ponomarenko-Abteilung (Kommandeur: Kajdalov, Kommissar: Snežlkov),

b) die Budennyj-Kavallerieabteilung (50 Pers.),

c) die (durch Aufgliederung der Budennyj-Abteilung) neu organisierte Abteilung,

d) die Abteilung „25 Jahre BSSR“ (65 Pers.),

e) die Timošenko-Abteilung (100 Pers.), 
f) die Voronov-Abteilung (70 Pers.),

g) die Vasilevskij-Abteilung (65 Pers.).

Die Führung der neu organisierten Abteilungen bestätige ich in folgender Zusammensetzung:

a) Kommandeur der Budennyj-Abteilung: Gen. Stepan Pavlovič Kokuš, zugleich stellvertretender Brigadekommandeur; Kommissar: Gen. Safonov.

b) Kommandeur der Timošenko-Abteilung: Gen. Aleksej Antonovič Lugar, der Abteilungskommissar i. V.: Pavel Akimovič Troeglazov, Stabschef: I. Michajlov.

c) Kommandeur der Abteilung „25 Jahre BSSR“: Gen. Michail Konstantinovič Verchovcev, Kommissar: Naum L'vovič Feldman, Stabschef: Gen. A. Zubkov.

d) Kommandeur der Voronov-Abteilung: Gen. Pavel Ivanovič Petrov, Kommissar: Gen. S. Tamarin, Stabschef: Gen. W. Kuz'min.

e) Kommandeur der Vasilevskij-Abteilung: Gen. Nikolaj Dmitrevič Maslovskij, Kommissar: Gen. Vasilij Jakovlevič Nazarov, Stabschef: N. Santorovič.

5. Als Operationsraum der Ponomarenko-Brigade lege ich den Raum Rubeževiči Kojdanovo fest. Das genaue Verzeichnis der Dörfer, die zur Zone der Brigade gehören, wird vom Rajonkomitee Ivenec der $\mathrm{KP}(\mathrm{b}) \mathrm{B}$ festgesetzt.

6. Die zu verlassenden Lager der Frunze-Brigade sind der Ponomarenko-Brigade zu übergeben.

7. In Bezug auf die operative Leitung unterstelle ich die Brigade dem Oblastzentrum. Die Parteiorganisation gehört zum Rajonkomitee Ivenec der KP(b)B. Meinem Gehilfen Gen. Dubov wird die Leitung und Kontrolle der Tätigkeit der Brigade auferlegt.

8. Der Führung der Abteilungen und dem Brigadekommando stelle ich folgende Aufgaben:

Die zahlenmäßige Stärke der Abteilungen durch Neuaufnahmen aus der örtlichen Bevölkerung zu erhöhen. Gegen die Verbindungslinien der deutschen Besatzer an der Bahnstrecke Stolbcy - Minsk Schläge zu führen. In der Winterzeit mindestens 40 Eisenbahnzüge des Gegners zu sprengen. Die Gleise zu sprengen, die Verbindungslinien zu zerstören, Bahnanlagen zu zerstören, die Verlegungen am Abschnitt der Chaussee Minsk - Stolbcy - Rubeževiči zu kontrollieren und aus Hinterhalten die Mannschaften des Gegners zu vernichten und Kraftfahrzeuge zu sprengen. Im Raum von Minsk und Kojdanovo Aufklärung für die Rote Armee zu leisten. Verräter an unserer Heimat zu vernichten.

Bevollmächtigter des Zentralstabes

der Partisanenbewegung beim Hauptquartier

des Oberkommandos und des ZK der KP(b)B

für die Oblast' Baranoviči

Generalmajor

Angefertigt in $5 \mathrm{Expl}$.

Expl. Nr. 1 - zu den Akten.

Expl. Nr. 2 - an die Ponomarenko-Brigade.

Expl. Nr. 3 - an die Ponomarenko-Abteilung.

Expl. Nr. 4 - an die Stalin-Brigade.

Expl. Nr. 5 - an Dubov.

F. 1329, op. 1, d. 29, 11. 140-141. 


\section{Dokument Nr. 12}

\section{Provisorische Instruktion über den medizinischen und Sanitätsdienst in der Oblast' Baranoviči vom 3. Januar 1944}

\section{Bestätigt:}

Die vorliegende provisorische Instruktion

wird zur Anleitung und Befolgung in allen Abteilungen und Brigaden der Oblast' Baranoviči eingeführt.

\section{Bevollmächtigter des Zentralstabes der Partisanenbewegung und des $Z K \operatorname{der} K P(b) B$ für die Oblast' Baranoviči Generalmajor Platon.}

\section{1. 1944.}

Das Fehlen einer bindenden Anordnung über die Rechte und Pflichten der Mitarbeiter des medizinischen und Sanitätsdienstes führt dazu, daß in den Abteilungen keine ausreichende persönliche Verantwortung für die medizinische und sanitäre Betreuung der Mannschaft der Abteilungen besteht. Es gibt keine konkreten Rechte und Pflichten, angefangen mit dem Sanitätsunterpersonal bis zum Abteilungsarzt. All das hat bewirkt, daß in mehreren Abteilungen die Lebensweise und die Versorgung der Partisanen, insbesondere der Verpflegungsdienst, einen unhygienischen Zustand aufweisen.

Das Fehlen der entsprechenden medizinischen Aufsichts- und Kontrollmaßnahmen hat das Auftreten von Haut- und Geschlechts- sowie Infektionskrankheiten in den Abteilungen möglich gemacht. Das Fehlen von Ambulanzen und Krankenstationen hat zur Folge, daß die Behandlung längere Zeit in Anspruch nimmt und die Partisanen die Kampffähigkeit für längere Zeit verlieren. Der Umstand, daß die unteren Gliederungen kein ihnen zugeteiltes medizinisches Personal haben, führt dazu, daß die medizinische Hilfe (besonders unter Gefechtsbedingungen) nicht rechtzeitig geleistet wird, was bei Verwundungen Komplikationen und oft unerwünschte Folgen nach sich zieht.

Zur Regelung des medizinischen und Sanitätsdienstes in den Partisanenabteilungen und Beseitigung der Mängel in der Arbeit des medizinischen und Sanitätsdienstes wird folgende Instruktion eingeführt:

\section{Instruktion über die Ausübung des medizinischen und Sanitätsdienstes}

\section{Provisorische Instruktion \\ Über die Ausübung des medizinischen und Sanitätsdienstes in den Partisanenabeilungen der Oblast' Baranoviči}

I. Organisation des medizinischen und Sanitätsdienstes in den Partisanenabteilungen

Der medizinische und Sanitätsdienst einer Partisanenabteilung wird vom Abteilungsarzt geleitet, der Gehilfe des Kommandeurs für den Sanitätsdienst ist. (In Abteilungen oder Gruppen, die keinen Arzt haben, werden die Obliegenheiten eines Arztes zeitweilig einem Mitarbeiter des Sanitätshilfspersonals mittlerer Stufe - einem Feldscher oder einer Krankenschwester - auferlegt.) 
$\mathrm{Zu}$ den Obliegenheiten eines Arztes gehört folgendes:

a) den gesamten medizinischen und Sanitätsdienst der Abteilung und das ihm unterstellte mittlere Sanitätshilfspersonal anzuleiten;

b) die Ambulanz und die stationäre Lazaretteinrichtung unmittelbar zu leiten;

c) die Abteilung mit einem Minimum an Instrumentarium, Medikamenten, Verbandszeug zu versorgen (in gleicher Weise wie der Kommandeur daran interessiert sein muß, die Abteilung mit Munition zu versorgen);

d) für die Mannschaften und die Bevölkerung im Wirkungsbereich der Abteilung hygienische Aufklärungsarbeit in Form von Vorträgen und Aussprachen zu leisten;

e) der Arzt trägt die Verantwortung für den allgemeinen Stand und die Organisation des medizinischen und Sanitätsdienstes in der Abteilung und ist in seinen Handlungen dem Kommandeur und dem Kommmissar der Abteilung rechenschaftspflichtig.

Anmerkung: Alle den Sanitätsdienst betreffenden Weisungen des Arztes sind, wenn zuvor mit der Abteilungsführung abgestimmt, für das gesamte Abteilungspersonal bindend.

Der Abteilungsarzt oder die ihn ersetzende Person, ein oberer Mitarbeiter des Sanitätsdienstes, und ein zweiter Arzt (wenn vorhanden) sind von jeder anderen, mit der Medizin nicht verbundenen Arbeit freizustellen. Das übrige medizinische Personal ist vorschriftsmäßig einzusetzen.

2. Wenn es in der Abteilung eine ausreichende Anzahl von medizinischen Mitarbeitern gibt, sind sie unbedingt den Kompanien zuzuteilen; sie haben folgende Aufgaben:

a) sanitäre Aufsicht über die Kochstelle der Kompanie;

b) sanitäre Aufsicht über den Zustand der Erdhütten der Kompanie;

c) Erste Hilfe in der eigenen Einheit;

d) Überwachung des Zustands der Mannschaften und der rechtzeitigen Befolgung hygienischer Maßnahmen (Besuch der Badeanlage, Wäschewaschen u. ä.);

e) Dienstverrichtung im Lazarett und Befolgung der medizinisch-prophylaktischen Weisungen des Arztes oder der ihn in der Abteilung ersetzenden Person;

f) allmorgendlicher Rundgang durch die Objekte seiner Einheit, um eventuelle Kranke festzustellen und entsprechende prophylaktische und sanitäre Weisungen zu erteilen;

g) Kochen für die Kranken der Kompanie, wenn eine stationäre Lazaretteinrichtung fehlt.

Medizinische Mitarbeiter der Kompanie sind dem Abteilungsarzt, dem Kompaniechef und dem Politleiter der Kompanie rechenschaftspflichtig. Alle den Sanitätsdienst betreffenden Verfügungen des medizinischen Mitarbeiters sind, wenn zuvor mit dem Kompaniechef abgestimmt, für die gesamte Mannschaft der entsprechenden Einheit bindend.

II. Prophylaktische Maßnahmen

1. Ins Lager neu Eintreffende werden ohne vorherige medizinische Untersuchung nicht aufgenommen. Personen, bei denen der Verdacht einer Infektionskrankheit vorliegt, werden nicht zur Abteilung zugelassen.

2. Systematisch, zweimal im Monat, ist eine medizinische Untersuchung der Mannschaft der Abteilung durchzuführen. 
a) Mitarbeiter der Feldküche werden allwöchentlich kontrolliert.

b) Personen, die eine längere Dienstreise gemacht haben, werden am Tag ihrer Ankunft untersucht.

3. Einweisung aller Fiebernden sowie aller Personen, die stationärer Behandlung bedürfen oder in Quarantäne genommen werden, ins Lazarett.

4. Beobachtung des sanitärmedizinischen Zustands der Ortschaften und der Bevölkerung, mit der die Mannschaft der Abteilung Kontakte unterhält (überaus wichtig für Abteilungen ohne festen Standort).

5. Unbedingte hygienische Überprüfung eines neuen Standortes und der angrenzenden Räume bei der Verlegung von Abteilungen.

III. Sanitäre und hygienische Maßnahmen

1. Beim Bau der Erdhütten ist darauf zu achten, daß sie höchstens 20 Personen Raum bieten sollen. Die Pritschen sind auf eine Weise zu verteilen, daß keine von mehr als zwei Personen benutzt wird; zwischen den Pritschen muß ein Abstand sein.

2. Der Austausch der Bettwäsche von Pritsche zu Pritsche ist zu verbieten.

3. In den Erdhütten muß es Diensthabende geben, die zu heizen, aufzuräumen und zu lüften haben. Der jeweilige Diensthabende ist für Sauberkeit und Ordnung in der Erdhütte verantwortlich.

4. Die Einquartierung von Abteilungen ohne festen Standort in den Dörfern erfolgt unter Berücksichtigung der Angaben der vorherigen hygienischen Untersuchung. 5. In jeder Abteilung müssen (bei ständiger Unterbringung) eine Badeeinrichtung mit Ankleideraum, Anlagen zum Wäschewaschen und -trocknen und eine primitive Entseuchungs- (Entlausungs-)Anlage gebaut werden.

a) Mindestens zweimal im Monat ist ein Bad zu nehmen und die Wäsche zu wechseln.

6. Brunnen dürfen nicht an vernachlässigten Ödplätzen angelegt werden, sie müssen von Verschmutzungsquellen entfernt sein und eine mindestens $0,75 \mathrm{~m}$ hohe Schachteinfassung haben. Jeder Brunnen muß einen Schwingbaum und einen zur allgemeinen Benutzung verfügbaren Schöpfeimer haben. Für das Vieh sind andere Brunnen zu graben.

7. Die Entfernung zwischen den Ställen und den Erdhütten und Kochstellen darf nicht weniger als $100 \mathrm{~m}$ betragen.

8. Die Toiletten müssen mindestens $100 \mathrm{~m}$ weit von denselben Objekten entfernt liegen.

9. Die Küche muß umzäunt, das Essen außerhalb der Küche ausgegeben werden, und zwar nach Kostprobenentnahme durch den Koch, den Oberfeldwebel und einen medizinischen Mitarbeiter.

a) In der Küche dürfen sich nur deren Mitarbeiter aufhalten.

b) Zur Kontrolle dürfen nur der zugeteilte medizinische Mitarbeiter, der Arzt, die Führung der Abteilung, der Kompanie, der Oberfeldwebel und der Diensthabende die Küche betreten. Allen anderen Personen ist der Eintritt streng verboten.

c) Die Hilfsarbeiter der Küche dürfen diese nicht betreten, ihnen wird ein besonderer Arbeitsort (außerhalb der Küche) zugewiesen.

d) Die Küche muß ein ständiges Personal haben.

e) Kupfer- und verzinktes Geschirr darf beim Zubereiten der Warmverpflegung nicht angewandt werden. 
10. In den Verpflegungslagern sind die Nahrungsmittel von anderem Lagergut streng getrennt zu halten.

11. Für das Schlachten von Vieh ist eine gesonderte Stelle anzulegen. Alle Abfälle werden sofort vergraben.

12. Das Lager ist täglich von Schmutz zu säubern.

13. Jede Abteilung muß eine ständige Wäscherin haben.

14. Das Betreten der Bäckerei ist Unbefugten verboten. In ihr dürfen sich nur der Bäcker und die ihn kontrollierenden Personen aufhalten.

a) Das Zubereiten der für die Mannschaft bestimmten Verpflegung ist in der Bäckerei verboten.

b) In der Bäckerei sind nur Mehl und daraus hergestellte Lebensmittel aufzubewahren. Das Aufbewahren alles anderen ist VERBOTEN.

c) Die Mitarbeiter des Verpflegungsdienstes der Abteilung erhalten Kopfbedeckungen, Schürzen und Ärmelschutz.

IV. Ärztliche Behandlungsmaßnahmen

1. Die primäre Krankenuntersuchung wird von den medizinischen Mitarbeitern der eigenen Einheit vorgenommen, unter Gefechtsbedingungen von ihnen auch Erste Hilfe geleistet.

2. Erforderlichenfalls führen die medizinischen Mitarbeiter Erkrankte dem Arzt zur Konsultation und fachgerechter Behandlung vor.

3. Über die eventuelle Einlieferung in eine stationäre Lazaretteinrichtung entscheidet der Abteilungsarzt oder die ihn vertretende Person.

4. Alle Behandlungsmaßnahmen werden vom Arzt oder der ihn vertretenden Person vorgeschrieben, die Erfüllung der Vorschriften obliegt im Lazarett dem diensthabenden medizinischen Personal und in den Kompanien ihren medizinischen Mitarbeitern.

Anmerkung: Chirurgische und ähnliche Eingriffe werden vom Arzt vorgenommen, für kleinere chirurgische Eingriffe ist das mittlere Personal zuständig.

5. Abteilungen, in deren Standort es keine ausreichende Anzahl von qualifizierten medizinischen Kräften gibt, konsultieren erforderlichenfalls die Ärzte anderer Abteilungen.

6. In jeder Abteilung wird eine stationäre Lazaretteinrichtung geschaffen, ausgehend von 7 Betten je 100 Personen.

Abteilungen ohne festen Standort bauen Lazarette an versteckten Stellen, von Ortschaften entfernt, wobei für Kranke und Betreuungspersonal ein dreimonatiger Lebensmittelvorrat sicherzustellen ist.

a) Die stationäre Lazaretteinrichtung muß einen Spezialraum für chirurgische Fälle, allgemeine und Infektionskrankheiten haben.

b) In der Lazaretteinrichtung (oder einem einzelnen Raum) ist eine Ambulanz einzurichten.

c) Die allgemeine Kontrolle der Befolgung der Behandlungsvorschriften, der Kost, des hygienischen Zustands und der Versorgung der stationären Lazaretteinrichtung obliegt dem höheren medizinischen Mitarbeiter oder (wenn verfügbar) einem zweiten Abteilungsarzt; über andere Fälle entscheidet der Sanitätschef der Abteilung.

d) Der Grad der vorübergehenden oder teilweisen Arbeitsunfähigkeit wird ausschließlich vom Arzt oder von der ihn ersetzenden Person bestimmt. 
Anmerkung: Für bettlägerige Kranke muß eine Sonderkost eingeführt werden; für ihre Zubereitung ist Hilfspersonal anzustellen.

7. Unter Gefechtsbedingungen, wenn die gesamte Abteilung eingesetzt ist, wird die medizinische Versorgung vom Abteilungsarzt durchgeführt, er entscheidet auch über den Grad des Einsatzes aller ihm unterstellten medizinischen Mitarbeiter.

a) Beim Einsatz einzelner Einheiten wird die Sanitätsbetreuung vom medizinischen Mitarbeiter der jeweiligen Einheit besorgt.

b) Bei Erfüllung eines Kampfauftrages durch eine Gruppe, deren Stärke unter der Stärke einer Kompanie liegt, entscheidet der Sanitätschef der Abteilung gemeinsam mit der Kompanieführung darüber, ob der medizinische Mitarbeiter mit eingesetzt wird.

c) Die vom Arzt für die Zeit des Einsatzes oder des Aufenthalts der Abteilung unter Gefechtsbedingungen ausgearbeiteten Sanitätsmaßnahmen werden von der Abteilungsführung bestätigt.

Anmerkung: Wegen der Spezifik einiger Abteilungen kann die vorliegende provisorische Instruktion nicht vollständig sein; deshalb werden diese Abteilungen darauf aufmerksam gemacht, daß ihre eigenen medizinischen Mitarbeiter die Initiative ergreifen und den Sanitäts- und medizinischen Dienst auf das erforderliche Niveau heben müssen.

Die vorliegende Instruktion ist umzusetzen und tritt mit dem Tag ihres Eingangs bei der Brigade und den Abteilungen in Kraft.

Gehilfe des Bevollmächtigten

des Zentralstabes und des ZK der KP(b)B

Chef des medizinischen Dienstes beim Gehilfen

des Bevollmächtigten des ZK der KP(b)B

(Sokolov)

(Tanc)

F. 3500, op. 4, d. 246, 11. 4-7.

\section{Dokument Nr. 13}

Befehl des Gehilfen des Bevollmächtigten des ZK der KP(b)B und des Belorussischen Stabes der Partisanenbewegung für die Oblast' Baranoviči vom 24. Januar 1944 über die Abschaffung des Partisanenehrengerichts

\section{Befehl}

Streng geheim

des Gebilfen des Bevollmächtigten des ZK der $K P(b) B$

und des Belorussischen Stabes der Partisanenbewegung

für die Oblast' Baranoviči

Pušča N.

Nr. 5

24. Januar 1944

Die in einigen Abteilungen bestehenden Partisanenehrengerichte sind als Form der administrativen und gerichtlichen Strafmaßnahme für Partisanen, die sich etwas haben zuschulden kommen lassen, nicht dazu angetan, die Rolle und Autorität der Führung der Abteilungen und Brigaden zu erhöhen, denn die vom Gericht getroffene Entscheidung (Haftdauer) ist unter unseren Bedingungen unerfüllbar. Doch 
können die Partisanenehrengerichte später als Form der gesellschaftlichen Einwirkung und moralischen Erziehung der Partisanen weitgehend praktiziert werden. Anhand des oben Dargelegten befehle ich:

1. die Partisanenehrengerichte als Form der administrativen und gerichtlichen Strafmaßnahme abzuschaffen;

2. die vom Gericht früher getroffenen Entscheidungen aufzuheben.

Gehilfe des Bevollmächtigten des ZK der KP(b)B

des Belorussischen Stabes der Partisanenbewegung

für die Oblast' Baranoviči

(Carjuk)

F. 1329, op. 1, d. 68, 1. 73 .

\title{
Dokument Nr. 14
}

\section{Befehl Nr. 009 vom 25. Februar 1944 des Bevollmächtigten des ZK der KP(b)B und des Belorussischen Stabs der Partisanenbewegung für das Vereinigte Rajonzentrum Ščučin über die Rekrutierung für Partisanenabteilungen}

\author{
Befehl
}

Streng gebeim

des Bevollmächtigten des $Z K$ der KP(b)B und des Belorussischen Stabs der Partisanenbewegung für das Vereinigte Rajonzentrum Ščččn,

\section{Oblast' Baranoviči}

Wald

Nr. 009

25. Februar 1944

Die Rote Armee schlägt die deutschen Besatzer an allen Fronten, treibt sie westwärts und säubert so das Sowjetland vom faschistischen Pack. Die zurückweichenden Deutschen äschern die Dörfer ein und deportieren die ganze Bevölkerung nach Deutschland zur Zwangsarbeit.

Zum Schutz der Sowjetmenschen und zur Verhinderung ihrer Deportierung nach Deutschland

befeble ich:

1. Lt. Befehl Nr. 006 vom 12.2.44 die Jahrgänge 1915 bis einschließl. 1925 in den Dörfern der Operationszone jeder Brigade in die Reihen der Partisanen zu rekrutieren.

2. Die Rekrutierung ist folgendermaßen durchzuführen: Die Kommandeure und Kommissare der Brigaden und Abteilungen haben in den zu mobilisierenden Dörfern die genannten Jahrgänge zu erfassen, darauf Versammlungen zur Erläuterung der Rekrutierungsfrage abzuhalten und die Rekrutierten sofort in die Partisaneneinheiten zu bringen.

3. Um keine Kranken aufzunehmen, muß bei der Aufnahme der Leute unbedingt ein Arzt oder ein militärischer Feldscher anwesend sein.

4. Mit der Durchführung dieser Arbeit werden nur Kommandeure und Kommissare der Brigaden sowie Kommandeure und Kommissare der Abteilungen herangezogen, und sie tragen auch die volle Verantwortung für die richtige Durchführung dieser Arbeit. 
5. Ich verpflichte die Kommandeure und Kommissare der Brigaden und Abteilungen, alle Maßnahmen zu treffen, um zu verhindern, daß die Familien der Rekrutierten sowie die übrige Bevölkerung nach Deutschland deportiert werden.

6. Zur Durchführung der Mobilmachung durch den Verband von Generalmajor Gen. Kapusta werden folgende Dörfer im Aktionsraum der Vorošilov-Brigade bestimmt: Pervye Goluby und Vtorye Goluby, Pervye Žačepiki und Vtorye Začepiki, Kolpinskie und Gončary. Die Mobilmachung ist vom 25. 2 bis 27. 2. 44 einzuleiten.

Bevollmächtigter des ZK der KP(b)B und des Belorussischen Stabs der Partisanenbewegung für das vereinigte Rajonzentrum Ščučin,

Oblast' Baranoviči Šupenja

F. 1329, op. 1, d. 82, 1. 59 .

\section{Dokument Nr. 15}

\section{Geschichte der Partisanenbrigade „Leninscher Komsomol“ (Mai 1942 - Juli 1944)}

\section{Geschichte der Partisanenbrigade „Leninscher Komsomol“ Westbelorußland}

(Mai 1942 bis einschl. 2. Juli 1944)

Im Herbst 1941, als die Lawine der deutschen Vandalen unser Land überschwemmte, als die deutsche Propaganda in der ganzen Welt den Sieg der deutschen Waffen, die Vernichtung der Roten Armee und ihre moralische Zersetzung hinausposaunte, nahmen die echten Sowjetmenschen, die treuen Söhne der Partei, tief im gegnerischen Hinterland den Kampf gegen die deutsch-faschistischen Besatzer auf. Die besten Söhne der Heimat nahmen die Waffe in die Hand, erhoben die Fahne des Partisanenkampfes und gingen in die Wälder.

Im Zusammenhang mit dem schnellen Rückzug der Roten Armee zu Beginn des Krieges kam es so, daß viele Rotarmisten, Einwohner Ostbelorußlands, sowjetische Aktivisten aus den Dörfern und ein Teil der leitenden Rajonfunktionäre auf dem Territorium der Rajons Vasilišskij, Radun'skij und Skidel'skij in der Oblast' Grodno, beim Zurückweichen in einen Kessel gerieten. Nach der Okkupation der oben genannten Rajons riefen die deutschen Besatzer alle kriminellen Elemente, meist von der Sowjetmacht Repressierte, ehemalige Gutsherren, in der Belagerung Gebliebene zu Hilfe und machten sie zu Dorfältesten, Polizisten, Dorfschulzen, Gemeindeverwaltern usw. Mit Hilfe dieser Elemente begannen die deutschen Besatzer von den ersten Tagen ihres Einmarsches an, massenweise alle sowjetischen Aktivisten zu vernichten: die Deputierten der Dorf- und Rajonsowjets, sowjetische Angestellte. Diejenigen von ihnen, die nicht aufgaben, an den Sieg der Roten Armee glaubten und den ganzen Ernst der entstandenen Lage verstanden, gingen sofort in die Wälder oder in den Untergrund, organisierten Gruppen und bereiteten den Boden für einen organisierten bewaffneten Kampf gegen den Feind vor. Den örtlichen Genossen, die sich vor der deutschen Okkupation versteckt hielten, schlossen sich 
allmählich ehemalige Rotarmisten und Kommandeure an, die aus Umzingelungen ausgebrochen oder aus der deutschen Gefangenschaft geflohen waren. Auf diese Weise bestanden drei Monate nach der deutschen Okkupation im Oktober 1941 schon Gruppen, die in den Wäldern auf dem Territorium des Rajons Vasilišskij lebten: die Gruppe von Leutnant A. I. Ivanov, 8-10 Mann stark; die Gruppe von B. I. Gordejčik, ehemaliger Direktor des [...] Kombinats von Vasilišskij, die sich aus 6 örtlichen Sowjetfunktionären zusammensetzte; die Gruppe des Hauptfeldwebels V. Mel'nikov, 7 Mann stark; die Gruppe des Rotarmisten A. N. Nevečenko, 4 Mann stark; die Gruppe von P. Žukovskij, ehemaliger Mitarbeiter eines Dorfladens, 5 Mann stark.

Auf dem Territorium des Ščučinskij Rajons entstand bei den Dörfern Spuša und Karaševo eine 7 Mann starke Gruppe unter Leitung des aus der Gefangenschaft geflohenen Rotarmisten I. W. Akiškin. Auf dem Territorium des Rajons Radun'skij gab es die Gruppe des Politleiters Osipenko und des Sowjetfunktionärs Bud'ko. Alle aufgezählten Gruppen hatten zu jener Zeit noch keine regelmäßige Verbindung miteinander, lebten in der Nähe der belorussischen Bevölkerung in kleineren Wäldern und waren mit einem begrenzten Kreis von örtlichen Bauern verbunden, die sie mit Lebensmitteln versorgten und jeweils vor Gefahren seitens der Deutschen warnten. An Bewaffnung hatten sie lediglich einen oder zwei rostige Stutzer je Gruppe, sonst nichts. Einige der Leiter der bestehenden Gruppen sowie eine Reihe Genossen, die in den Gehöften illegal lebten, leisteten parallel zur Organisation und Bewaffnung der in den Wäldern befindlichen Gruppen antifaschistische Agitationsarbeit unter der örtlichen Bevölkerung und organisierten in den Dörfern antifaschistische Widerstandsgruppen. Schon im November 1941 existierten zwei antifaschistische Untergrund-Organisationen: eine auf dem Territorium des Narašanskij-Dorfsowjets, Vasilišskij Rajon bestehend aus [...] Personen, die von T. T. Gordejčik und P. Žukovskij organisiert wurde, und eine zweite auf dem Territorium des OstrinskijDorfsowjets, Vasilišskij Rajon. Auf dem Territorium des Skidel'skij Rajons gab es 6 Gruppen, ingesamt 25 Mann stark; im Mai 1942 fand eine Konferenz statt, bei der alle Gruppenleiter und Delegierten der antifaschistischen Widerstands-Gruppen aus den Dörfern der Ščučinskij, Vasilišskij und Skidel'skij Rajons anwesend waren.

Die Konferenz wählte vor allem ein Antifaschistisches Kreiskomitee zur Leitung der Kampf-, Diversions- und antifaschistischen Agitationsarbeit. Ins Komitee wurden gewählt:

Karpuchin - Komiteevorsitzender und Kommandeur der Diversionsgruppen; Ivanov, A. I. - stellvertretender Kommandeur der Diversionsgruppen;

Potapov, A. A. - Sekretär des Komitees, Stellvertreter für antifaschistische illegale Arbeit;

Gordejčik, B. I. und

Žukovskij, P. - Mitglieder des Komitees.

Dem gewählten Komitee wurde auf der Konferenz aufgetragen:

1. aus allen in den Wäldern lebenden Leuten Diversionskampfgruppen zu organisieren, Gruppenkommandeure zu ernennen und alle Maßnahmen zu ihrer Bewaffnung zu treffen;

2. Rajonparteikomitees zu organisieren (zu wählen) und das Netz der konspirativen Gruppen in den Dörfern zu erweitern;

3. die Herausgabe von Flugblättern zu organisieren und Verbindung mit der Roten 
Armee oder den Partisanenabteilungen, die Verbindung mit Moskau hatten, herzustellen.

Nach seiner Wahl entfaltete das Kreiskomitee eine aktive Tätigkeit. Bis zum 1. Juni 1942 wurden fünf Diversionskampfgruppen organisiert:

Gruppe Nr. 1 Kommandeur Hauptfeld webel „Volga“

35 Pers.

Gruppe Nr. [2] Ivanov, A. I.

30 Pers.

Gruppe Nr. [3] Potapov, A. A.

28 Pers.

Gruppe Nr. [4] Taraščuk, D.

20 Pers.

Gruppe Nr. [5] Žukovskij, P.

12 Pers.

Von den 125 Personen, die die Gruppen umfaßten, waren 50 schon mit Gewehren bewaffnet, die der örtlichen Bevölkerung, Forstaufsehern, Dorfältesten usw. weggenommen worden waren.

Im Rahmen der antifaschistischen Arbeit wurden Rajonkonferenzen organisiert und durchgeführt, auf denen konspirative antifaschistische Rajonkomitees gewählt wurden und das Netz der antifaschistischen Gruppen bedeutend erweitert wurde. Im Juni wurden 3 antifaschistische Rajonkomitees gewählt und gingen an die $\mathrm{Ar}$ beit; sie vereinigten bis zu 35 einzelne illegale Gruppen, eine jede 3-6 Mann stark. Insgesamt zählte die antifaschistische Organisation bis zu 150 Personen; diese lebten in den Dörfern legal und führten Aufträge des Kreis- und des Rajonkomitees aus.

Beim Kreiskomitee wurde die Herausgabe von Flugblättern organisiert, sie waren handgeschrieben oder getippt. In den Flugblättern wurde die Bevölkerung aufgerufen, alle Maßnahmen der deutschen Behörden zu sabotieren: nicht nach Deutschland zu fahren, in die Wälder zu gehen und den Partisanen Hilfe zu leisten. Im Juni und Juli wurde auf Befehl des Kreiskomitees eine Reihe von Kampfoperationen durchgeführt.

Hervorgehoben sei der Überfall auf die Ortschaft [...], Skidel'skij Rajon: An der Operation waren 50 bewaffnete Personen beteiligt. Die Gmina (Dorfverwaltung) wurde zerstört, alle Gmina-Dokumente wurden vernichtet, die Geldkasse wurde beschlagnahmt, die von den Deutschen Verhafteten aus dem Gefängnis entlassen. Die Deutschen nahmen in einem Steingebäude Deckung, und es gelang nicht, sie gänzlich zu vertreiben. Die Partisanen zogen sich zurück, sie verloren einen Mann. Außerdem wurde ein Überfall auf die deutsche Grenzwache in Kobravcy, Vasilišskij Rajon, unternommen, er endete mit gegenseitigem Beschuß und blieb ohne Resultate. In derselben Zeit wurden mehrere Milchverarbeitungsbetriebe und Gemeindeämter zerstört, die nach der Zerschlagung ihre Tätigkeit aufgaben oder in größere Orte unter den Schutz der deutschen Garnisonen zogen. Nach mehreren Kampfoperationen wurde vielen Partisanen, besonders den Kommandeuren klar, daß es sehr schwer ist, erfolgreich gegen den Feind tief in seinem Hinterland zu kämpfen, wenn man keine Verbindung mit Moskau hat, keine zusätzlichen Waffen und besonders keine Munition erhält. Diese Schwierigkeiten waren um so größer, als unsere Organisation am westlichsten lag und auf dem Territorium des sogenannten Žeša (Deutschland) ${ }^{24}$ agierte, wo die Deutschen alle Gesetze einführten, die in Deutschland selbst in Kraft waren, und besonders gegen die Entwicklung der Parti-

24 Žeša = polnisch Rzesza, das Reich. Gemeint sind die vom Dritten Reich unmittelbar annektierten und an Ostpreußen angegliederten Gebiete um Bialystok. 
sanenbewegung auf diesem Territorium kämpften. Deshalb wurde auf Beschluß des Kreiskomitees zur Herstellung der Verbindung mit der Front oder mit Partisanenabteilungen, die eine solche Verbindung schon hatten, im August 1942 eine Aufklärungsgruppe ostwärts entsandt. Sie bestand aus den 26 besten Partisanen, die mit den besten Waffen ausgestattet waren und vom Kommandeur der Partisanengruppen Karpuchin geführt wurden. Die Aufklärungsgruppe hatte den Auftrag, die Verbindung mit der Front herzustellen und zurückzukehren, aber diese Aufklärungsgruppe kehrte nicht zurück, und ihr Schicksal ist bis heute unbekannt.

Nach Karpuchins Weggehen wurde Leutnant A. I. Ivanov zum Kommandeur der Partisanengruppe.

Die Zeit von August bis Oktober 1942 zeichnete sich durch Massenrepressalien und Strafexpeditionen gegen die Partisanen und die örtliche Bevölkerung aus. Unter den Kampfoperationen dieser Zeit sei die massenhafte Vernichtung von Getreide in den ehemaligen Landgütern hingewiesen, die in den Besitz der Deutschen übergegangen waren. Diese Operation begann am 13. September 1942 um 22 Uhr; die Partisanengruppen und die konspirativen antifaschistischen Gruppen operierten gleichzeitig, das in Speichern und Mieten von 22 Besitzungen gelagerte Getreide wurde verbrannt. Verbrannt waren nach annähernden Berechnungen mindestens 1300 Tonnen Getreide in den Vasilišskij, Ščučinskij und Skidel'skij Rajons in der Oblast' Grodno. Nach der Vernichtung des Getreides traf in den Raum der Unterbringung der Partisanengruppen eine große Strafabteilung der Gestapo ein, es begannen Massenverhaftungen in der Zivilbevölkerung und die Verfolgungen der Partisanen.

In den Dörfern Konjuchi, Bondary, Strel'cy, Golovači, Sinij Kamen', Skidel'skij Rajon, und dem Dorf Sčenec, Rajon Vasiliškovskij, wurden Anfang Oktober in jedem Dorf je 20-30 Personen verhaftet und entweder erschossen oder nach Deutschland deportiert. Zugleich gelang es der Gestapo in der Nähe der Stadt Skidel' mit Hilfe örtlicher Spione, einige antifaschistische konspirative Gruppen auszumachen. Thre aktivsten Mitglieder, darunter 8 Komsomolzen, wurden von den Deutschen Anfang Oktober 1942 in der Stadt Skidel', Oblast' Grodno, öffentlich erhängt.

\section{Tätigkeit und Entstehung von Partisanengruppen im Radun'skij Rajon}

(Oktober 1941 bis einschl. Oktober 1942)

Bis Oktober 1942 hatte das Antifaschistische Kreiskomitee keine regelmäßige Verbindung mit den Gruppen Bud'ko und Osipenko, die sich im Radun'skij Rajon befanden. Eine regelmäßige Verbindung und die Zusammenarbeit mit diesen Gruppen wurden erst nach der zweiten antifaschistischen Kreiskonferenz vom 26. Oktober 1942 hergestellt. Initiatoren und Organisatoren der Partisanenbewegung im Radun'skij Rajon, Oblast' Baranoviči, waren Soldaten und Kommandeure der Roten Armee, die aus dem Kessel ausgebrochen oder aus der Gefangenschaft geflohen waren und in die Wälder kamen. Zuerst unternahmen sie keine Kampfhandlungen, weil viele unbewaffnet waren und zudem nicht untereinander in Verbindung standen. Die belorussische Bevölkerung der Dörfer in der Umgebung der Pušča half ihnen mit Lebensmitteln und Kleidung, zeigte ihnen als Verstecke geeignete sichere Stellen im Wald. Der Kommunist und RKKA-Politruk Ivan Ivanovič Osipenko und seine Genossen, der Politleiter Filip Anisimovič Romanenko und Leutnant Petr Charitonovič Podkolzin, waren aus einem Kessel in Westlitauen ausgebrochen und schlugen sich durch Wälder und Sümpfe bis zur Russkaja Pušča, einem Wald- 
massiv an der Grenze des Radun'skij und des Vasiliškovskij Rajons zur LSSR, durch. Hier trafen sie auf weitere Soldaten und Kommandeure, darunter den Sergeanten Il'ja Israilevič Grejs sowie örtliche Sowjetangestellte und Aktivisten, die sich vor den blutrünstigen Hitlerleuten versteckt hielten, und beschlossen, hier zu überwintern. Herz und Seele dieser Gruppe war I. I. Osipenko. Kühn und energisch, ein wahrer Bolschewik, glaubte er nicht an die deutschen Lügen und sagte seinen Genossen immer wieder: „Wir werden trotzdem siegen.“ Die Jungen gruben Erdhütten im tiefen Wald aus, schleppten Lebensmittel auf den Schultern heran und bereiteten sich auf den Winter vor. Ihre Bewaffnung bestand aus einigen Gewehren und Pistolen. Osipenko stellte immer breitere Kontakte mit der Bevölkerung her. Er setzte sich das Ziel, einen Rundfunkempfänger zu beschaffen sowie Waffen und Munition zu sammeln. Große Hilfe erwies ihm dabei der Aktivist Konstantin Osipovič Bud'ko, ein Bauer aus dem Dorf Kolocevo, Dorfsowjet Zabolotskij, Radun'skij Rajon. Es wurden Funkbatterien beschafft, statt eines Akkumulators stellte Osipenko [galvanische] Elemente aus alten Batterien her, und zu ihrer großen Freude hörten sie die Stimme von Moskau! Sie berichtete über einen großen Sieg bei Moskau. Osipenko saß Tag und Nacht an einem selbstgebastelten kleinen Tisch in der Erdhütte, schnitt aus Gummi Buchstaben, die Buchstaben fügte er zu Wörtern und Sätzen zusammen, und als sie in hunderten Exemplaren gedruckt waren, brachten sie dem Volk freudige, ermunternde Nachrichten über das Heldentum und die Tapferkeit der sowjetischen Kämpfer. In seiner primitiven Druckerei druckte Osipenko Nachrichten des Sowjetischen Informbüros, Artikel aus Zeitungen, Flugblätter und Aufrufe an die Bevölkerung. Er brachte sogar zwei Ausgaben einer Partisanenzeitung heraus. All diese Ausgaben waren mit Karikaturen und Zeichnungen geschmückt, für die er aus weichem Weidenholz Klischees schnitt. Papierblätter mit der Aufschrift „Tod den deutschen Besatzern!“ gingen in den Dörfern von Hand zu Hand und erreichten schließlich auch die Kommandanten der deutschen Garnisonen. Sie erweckten in den Sowjetmenschen Freude und Hoffnung und alarmierten die Deutschen.

Anfang 1942, im Winter, schlossen die Deutschen Teile des Vasiliškovskij- und des Radun'skij Rajons an Deutschland an. Die Grenze verlief mitten durch die Pušča. In den Walddörfern brachten sie Garnisonen, in größeren Ortschaften Gendarmen unter. Die Deutschen beobachteten die Partisanen, es setzten Morde und Erschießungen von Menschen ein, die der Verbindungen mit den Partisanen verdächtigt wurden. Osipenko und seine Genossen wechselten in die sogenannte „Belarus“ über. Hier lebten sie in der Nähe des Guts Bud'ki, unweit des Dorfes Dubiči. Die Gruppe war streng konspirativ. Über ihren Aufenthaltsort waren nur wenige Verbindungsmänner informiert. Die Gruppenmitglieder bewaffneten sich und warteten auf das Frühjahr, unterdessen leisteten sie politische und Propagandaarbeit. Im April und Mai 1942, als die Massenmorde an den Juden in Ghettos begannen, kamen noch Hunderte Juden in den Wald, die vor den deutschen Henkern geflohen waren. In der Načinskaja-Pušča, im Wald von Dubiči und in anderen Wäldern bewaffneten und organisierten sich Gruppen von Juden. Sie beschlossen, gegen die Okkupanten mit der Waffe in der Hand zu kämpfen. Der Sommer 1942 war die Zeit der Aufstellung dieser Gruppen. Die Gruppe Osipenko hatte schon einige Kämpfe hinter sich. Es wurde eine große Brücke über den Fluß Ditva beim Dorf Myto (an der Chaussee Lida - Grodno) niedergebrannt, sie töteten auch viele Verräter (Konjuchovskij, den 
Stabschef der Geheimpolizei des Radun'skij Rajons). Gleichzeitig begann in der Načinskaja Pušča die Gruppe Saška (Evdokimov) zu operieren. Sie zerstörte die deutschen Gemeindeverwaltungen, Molkereien und liquidierte Spione. Aber außerdem machte sie sich der Plünderungen und der Gewaltanwendung schuldig. Das lag daran, daß in die Gruppe Banditenelemente eindrangen, frühere Kriminelle und Häftlinge, die vor dem Krieg beim Bau eines Flugplatzes in Nača und Gorodenka (Radun'skij Rajon) beschäftigt waren. Osipenko sah das und beschloß, die Gruppen zu vereinigen und auf den richtigen Weg zu lenken. Verhandlungen wurden geführt, und im Ergebnis kam es zu einer Spaltung. Einige Gruppen (die von Janoveckij, die von Konjuchovskij) gingen zu Osipenko über und passierten zusammen mit ihm die Grenze. Die Banditenelemente blieben in der Pušča, wo sie auch weiter ihr schmutziges Handwerk trieben. Sie waren ganz gut bewaffnet, hatten leichte Maschinengewehre und genügend Patronen. Die Gruppe Osipenko war ausschließlich mit Gewehren bewaffnet, je Gewehr hatten sie nicht über 20-30 Patronen. Trotzdem operierten diese Gruppen. Die Gruppe Konjuchovskij organisierte bei Radun einen Hinterhalt, bei dem ein Gendarmeriekommandant und mehrere Polizisten getötet wurden. Mehrmals wurden die Gleise zerstört. Züge zum Entgleisen zu bringen, gelang nicht, weil kein Sprengstoff da war. Die Gleise wurden mittels Granaten und eines daran befestigten Gewehrs gesprengt. Mit einem Strick zog der Sprengmeister den Abzug und löste durch den Schuß die Explosion aus. Doch die Stärke der Explosion war gering, es fehlte auch an Granaten. Außerdem zerstörte die Gruppe die Fernsprech- und die Telegrafieverbindung an den Chausseen. Das Anwachsen der Partisanenbewegung machte die Deutschen immer unsicherer. Sie verstärkten ihre Garnisonen, veranstalteten Razzien und Verhaftungen in den Dörfern. Vor den Partisanen stand die ernste Frage der Vorbereitung auf den Winter. Die Gruppen von Osipenko beschlossen, jenseits der Grenze, in der Pušča zu überwintern. Erdhütten wurden vorbereitet. Den ganzen Herbst 1942 über wurden Lebensmittel beschafft. Alle zogen in Betracht, daß man im Winter den Wald vielleicht nicht werde verlassen können. Auf dem Rücken schleppten die Partisanen die Verpflegung Dutzende Kilometer weit durch die versumpfte Gegend in den tiefsten Wald hinein. Man schuf Basen mit Vorräten für den ganzen Winter. Die Arbeit ging organisiert vor sich. Aber innerhalb der Gruppe kam es zu Streitereien. Nicht alle wollten sich Osipenko unterordnen. Im Sommer war Bud'ko zur „Gruppe der Russen“ übergegangen. Romanenko war ebenfalls in vielen Fragen nicht mit Osipenko einverstanden. Bei einer allgemeinen Versammlung der Gruppe wurde Osipenko zum Kommandeur gewählt, außerdem wurden Zug- und Unterabteilungskommandeure ernannt. Der Oktober nahte, eine umfangreiche Propagandaarbeit begann. Viele Flugblätter wurden herausgegeben, Versammlungen durchgeführt. Der Festtag (7. November) wurde feierlich begangen, es kamen Verbindungsleute aus den Dörfern und die örtlichen Aktivisten. $\mathrm{Zu}$ dieser Zeit traf auch eine Partisanengruppe aus der Zubrovskaja Pušča zur Herstellung der Verbindung ein.

\section{November 1942 bis einschl. März 1943}

Der Herbst 1942 brach an; trotz aller vom Kreiskomitee getroffenen Maßnahmen gelang es nicht, eine Verbindung mit der Front herzustellen. Die politische Lage im Hinterland war ungünstig. Die Deutschen waren im Sommer 1942 tief ins Sowjetland vorgedrungen. Die deutsche Propagada rief lauthals die völlige Zerschlagung 
der Roten Armee und das baldige Kriegsende aus und rief alle Menschen in den Wäldern auf, den Wald zu verlassen und sich den deutschen Behörden zu ergeben. In dieser Situation fanden sich in den Partisanengruppen nicht wenig Leute, die der Meinung waren, daß man im Wald nicht überwintern könne, daß „die Deutschen alle abfangen" würden. Die einen sagten, man müsse ostwärts gehen und die Frontlinie überqueren, andere meinten, man müsse sich den Deutschen ergeben, und wieder andere sagten, man sei sowieso ausgeliefert. Deshalb tranken sie Wodka und plünderten die Bevölkerung aus. Um mit der Zersetzung der Partisanengruppen Schluß zu machen, beschloß das Antifaschistische Kreiskomitee, unverzüglich eine Konferenz einzuberufen, um eine provisorische Partisanendienstvorschrift zu erörtern und anzunehmen, einen entschlossenen Kampf gegen die Verletzer der Partisanendisziplin zu führen sowie die Frage der Vorbereitung auf den Winter zu erörtern und den Rechenschaftsbericht des Komitees über die in der vergangenen Periode geleistete Arbeit entgegenzunehmen.

Die Konferenz fand am 26. Oktober 1942 statt. Sie erörterte die provisorische Partisanenvorschrift, nahm sie an und forderte alle Kommandeure der Partisanengruppen auf, einen entschlossenen Kampf, bis hin zur Erschießung, gegen alle Trinker, Marodeure und Deserteure zu führen. In Anbetracht der zahlreichen deutschen Garnisonen im Partisanengebiet schlug die Konferenz vor, eine sorgfältige Vorbereitung auf den Winter durchzuführen, Lebensmittelvorräte für den ganzen Winter anzulegen sowie für strenge Tarnung und Geheimhaltung zu sorgen. Nach der Konferenz wurden einige Leute, korrupte Elemente, deren einzige Beschäftigung das Marodieren war, erschossen, 22 Personen lehnten die Beschlüsse der Konferenz ab, desertierten aus den Partisanengruppen und verließen unseren Operationsraum. Es blieben die besten Leute, die trotz aller Schwierigkeiten beschlossen, den Kampf gegen die deutschen Besatzer in den alten Rajons fortzuführen. Auf dieser Konferenz waren, im Unterschied zur ersten, Delegierte der Partisanengruppen des Rajons Radun'skij anwesend, und sie stimmten den Beschlüssen der Konferenz zu. Zur Realisierung dieser Beschlüsse entsandte das Kreiskomitee fünf der besten Partisanen mit Gen. Ionko an der Spitze zu ihnen. Um diese Zeit gab es im Radun'skij Rajon 5 Partisanengruppen, sie waren insgesamt 80 Mann stark. Von diesen Gruppen waren drei ausschließlich jüdisch. Als der Winter kam und der erste Schnee fiel, trafen deutsche Spezialabteilungen für Partisanenbekämpfung ein. Der Bevölkerung war es verboten, in den Wald zu gehen oder zu fahren. In den Wald gingen nur die Deutschen mit Hunden und suchten nach den Erdhütten der Partisanen. Es gelang den Deutschen, mit Dazutun örtlicher Spione unter den Forstaufsehern, die Gruppe Nr. 5 von Žukovskij im Baranicha-Wald bei der Ortschaft Ostrino, Vasiliškovskij Rajon, zu finden; von den 5 Personen konnte sich nur einer retten. Ferner machten sie die neuorganisierte Gruppe Andrej „Chochol“ beim Dorf Novaja Ruda, Skidel'skij Rajon, aus. Von den 5 Mann dieser Gruppe rettete sich nur Andrej „Chochol“ (Ščerbina). Die Deutschen wußten nun, daß die Partisanen in kleinen Gruppen lebten und keine guten Waffen hatten; sie wurden nach den ersten Erfolgen frech und zogen in 15 bis 20 Mann starken Gruppen durch die Wälder. Im April 1942 stießen 12 Gestapoleute in der Zubrovskaja Pušča, im Forst Volči nory beim Dorf Kozliški, Vasiliškovskij Rajon, auf Partisanenerdhütten, in denen die Gruppen Jevdokimov, Grejs, Konjuchov und Ljubecki überwinterten. Die Deutschen hatten Angaben, daß darin nur 7 mit Stutzern bewaffnete Partisanen lebten, aber sie wurden von beinahe 50 mit Ge- 
wehren bewaffneten Partisanen umzingelt. Nach einem dreistündigen Gefecht wurden 8 Deutsche getötet, die übrigen warfen ihre Filzstiefel und Pelze hin und flohen. Am Tag darauf wichen die Partisanen zurück, während eine 150 Mann starke deutsche Strafabteilung das Dorf Kozliški in Brand steckte und bis zu 120 Zivilpersonen, darunter Kinder, alte Leute und Frauen, erschoß. Zur gleichen Zeit, Anfang Februar 1943, stieß die Gruppe Jevdokimov, die sich in die Dörfer zur Agitationsarbeit begab, beim Dorf Nača, Radun'skij Rajon, auf der Straße auf einen deutschen Polizeitrupp. Nach einem Gefecht wurden 9 von den 10 Polizisten getötet, nur der Polizeikommandant konnte, obwohl verwundet, fliehen. Die Partisanen hatten keine Verluste, obwohl die Kräfte gleich waren. Bis März 1943 sank die Stärke der Partisanengruppen, die sich in den Rajons Vasiliškovskij und Skidel'skij befanden, auf 70 Mann, dafür hatten sie sich von verbrecherischen Elementen gesäubert. Die Leute, die übriggeblieben waren, hatten sich in den Gefechten mit den Deutschen gestählt, gewöhnten sich an die Schwierigkeiten, lernten die Methoden des Partisanenkampfes und waren einig in ihrem Streben, auch unter Einsatz des eigenen Lebens gegen die Deutschen in deren Hinterland zu kämpfen.

In den Gruppen des Rajons Radun'skij hatte sich um diese Zeit ein Teil der kriminellen Elemente noch erhalten: ehemalige Häftlinge, die unter der Sowjetmacht auf dem Flugplatz in Nača gearbeitet hatten. Sie fuhren durch die Dörfer, soffen, vergewaltigten Frauen. Als der Politleiter Osipenko sie zur Ordnung rufen wollte, lockten sie ihn in einen Hinterhalt und töteten ihn. Die Anführer dieser Bande waren: „Mitka“, „Nikolaj“, „Ivan“, „Petka“, „Kolka“; später wurden sie sämtlich wegen Marodierens und Plünderungen von der Führung der Abteilung „Leninscher Komsomol" erschossen, mit Ausnahme von "Ivan“, dem es gelang, zu fliehen und bei reichen Polen unterzukommen.

\section{Organisation und Tätigkeit der Abteilung "Leninscher Komsomol“ (März - September 1943)}

Ende Februar 1943 traf am Quartier der Partisanengruppen eine von Gen Stankevič geleitete siebenköpfige Partisanengruppe aus der Abteilung „Rächer“ (Mstitel'), Brigade von "Onkel Vasja“ ein, der in der Oblast' Minsk, Begoml'skij Rajon, operierte. Die Gruppe hatte die Aufgabe, alle Partisanengruppen unserer Rajons geschlossen ostwärts zu bringen und in die Abteilung „Mstitel'“ einzugliedern. Alle Partisanen waren über die Ankunft der Gruppe Stankevič hoch erfreut, weil das die erste Gruppe aus einer Abteilung war, die schon mit dem Stab der Partisanenbewegung Verbindung hatte. Bei einer Beratung der Gruppenkommandeure und der Mitglieder des Kreiskomitees mit den Genossen, die gekommen waren, wurde beschlossen, aus den vorhandenen Gruppen eine Abteilung „Leninskij Komsomol“ zu organisieren. Das geschah denn auch am 17. März 1943. Zum Kommandeur wurde Gen. Stankevič gewählt (im März 1944 im Kampf gegen die Weißpolen gefallen), zum Kommissar Gen. Romanenko, zum Stabschef der Abteilung Gen. Ionko (in der Zubrovskaja Pušča aus einem deutschen Hinterhalt getötet), zum Leiter der Sonderabteilung Gen. Marusik (im März 1944 in einem Gefecht gegen die Weißpolen beim Dorf Bol'šie Berezovcy, Rajon Vasiliškovskij, gefallen), zum stellvertretenden Abteilungkommandeur Gen A. Ivanov. Im Mai war diese Führung vom Bevollmächtigten des Belorussischen Stabs der Partisanenbewegung und des ZK der $\mathrm{KP}(\mathrm{b}) \mathrm{B}$ für die Oblast' Baranoviči, Gen. Platon, bestätigt. 
Sofort nach der Aufstellung der Abteilung wurden eine Partei- und eine Komsomolorganisation gebildet. Zum Sekretär der Parteiorganisation wurde Gen. A. A. Potapov, zum Sekretär der Komsomolorganisation P. Tarasov gewählt. Zuerst lag die Abteilung in der Načinskaja Pušča, Radun'skij Rajon. Zur antifaschistischen Agitation in der örtlichen Bevölkerung und für die Leitung der Arbeit von Untergrund-Komitees im Vasiliškovskij Rajon blieb beim Dorf Karpanovcy eine spezielle fünfköpfige Gruppe unter Leitung von Gen. B. I. Gordejčik zurück. In erster Linie kämpften die Abteilungsleitung und die Parteiorganisation entschlossen für die $\mathrm{Fe}$ stigung der Disziplin in der Abteilung und für die Beseitigung von Suff und Marodieren. Zu diesem Ziel wurde systematisch politische Erziehungsarbeit unter den Partisanen geleistet und ihre Ausbildung im Militärwesen und in den Methoden des Partisanenkampfes gegen den Feind organisiert. Die Ergebnisse von Kampfoperationen bestätigten den Nutzen der Ausbildung. Zugleich wurde eine Aufklärungsgruppe in den Osten entsandt; sie stellte Verbindung mit dem Bevollmächtigten des Belorussischen Stabs der Partisanenbewegung und des ZK der KP(b)B für die Oblast' Baranoviči, Gen. Platon (heute Held der Sowjetunion Generalmajor Černyšev), her. Unsere Abteilung wurde in den Verband von Platon eingegliedert und erhielt ab April 1943 Aufträge von ihm, wenn auch nicht regelmäßig, weil wir von der Nalibockaja Pušča, wo sich der Stab des Genossen Platon befand, durch $180 \mathrm{~km}$ gefährlichen Weges getrennt waren. Die zur Festigung der Abteilung geleistete Arbeit zeitigte rasch Resultate, einen Monat später wuchs die Abteilung von 100 auf 170 Mann; ihr schlossen sich allmählich einzelne Gruppen, die durch die Wälder umherirrten, sowie frühere Rotarmisten, die aus deutschen Kriegsgefangenenlagern geflohen waren, an.

Die Parteiorganisation der Abteilung erstarkte schnell und verschaffte sich Autorität unter den zu ihr gehörenden Partisanen. Bei ihrer Entstehung zählte die Organisation 3 Parteimitglieder und 3 Kandidaten der Partei, im Mai 1943 aber schon 19 Personen; sie organisierte faktisch die Kämpfe und die politische Erziehungsarbeit unter den Partisanen und in der örtlichen Bevölkerung. Es stießen viele Leute zur Abteilung, aber an Waffen und Patronen mangelte es nach wie vor. Besonders akut war der Mangel an TNT und Munition. Im Durchschnitt gab es 15-20 rostige, unzuverlässige Patronen je Gewehr.

Bei dieser Munitionsmenge konnten keine größeren Kämpfe gegen die Deutschen durchgeführt werden, deshalb bekämpfte die Abteilungsführung vor allem die Verbindungen des Gegners. Es begann eine massive Vernichtung von Fernsprechverbindungsanlagen und ein Niederbrennen von Brücken. In einem Umkreis von 50-100 km sammelten wir herumliegende Geschosse und Bomben und schmolzen daraus TNT, damit gingen unsere Sprengmeister zur Eisenbahn, sprengten die Gleise und brachten die gegnerischen Züge zum Entgleisen. Die Tätigkeit der jungen Abteilung alarmierte die Deutschen. Anfang Juni 1943 zogen sie rd. 5000 Soldaten, 3 Kleinpanzer und 7 Flugzeuge zusammen, kreisten die Načinskaja Pušča ein und veranstalteten eine Razzia. Die Führung war vor der bevorstehenden Razzia gewarnt und schaffte es, die Abteilung nach jenseits der Grenze, nach „Žeša" 25 , in die Russkaja Pušča abzuziehen. In der Načinskaja Pušča blieb nur ein Zug als Deckung zurück, er brach aus der Einkreisung unter Kämpfen aus. Die Partisanen 
verloren einen Mann, zwei weitere gelten als verschollen, die Deutschen verloren 8 Mann. Die größten Opfer hatten aber die jüdischen Familienabteilungen, die in der Načinskaja Pušča lebten. Nach der Razzia verminderte sich die Munitionsmenge in der Abteilung beträchtlich.

Am 23. Juni 1943 wurde eine 11 Mann starke Gruppe unter dem Abteilungskommissar Gen. Romanenko ostwärts zum Gen. Platon entsandt. Sie hätte TNT und Waffen holen sollen. Aber die Gruppe geriet in eine starke Razzia und kehrte erst Ende August zurück. Sie brachte $35 \mathrm{~kg}$ TNT und 1500 Patronen mit. Außerdem empfing die Aufklärung den Beschluß des Untergrund-Parteikomitees der KP(b)B der Oblast' Baranoviči, der das Untergrund-Parteikomitee der KP(b)B des Rajons Vasilišk kovskij bestätigte. Das Komitee setzte sich aus den Genossen A. A. Potapov, F. A. Romanenko und B. I. Gordejčik zusammen. Während des Marsches ostwärts hatte sich der Abteilungskommissar Gen. Romanenko, der auch bis dahin nicht die erforderliche Autorität bei den Partisanen hatte, endgültig kompromittiert. Bei der von den Deutschen in der Nalibockaja Pušča durchgeführten Razzia und Blockierung zeigte er Feigheit vor dem Feind, riß sich die Dienstgradabzeichen des Politleiters ab, und alle faßten das als Vorbereitung dazu auf, sich dem Feind zu ergeben. Romanenkos Verhalten wurde in einer Parteiversammlung erörtert, die Kommunisten verurteilten ihn, erteilten ihm eine strenge Rüge mit Verwarnung und baten Gen. Platon, ihn vom Posten des Abteilungskommissars abzusetzen, was Gen. Platon auch tat. Statt Romanenkos wurde Gen. Potapov zum Abteilungskommissar ernannt und zum Sekretär Gen. N. A. Nagornyj gewählt. Bis zum September 1943 war die Abteilung bedeutend gewachsen und war 270 Mann stark. Da es in der Nähe der Pušča viele deutsche Garnisonen gab und im Umkreis von $100 \mathrm{~km}$ keine anderen Partisanenabteilungen operierten, war es sehr schwer, eine so hohe Anzahl von Menschen vor den Deutschen zu verbergen. Es war auch unmöglich, offen zu leben, weil die Deutschen jederzeit die erforderlichen Kräfte konzentrieren konnten, um eine solche Abteilung zu vernichten. Deshalb dezentralisierte die Abteilungsführung schon im Juni die Abteilung nach Zügen, und zwar so, daß die einzelnen Gruppen gleichzeitig in verschiedenen Rajons in einer Entfernung von $100-150 \mathrm{~km}$ voneinander agieren konnten.

Diese Art der Unterbringung leitete die Deutschen irre, sie konnten die Partisanenkräfte nicht schnell errechnen und mußten zur Partisanenbekämpfung ihre Kräfte zersplittern, und kleine deutsche Garnisonen waren für die Partisanen weniger gefährlich. Doch ebendiese Unterbringung der Abteilung, bei der der Stab 30-50 km von den Zügen entfernt war, erschwerte die Leitung der Züge und die operative Ausführung einzelner Aufträge. Deshalb wurde Anfang September 1943 bei einer erweiterten Sitzung des Untergrund-Rajonkomitees der $\mathrm{KP}(\mathrm{b}) \mathrm{B}$ beschlossen, die Abteilung in eine Brigade umzustrukturieren.

\section{Entstebung und Tätigkeit von weißpolnischen Banden}

Ab Juli 1943 kam zu den deutschen Kampfformationen verschiedener Nationalitäten, die gegen die Partisanen vorgingen, ein weiterer sehr starker und heimtückischer Feind der Parisanen hinzu: die Banden von Weißpolen. $\mathrm{Zu}$ Beginn der deutschen Okkupation bildeten sie weitverzweigte konspirative Organisationen in der polnischen Bevölkerung, kämpften jedoch nicht etwa gegen die Deutschen, sondern gegen die Partisanen. Hierbei wandten sie Provokationen an, griffen, als Deutsche 
oder als „russische Partisanen“ verkleidet, kleine Partisanengruppen an und gaben ihre Operationen in der örtlichen Bevölkerung als Kampf gegen das Bandenunwesen oder gegen die Juden aus. Ab Juli 1943 tauchten in den Rajons Radun'skij, Vasiliškovskij, Lidskij und Želudkovskij, Oblast' Baranoviči, Vertreter der Londoner Exilregierung auf. Sie trafen geheime Abmachungen mit Vertretern der deutschen Behörden in der Stadt Lida, beseitigten aus der polnischen Untergrund-Bewegung jene Leiter, die den Partisanen positiv gegenüberstanden und gegen die Deutschen kämpfen wollten, übertrugen die Leitung ehemaligen Gutsherren, Kolonisten und Polizisten. In ihrer Untergrund-Presse entfalteten sie eine wütende antisowjetische Agitation, stellten ganze Verbände aus den weißpolnischen Banden auf und begannen einen offenen Kampf gegen die Partisanen, wobei sie ihre Aktionen mit den Deutschen abstimmten. Ab Herbst 1943 operierten auf dem Territorium der oben genannten Rajons weißpolnische Verbände, so z.B. das Bataillon von Krisia [Krysia, B.M.], Panurno [Ponury, B.M.] und Ragner, bis zu 3000 Mann stark. Sie überfielen Partisanen, die zu Diversionen und Gefechten auszogen, veranstalteten Razzien in den Wäldern, in denen sich Partisanen befanden, ermordeten Verbindungsleute der Partisanen und steckten Gehöfte und Dörfer in Brand. So verbrannte eine weißpolnische Bande im März 194428 Gehöfte beim Dorf Bol'šie Berezovcy, Vasilišskovskij Rajon, und erschoß bis zu 30 Zivilpersonen. Unsere Brigade lieferte den Weißpolen allein binnen 10 Monaten mindestens 20 Gefechte. Sie töteten den Brigadekommandeur Stankevič, den Vertreter des illegalen Rajonkomitees der KP(b)B im Komitee der polnischen Patrioten Gen. Marusik und 40 Partisanen. Als Gegengewicht zur weißpolnischen Agitation und zur Zersetzung der weißpolnischen Banden wurde im März 1944 auf Empfehlung des vereinigten Rajonzentrums Ščučin und nach Beschluß des illegalen Parteikomitees der KP(b)B im Vasiliškovskij Rajon ein Vereinigtes antifaschistische Rajonkomitee der polnischen Patrioten gebildet, das eine breite Agitation in der polnischen Bevölkerung und sogar unter den polnischen Banden entfaltete. Im Ergebnis verließen viele von den polnischen Anführern betrogene Polen die weißpolnischen Verbände und zeigte ein Teil der Bevölkerung Unzufriedenheit mit den Operationen der weißpolnischen Banden, obwohl er diese früher unterstützte. Die Führung der Polen ließ nichts unversucht, um die polnischen Patrioten zu vernichten. Im Wald, wo sich das Komitee befand, wurden zwei Razzien durchgeführt, aber ihnen fiel nur Gen. Marusik zum Opfer.

\section{Organisation und Tätigkeit der Brigade September 1943 bis einschl. 12. Juli 1944}

Anfang September 1943 wurde die Abteilung „Leninskij Komsomol“ in die gleichnamige Brigade umorganisiert.

Der 1. und der 3. Zug bildeten die Abteilung „Kotovskij“, der 2. und der 4. Zug die Abteilung „A. Matrosov“. Zum Kommandeur der Kotovskij-Abteilung wurde A. Jevdokimov, zum Kommissar Gen. M. V. Michalev, zum Kommandeur der Matrosov-Abteilung Gen. A. I. Ivanov, zum Kommissar Gen. B. I. Gordejčik ernannt. Die Kotovskij-Abteilung war zuerst im Radun'skij Rajon beim Dorf Dubiči stationiert, wurde jedoch einen Monat später von den Weißpolen vertrieben und ging für den Winter in die Zubrovskaja Pušča beim Dorf Jakubovič, Vasiliškovskij Rajon, wo der Brigadestab und die Matrosov-Abteilung untergebracht waren, über. Die Umbildung der Abteilung in eine Brigade zeitigte rasch positive Resultate, die zah- 
lenmäßige Stärke wuchs, die Bewaffnung der Abteilungen verbesserte sich, ihre Manövrierfähigkeit und Beweglichkeit nahmen zu, vor allem aber aktivierte sich die Gefechts- und Diversionstätigkeit der Abteilungen. Im Herbst 1943 geriet unsere Brigade in eine außerordentlich schwere Lage. Die Deutschen legten um die $\mathrm{Zu}$ brovskaja und die Russkaja Pušča, in denen unsere Brigade stationiert war, ihre Garnisonen an, die jede Möglichkeit, den Wald zu verlassen, blockierten, während alle Wege, die über die Grenze in das so genannte „Belarus'“ in der Načinskaja Pušča führten, von den Weißpolen abgesperrt waren. Im Durchschnitt entfielen auf jeden Partisanen, der sich im Oktober in den Wäldern befand, mindestens 10 ständig in den Garnisonen um die Pušča lebende Deutsche und ungefähr ebensoviele Weißpolen, die im Radun'skij und im Vasiliškovskij Rajon jenseits von „Žeša “26, in Belorußland operierten. Diese schwere Lage verschlechterte sich noch mehr, als im November 1943 der Partisanenverband von Generalmajor Kapusta in der Zubrovskaja Pušča eintraf. Die Führung dieses Verbandes hörte damals nicht auf die Ratschläge unserer Brigadeführung, die empfahl, sich unbemerkbar für die Deutschen in den Raum der Zubrovskaja Pušča, in kleineren Gruppen von je 50-70 Mann zu bewegen, dort Stützpunkte zu bilden, sich festzusetzen und erst dann mit den Operationen zu beginnen. Aber der etwa 1500 Mann starke Verband samt einem großen Troß von 500 Fuhren mit Kanonen und Geschossen zog mit viel Lärm vor den Augen der Deutschen dahin. Noch in der Nacht, da der Verband ins Dorf Senki, Vasiliškovskij Rajon, kam, um dort zu übernachten, wurde er von den Deutschen eingeschlossen. Nach einem harten Gefecht konnte er am Morgen aus der Einkreisung ausbrechen und in die Zubrovskaja Pušča entkommen. Aber die Deutschen blieben den müden Partisanen auf den Fersen und jagten sie in der nächsten Nacht endgültig auseinander. Der Verband ließ den Troß, die Kanone, die Geschosse, TNT und anderes Material liegen und konnte nur dank der Hilfe von Begleitern aus unserer Brigade durch schwer passierbare Sümpfe aus der Einkreisung ausbrechen und in die Lipičanskaja Pušča jenseits des Neman zurückkehren. Nach dem Abzug von Generalmajor Kapusta durchkämmten die Deutschen die Wälder nach den dort zurückbleibenden Partisanen und sammelten die Beute. Unsere Abteilungen mußten Tag und Nacht in der Pušča manövrieren; dabei gab es in den Abteilungen viele kampfunfähige Leute. Die Führung mußte sich entscheiden: Es hieß, entweder diese Menschen zurückzulassen und in die Lipičanskaja Pušča jenseits des Neman zu ziehen, was Gen. Platon kategorisch verbot, oder die Abteilungen von überflüssigen Leuten zu befreien und so kampffähiger und mobiler zu machen. Man entschloß sich zur zweiten Variante. 70 unbewaffnete Männer, ferner Frauen und Halbwüchsige, meist waren das Juden, wurden in eine Partisanengegend nach jenseits des Neman entsandt und in die Befehlsgewalt des vereinigten Šcučinskij-Zentrums übergeben. Danach bezogen die Partisanenabteilungen Stellung in der Nähe der Partisanendörfer, nahmen die Kampf- und Diversionstätigkeit auf und beschafften sich zugleich Lebensmittel für den Winter bei den Bauern, die ihnen freiwillig halfen, wobei den Abteilungen die konspirativen antifaschistischen Komitees Beistand leisteten. Die Deutschen wußten nichts davon. Besonders aktiv halfen den Partisanen die Bewohner der Dörfer des Dorfsowjets Narašanskij, Vasiliškovskij Rajon, und das illegale antifaschistische Komitee unter Leitung der örtlichen Ge- 
nossen N. I. Šadura und I. Brykač. Die Abteilungen gruben in der Zubrovskaja Pušča Erdhütten aus, diese lagen auf kleinen Inseln mitten in den Sümpfen und waren $3 \mathrm{~km}$ vom Dorf Jakuboviči, Vasiliškovskij Rajon, entfernt. Dort wollten die Abteilungen überwintern. Dank einem schneelosen und warmen Winter wurde die Diversions- und Kampftätigkeit der Brigade nicht eingestellt, im Gegenteil, sie aktivierte sich, weil sich die Partisanen in beschränktem Umfang bewaffnet und sich $\mathrm{Pa}$ tronen sowie mehrere Dutzend Kilogramm TNT beschafft hatten, das der Verband von Gen. Kapusta zurückgelassen hatte.

In der Nacht zum 22. Januar 1944 schlossen bis zu 500 Deutsche überraschend das Dorf Zinjaki des Dorfsowjets Narašanskij, Vasiliškovskij Rajon ein, brannten das ganze Dorf und die Gehöfte dieses Dorfes zusammen mit den Bewohnern nieder. Hierbei verbrannten 416 Männer, Frauen, alte Leute und Kinder lebendigen Leibes. Später wurde bekannt, daß das Dorf, das den Partisanen alle mögliche Hilfe erwiesen hatte, von dessen Dorfschulzen verraten worden war. Außerdem konnten die Deutschen die Tatsache nicht vergessen, daß bei diesem Dorf das Gefecht mit dem Verband von Generalmajor Kapusta stattgefunden hatte und sie dabei geschlagen worden waren. Im Zusammenhang mit der Vernichtung des Dorfes Zinjaki gab das Untergrund-Rajonkomitee der $\mathrm{KP}(\mathrm{b}) \mathrm{B}$ einen speziellen Aufruf an die örtliche Bevölkerung heraus, der in den Dörfern aktiv verbreitet wurde. Die Vernichtung des Dorfes Zinjaki schüchterte die örtliche Bevölkerung entgegen den Erwartungen der Deutschen nicht ein, im Gegenteil, der Haß gegen die Deutschen verstärkte sich noch mehr und bildete einen Impuls zu einer noch größeren Erweiterung der Partisanenbewegung. Örtliche junge Männer kamen, um sich in die Partisanenabteilungen einzureihen. Deshalb wurde Ende Dezember auf Beschluß des illegalen Rajonkomitees der $\mathrm{KP}(\mathrm{b}) \mathrm{B}$ in der Brigade eine dritte Abteilung, „Für Sowjet-Belorußland", aufgestellt. Ihren Kern bildete eine Sondergruppe, die in den Wäldern des ehemaligen Fürsten Sapieha bei den Dörfern Spuša und Karaševo, Ščučinskij Rajon, untergebracht war. Zum Abteilungskommandeur wurde Gen. V. I. Primak, zum Kommissar Gen. I. G. Bubnov ernannt. Bis zum April wuchs diese Abteilung von 25 auf 100 Mann an. Der Abteilungskommandeur Gen. Primak konnte wegen seiner ungenügenden Bildung die Abteilung nicht leiten und wurde durch Gen. Danilov, einen energischen Leutnant mit Erfahrungen beim Partisanenkampf, ersetzt. Als sich diese Abteilung am 12. Juli 1944 mit der Roten Armee vereinigte, zählte sie 131 Partisanen, die ausschließlich auf Kosten des Feindes bewaffnet waren. Sie hatte sehr viele erfolgreiche Kampfoperationen durchgeführt und nahm den ersten Platz in der Brigade ein. Anfang Februar 1944 konnten die Deutschen die Winterlager der Matrosov- und der Kotovskij-Abteilung ausmachen, mehrmals versuchten sie, die Partisanen überraschend anzugreifen, aber diese beschossen sie jedesmal aus dem Hinterhalt. Als die Deutschen zur Vernichtung der Partisanen ihre Kräfte konzentrierten, zogen die Abteilungen zu anderen Orten. Mitte Februar wurden der Kommandeur und der Kommissar der Brigade zu einer Beratung bei Gen. Šupenja, Bevollmächtigter des Belorussischen Stabs der Partisanenbewegung und des ZK der $\mathrm{KP}(\mathrm{b}) \mathrm{B}$ für das vereinigte Rajonzentrum Šcučin, beordert. Sie mußten $70 \mathrm{~km} \mathrm{zu-}$ rücklegen, um ans andere Nemanufer zu kommen. Auf dem Rückweg machte die Brigadeführung in den Gehöften des Dorfes Bol'šie Berezovcy, in dem ein Zug der Matrosov-Abteilung lag, halt. Am Morgen des 15. Februar 1944 griff eine 150 Mann starke weißpolnische Bande diese Gehöfte an. Die Weißpolen setzten sich das Ziel, 
die Partisanen vom Wald abzuschneiden, die Gehöfte, in denen sich die Führung befand, einzuschließen und zu vernichten. Aber ihr Plan scheiterte, die Gruppe der Weißpolen, die die Partisanen hätte vom Wald abschneiden sollen, kam zu spät, und eine andere Gruppe, die sich durch ein offenes Feld bewegte, wurde aus der Ferne entdeckt. Die Partisanen zogen sich an den Waldrand zurück und nahmen den ungleichen Kampf auf, in dem der Brigadekommandeur Gen. Stankevič und sein Adjutant L. Kac fielen. Bei den Weißpolen wurden der Kommandeur der Einheit, der die Operation leitete, und 12 Gemeine getötet, 8 weitere Weißpolen verwundet. Nach dem Tod des Brigadekommandeurs Gen. Stankevič wurde Gen. A. A. Potapov zum Brigadekommandeur und Gen. B. I. Gordejčik, Kommissar der MatrosovAbteilung, zum Brigadekommissar ernannt. Gleichzeitig wurde Gen. Všivkov zum Stellvertreter des Brigadekommandeurs für Aufklärung ernannt und eine Umbildung der Arbeit der Brigade vorgenommen. Vor allem bekamen jetzt alle Abteilungen Monatsaufträge über Diversions- und Kampfoperationen, die Verstärkung und Bewaffnung der Abteilungen. Ferner ging man seitdem zu gleichzeitigen Diversionshandlungen aller Abteilungen an verschiedenen Orten über. Zum Beispiel: die gleichzeitige Zerstörung der Fernsprech- und der Telegrafieverbindung in allen anliegenden Rajons (Befehl Nr. 6 vom 31. März 1944), die gleichzeitige Vernichtung von Brücken (Befehl Nr. 15 vom 31. Mai 1944), gleichzeitige Hinterhalte, die den Hitlerleuten an verschiedenen Orten gelegt wurden.

Außerdem entfalteten das Diversionskomitee der $\mathrm{KP}(\mathrm{b}) \mathrm{B}$ und die Brigadeführung gemäß dem Beschluß des ZK der KP(b)B „Über die Erweiterung der Partisanenbewegung in Belorußland und Verstärkung der Schläge gegen die Verbindungswege im gegnerischen Hinterland" eine breite Agitations- und politische Arbeit unter den Partisanen und in der örtlichen Bevölkerung. Im Ergebnis aller getroffenen Maßnahmen erzielte die Brigade im Mai 1944 in der Kampf- und Diversionstätigkeit die Rekordergebnisse der ganzen Zeit ihres Bestehens. So wurden im Mai 100 neue Partisanen aus der örtlichen Jugend in die Brigade aufgenommen, 8 gegnerische Züge zum Entgleisen gebracht, 7 Gefechte gegen die Deutschen durchgeführt und dabei 147 Hitlerleute getötet.

Anfang Mai unternahmen die Deutschen ihre letzte Strafexpedition mit einer Razzia im Wald beim Dorf Karpanovcy, Vasiliškovskij Rajon. Bei dieser Razzia wurden Gen. N. L. Nagornyj, Stabschef der Brigade und Sekretär der Parteiorganisation der Matrosov-Abteilung, und Gen. V. Trojan, Schreiber des Brigadestabs, in einen Hinterhalt gelockt und getötet.

Die Deutschen, denen die Partisanen empfindliche Schläge versetzt hatten, bekamen Angst, bauten große Befestigungen in den Ortschaften, in denen sie lagen, und tauchten in den Wäldern bis zum Anrücken der Roten Armee nicht mehr auf. Zwischen Mai bis zum 12. Juli, d.h. bis zur Vereinigung mit der Roten Armee, verlief die Kampf- und Diversionsarbeit erfolgreich. Zahlreiche Jugendliche schlossen sich den Partisanen an, aber es herrschte ein akuter Mangel an Waffen und TNT. Die wiederholten Forderungen der Brigadeführung an den Belorussischen Stab der Partisanenbewegung, mit einem Flugzeug Waffen und TNT zu schicken, blieben unbeachtet. Zugleich hatte die Gruppe von Hauptmann Davydov, die im Gebiet der Brigade operierte, ihr eigenes tragbares Funkgerät hatte und den NKVD-Organen unterstellt war, zu viel TNT, so daß nach dem Anrücken der Roten Armee ganze $70 \mathrm{~kg}$ in der Erde vergrabenes TNT zurückgelassen werden mußten. Hauptmann Davy- 
dov, der diese Gruppe leitete, wohnte in einem prächtigen Seidenzelt, trank Schnaps und schickte Partisanen aus, die ihm süßes Gebäck und Butter beschafften. Über sein Funkgerät übermittelte er von unserer Brigade gesammelte Aufklärungsangaben, schrieb sie sich zu, ließ bis zu 20 Züge im Monat „entgleisen“, ohne kontrolliert zu haben, ob sie auch wirklich zum Entgleisen gebracht wurden, denn er zählte nur die Detonationen; zudem teilte er seinen Vorgesetzten von Zeit zu Zeit allerlei Klatsch über die Führung der Abteilungen und der Brigade mit. Das war auch schon die ganze Hilfe, die Hauptmann Davydovs (denn diesen Auftrag hatte er), der Brigade zu erweisen wußte.

Am 11. Juli 1944 begegnete die Brigade ohne besondere Vorkommnisse einem ersten Aufklärungstrupp der Roten Armee beim Dorf Jakubovič, Vasiliškovskij Rajon, Oblast' Grodno.

Am 12. Juli besetzten die Abteilungen der Brigade den Ort Ostrino und gingen daran, unter Leitung des Untergrund-Rajonskomitees der KP(b)B die Sowjetmacht wiederherzustellen. Die meisten Kommandeure und viele Partisanen sind bis heute in den Sowjet-, Partei- und Versorgungsorganisationen des Rajons tätig.

Kommission für die Beschreibung der Geschichte der Brigade:
1. Brigadekommandeur
(Potapov)
2. Brigadekommissar
(Gordejčik)
3. Stabschef
4. Kommandeur der Matrosov-Abteilung
(Onuprienko)
5. Kommissar der Kotovskij-Abteilung
(Ivanov)
6. Gehilfe des Stabschefs der Brigade
(Michalev)
(Morgolis)

F. 3500, op. 4, d. 261, 11. 135-165.

\section{Dokument Nr. 16}

\section{Entstehungsgeschichte der Abteilungen der Brigade „Pervomajskaja“ \\ Entstehung von Abteilungen, die sich zur Partisanenbrigade "Pervomajskaja“ zusammenschlossen}

I. $[\ldots]^{27}$

1. Die deutschen Besatzer besetzten diese Rajons kampflos.

Die Bevölkerung ist den Deutschen feindlich gesonnen, aber in den ersten Kriegsjahren war sie ganz von den deutschen Lügen abhängig. Die sowjetischen Aktivisten wohnten weiter in ihren Häusern, verbargen sich jedoch, sobald die Deutschen oder Polizisten kamen. Die ehemaligen Kulaken und einzelne Verräter nahmen den Dienst bei den Okkupanten auf. Sie halfen den Deutschen, Sowjetmenschen zu fangen und hinzurichten, und raubten deren Besitz. In diesen Rajons waren sehr viele Kommandeure und Politoffiziere sowie Rotarmisten zurückgeblieben, die aus der Gefangenschaft geflohen oder aus einer Einkreisung ausgebrochen waren.

27 Gekürzt: Beschreibung der Oblast', auf dem die Brigade hauptsächlich agierte: die Rajons Novomyš', Gorodišče und Kareliči. 
Die deutschen Garnisonen befanden sich an allen Eisenbahnknotenpunkten, d.h. in allen Rajonzentren, wie z. B. in Kareliči, Gorodišče, Novomys', aber auch in großen Dörfern wie Valevka, Kotlovo u.a.; außerdem trafen wenige Monate vor dem Anrücken der Roten Armee in den Rajons Novomyš’, Gorodišče und Kareliči über 10 Regimenter der Weißkosaken ein, die unter Anwendung der Partisanenkampfmethoden die Partisanen aus den Ortschaften zu vertreiben und so die Partisanen um ihre Lebensmittelbasis zu bringen suchten.

Die Weißkosaken halfen den Deutschen aktiv bei der Partisanenbekämpfung und beim Transport der Zivilbevölkerung in die deutsche Sklaverei. So wurde die Bevölkerung der Dörfer Cirin, Ostašino, Ljubaniči, Servač u.a. (im Kareličskij Rajon allein) vollzählig deportiert.

2. Organisation der Partisanenbrigade „Pervomajskaja“.

1942 gaben die Deutschen bekannt, daß sich alle in dieser Gegend lebenden Ostbelorussen zur Registrierung und Entsendung zur Arbeit in Deutschland zu melden hatten. Diese Nachricht durchflog sofort alle Ortschaften, besonders beunruhigt waren die Ostbelorussen. Die meisten von ihnen waren zwar registriert, weigerten sich jedoch selbstverständlich, nach Deutschland zur Arbeit zu fahren. Die Ostbelorussen versammelten sich gruppenweise, um die neue Situation zu erörtern. Den Ostbelorussen, die in den Ortschaften der Oblast' Baranoviči lebten, war klar, daß sie gefährdet waren. Viele von ihnen waren patriotisch gesinnt und beschlossen, lieber im Kampf für die Heimat zu sterben.

Michail Kamušev, ein junger Rotarmist, der im Dorf Ogorodniki, Gorodiščevskij Rajon, lebte, versammelte in seiner Freizeit seine Kameraden, sie beschafften sich Waffen, und er bereitete die Genossen allmählich auf einen offenen Kampf vor. Als bekannt gegeben wurde, daß alle zum Abtransport nach Deutschland in der polizeilichen Meldestelle erscheinen mußten, ging Kamušev zusammen mit seinen Kameraden zu den Partisanen. Um Kamušev, der sich Strel'kov nannte, gruppierten sich 10-12 Ostbelorussen, die mit Gewehren und MPis bewaffnet waren. Nachts zerstörten sie Molkereien und Gemeindeverwaltungen, töteten einzelne Verräter und griffen kleine Gruppen von Okkupanten und ihren Helfershelfern an.

Im weiteren gruppierten sich um Strel'kov erfahrene Kommandeure der Roten Armee aus Ostbelorußland; sie halfen dem wenig erfahrenen Strel'kov im Kampf gegen die deutschen Eindringlinge. In seine Abteilung kamen Flüchtlinge aus den Kriegsgefangenenlagern von Baranoviči und Lesnaja, einige von ihnen waren bewaffnet. Zur Abteilung stießen auch örtliche junge Leute, die sich an den verhaßten Besatzern für den Tod ihrer schuldlos ermordeten Angehörigen rächen wollten. Die Partisanen der Abteilung Strel'kov drangen verkleidet in die Stadt Baranoviči ein und verübten kleinere Diversionsakte. In Baranoviči verursachte das Unruhe, und $\mathrm{da}$ in der Abteilung Strel'kov die gebührende Kontrolle fehlte, schleuste man Spione ein, die den Auftrag hatten, das Anwachsen der Partisanenabteilungen zu verhindern, die jungen Leute durch provokatorisches Marodieren, den Mord an schuldlosen Menschen und Trinkerei gegen die örtliche Bevölkerung aufzuhetzen. Das Ziel war, zuerst die Führung und dann die ganze Abteilung zu vernichten. Über Verbindungsleute der Abteilung, die mehrmals nach Baranoviči gingen, lernte der Spion Vladimir Veg, Organisator einer Spionagegruppe in Baranoviči, die unter dem Aushängeschild „Verband der parteilosen Bol'ševiki“ wirkte, Strel'kov kennen. Strel'kov geriet in hohem Grade unter Vegs Einfluß. Im Ergebnis wurden 
13 schuldlose Ostbelorussen, die aus Kriegsgefangenenlagern geflohen waren, erschossen, nur weil sie Veg erkannten und der Abteilungsführung meldeten, daß er ein Spion war. Aus Angst vor Entlarvung fuhr Veg nach Baranoviči und beschaffte sich im SD falsche Dokumente. Bevor diese 13 Personen erschossen wurden, hatte Veg sie gefoltert, was er in der deutschen Gestapo gut gelernt hatte. Auf Vegs Anweisung gruben die Deutschen die verkohlten und verunstalteten Leichen aus und zeigten sie dann in den Lagern den Gefangenen, um ihnen Angst zu machen; dabei erklärten die Deutschen: Auf diese Weise empfangen die Banditen jene, die von uns $\mathrm{zu}$ ihnen fliehen. Um Strel'kov zu beeinflussen, verleumdete Veg die Partei- und Regierungsführung, außerdem schürte er in der Abteilung eifrig Judenhaß. Vor der Aufstellung der Brigade war Veg nicht nur nicht entlarvt worden, er schlich sich sogar in die Untergrundorganisationen der Oblast' ein. $\mathrm{Da}$ die Abteilung keinen Sprengstoff und auch keine erfahrenen Sprengmeister hatte, führten sie keine Sprengungen durch. Es kam vor, daß die Partisanen den Eisenbahnkörper oder die Verbindungsanlagen beschädigten. Sie operierten ausschließlich nachts, und tagsüber hielten sie sich in Verstecken in der Nähe der Gehöfte und tranken Schnaps.

Im Gorodiščenskij Rajon tauchte zu jener Zeit eine siebenköpfige Gruppe unter Führung von Boris Mičurin, der sich Groznyj [der Schreckliche-Anm. d. Übers.] nannte. Boris Groznyjs Stellvertreter Vas'ka Kosoj (im Kampf gefallen) wurde nicht nur von den Abteilungsmitgliedern, sondern auch von Boris Groznyj selbst gefürchtet. Wenn es keine Kämpfe gab, war Vas'ka Kosoj düster und soff Selbstgebrannten, der auf ihn keine Wirkung auszuüben schien. Ging Vas'ka Kosoj durch das Dorf, so knallte er alle Hunde nieder, die ihn anzubellen wagten. Es machte ihm nichts aus, auch einen schuldlosen Menschen zu töten. Vor allem die örtlichen Bewohner und jene Ostbelorussen, die der Abteilung noch nicht beigetreten waren, hatten Angst vor den Leuten von Groznyj. Die Ostbelorussen, die noch nicht der Abteilung angehörten, wurden von diesen Leuten erschossen. Es kam insbesondere vor, daß sie mit Orden ausgezeichnete RKKA-Kommandeure erschossen. Die Abteilung Groznyj operierte ebenso wie die Abteilung Strel'kov. Aus Baranoviči floh der Fahrer Markov mit einem Kameraden, sie ließen den Wagen auf der Straße stehen und gingen zu den Partisanen. Im weiteren bildete sich unter Markovs Leitung eine selbständige Gruppe, die sich Abteilung Markov nannte.

Im Kareličskij Rajon entstand eine Gruppe, die sich nach ihrem Leiter Abteilung Zolotov nannte. Zolotov fiel im Kampf. Später, nachdem Gromov getötet worden war, vor dem die Deutschen und die Polizei zitterten, trat Čumačenko an die Spitze dieser Gruppe. Gromov wurde von einem Partisanen getötet, den die GromovLeute später fingen und erschossen. Die restlichen Leute von Gromov schlossen sich mit den Zolotov-Leuten zusammen. Die Kommandeure dieser beiden Gruppen waren miteinander bekannt. Eines Tages trafen sie sich und beschlossen, die Gruppen zu vereinigen, aber aus dieser Vereinigung wurde nichts.

Im Winter 1942/43 erhielt die Führung der Lenin-Brigade, die in der Lipičanskaja Pušča stationiert war, Nachrichten, daß in diesen Rajons Partisanenabteilungen seien, und beschloß, sie sich zu unterstellen. Zu diesem Zweck fuhr Boris Bulat (der Einarmige) zu ihnen und schlug ihnen vor, sich in die Lenin-Brigade einzugliedern. Die Kommandeure wollten ihre Selbstständigkeit nicht verlieren und weigerten sich, aber Boris Bulat zeigte ihnen den fertigen Befehl mit der Forderung der sofortigen Unterordnung. So entstand die Abteilung "Groznyj" mit Boris Mičurin als 
Kommandeur. Ihr gehörten an: die Kompanie Strel'kov, 120 Mann stark, die Kompanie Markov, 60 Mann stark, die Kompanie Zolotov, 87 Mann stark, und die Kompanie „Groznyj“, 75 Mann stark.

Im Mai 1943 traf in der Lipičanskaja Pušča der Bevollmächtigte des Stabs der Partisanenbewegung Gen. Šupenja ein. Er berief alle Kommandeure der Abteilungen, die in dieser Pušča und den umliegenden Rajons operierten, zu einer Beratung ein. Der Beratung wohnten Boris "Groznyj", Zolotov, Čumačenko und Strel'kov bei. Bei dieser Beratung wurde festgestellt, daß auch die Eingliederung der Abteilung "Groznyj" in die Lenin-Brigade die Führung dieser Abteilung nicht besser machte, daß darin nicht einmal die nötige Ordnung geschaffen werden konnte.

Am 22. Mai 1943 erteilte Gen. Supenja den Befehl, auf der Grundlage der Abteilung "Groznyj" die Partisanenbrigade „Pervomajskaja“ aufzustellen. Zum Kommandeur der Partisanenbrigade „Pervomajskaja“ wurde der ehemalige Kommandeur der Moskauer Abteilung „Oktober" Gen. Naum Gavrilovič Kovalev, zum Brigadekommissar Hauptmann Deev, ehemaliger Kommissar der Abteilung „Iskra“, ernannt. Zum Stabschef der Brigade wurde Boris Mičurin, ehemaliger Kommandeur der Abteilung "Groznyj“, zum Stellvertreter des Brigadekommandeurs für Aufklärung Leutnant Smirnov ernannt.

Mit Gen. Šupenja wurde vereinbart, daß die ganze Abteilung „Oktober“ mit mir in diese Brigade einzugliedern war.

Folgende Abteilungen wurden aufgestellt:

1. Abteilung "Groznyj“

2. Kotovskij-Abteilung

3. Pervomajskaja-Abteilung

4. Suvorov-Abteilung
Kommandeur: Leutnant Kirin

Abteilungskommissar: Gen. Čertkov

Abteilungskommandeur: Gen. Markov

Abteilungskommissar: Gen. Levakov

Abteilungskommandeur: Gen. Čumačenko

Abteilungskommissar: Gen. Lopatskij

Abteilungskommandeur: Gen. Kamyšev, S. K.

Abteilungskommissar: Gen. Čelganov, F. V.

\section{Dislozierung der Abteilungen:}

Die Suvorov-Abteilung operierte von Baranoviči bis incl. Koldyčev und Slonim. Die Kotovskij-Abteilung: Molčad', Dvorec, Gorodišče, Jatra und Kobyl'niki.

Die Abteilung „Groznyj“: Dvorec - Novoel'naja - Ochonovo, Valevka.

Die Pervomajskaja-Abteilung: Kareliči - Ostašino, Cirin, Gorodišče, Valevka und Novogrudok.

Die Abteilung „Oktjabr'“: Svitjaz'-See, Valevka, Plužiny, Romany.

Im Mai wurde in dem Raum, in dem die Abteilung „Groznyj“ operierte, eine Razzia veranstaltet. Die Abteilung mußte aus diesem Raum in den Raum Žuravel'niki nördlich von Novogrudok weichen.

Nach der Aufstellung der Abteilung begab sich die Brigade am 28. Mai über Nikolaev zum Kroman'-See, wo sie im Lager am Fluß Černaja Halt machte. Am 1. Juni traf die Abteilung „Oktjabr"“ ein.

\section{Dienst der Gefechtssicherstellung}

Die Abteilungen der Pervomajskaja-Partisanenbrigade waren ständig in Ortschaften der Rajons Novomyš', Gorodišče und Kareliči untergebracht. In der Umge- 
bung all der Ansiedlungen, wo die Abteilungen disloziert waren, lagen Garnisonen des Gegners.

Die Abteilungen der Pervomajskaja-Brigade waren folgenderweise disloziert:

Die Abteilung „Oktjabr"“ und die Pervomajskaja-Abteilung: im Rajon Kareliči.

Die Abteilung "Groznyj“ und die Kotovskij-Abteilung: im Westen des Rajons Gorodišči.

Die Suvorov-Abteilung und später die Budennyj-Abteilung: im Rajon Novomyšski und im Südwesten des Rajons Gorodišči.

Die Führung der Abteilungen verfügte über ein gut entwickeltes Agentennetz, mit dem die Abteilungen und die Brigadeaufklärung ständig in Verbindung waren, und stellte aufgrund der Angaben der Aufklärung über die Lage der gegnerischen Garnison den Unterbringungsplan für jeweils fünf Tage auf. Die Verlegung der Abteilungen zum nächsten Quartier geschah wie folgt: Anhand der Angaben der Aufklärung über die Lage der gegnerischen Garnison setzte der Abteilungskommandeur die Ortschaft fest, in die die Abteilung am Abend, mit Anbruch der Dunkelheit ausziehen sollte. Mit Anbruch der Dunkelheit schickte der Abteilungskommandeur die Kavallerieaufklärung in die betreffende Ortschaft sowie die Aufklärung in die nahen Ortschaften aus. Nach der Aufklärung setzte sich die Abteilung in Marsch und zog unter Wahrung der Sicherheitsmaßnahmen zum festgesetzten Haltpunkt. Sehr oft begab sich die Abteilung zur Irreführung der deutschen Spione auf Umwegen zum Bestimmungsort. Nach der Unterbringung der Abteilung erarbeitete der stellvertretende Abteilungskommandeur für Aufklärung den Plan der Sicherung der Abteilung für die nächsten 24 Stunden. In Richtung der Garnisonen des Gegners wurde ein Aufklärungstrupp mit der Aufgabe ausgeschickt, unter Einbeziehung der Aufklärung die Lage in der Garnison ständig zu beobachten. Im Vorfeld der Ortschaft wurden Hinterhalte mit leichten Maschinengewehren angelegt, zusätzlich Trupps mit dem Auftrag ausgesandt, in die nächsten Ortschaften zu fahren und in den Aufenthaltsort der Abteilung mit entsprechenden Berichten zurückzukehren. Unverzüglich wurde Verbindung mit den benachbarten Partisanenabteilungen aufgenommen. Die örtlichen Partisanen hatten keine Angst vor den Garnisonen des Gegners, weil keine einzige davon genügend Kräfte hatte, um eine Partisanenabteilung selbständig zu überfallen. Wenn es solche Versuche auch gab, endeten sie für die Deutschen und die Polizei traurig. Im weiteren wagten sich die Garnisonen des Gegners ohne starke Unterstützung großer Einheiten aus ihren Befestigungen nicht heraus.

Waffen hatten wir von der örtlichen Bevölkerung, weil Belorussen und Polen während des Rückzuges der Roten Armee zurückgelassene Waffen und Munition eingesammelt und versteckt hatten. Die Partisanen erfuhren über ihre Agenten, die es in jeder Ortschaft gab, daß beispielsweise der Bauer N. ein Gewehr und Patronen versteckt hatte. Zum Bauern begaben sich der Abteilungkommandeur, der Kommissar oder, in den meisten Fällen, der Stellvertreter des Abteilungskommandeurs für Aufklärung. Es kam vor, daß man ein und dieselbe Person mehrmals aufsuchen mußte, bevor so ein Bauer sich entschloß, den Partisanen die Waffe abzugeben. Auch einfache Kämpfer beschafften sich Waffen. Die örtliche Jugend strebte danach, in eine Partisanenabteilung einzutreten. Um einen örtlichen Burschen in eine Abteilung aufzunehmen, mußte man ihn über unsere Agenten überprüfen, um zu wissen, was für einer er war. Sobald die Aufnahme beschlossen war, erhielt der Partisan den 
Auftrag, eine Waffe zu beschaffen. Wer eine Waffe hatte, wurde sofort in eine Partisanenabteilung aufgenommen.

Die zweite Waffenbeschaffungsquelle sind die Garnisonen des Gegners. Eine ganze Reihe von Polizisten suchten aus Angst, daß sie sich mit Einzug der Roten Armee zu verantworten haben würden, unter Lebensgefahr nach Kontakten mit einer Partisanenabteilung, um dort die Bescheinigung zu bekommen, daß sie den Partisanen geholfen hätten. Wir benutzten solche Fälle und stellten solchen Polizisten die Aufgabe, der Partisanenabteilung Waffen, Munition, Medikamente oder Angaben über die Lage in der Garnison zu liefern. Außerdem hatten die Partisanenabteilungen ihre bewährten Agenten in den Garnisonen des Gegners, und solche Agenten versorgten die Abteilungen mit Waffen und Munition. Die dritte und wichtigste Quelle waren Gefechte mit Polizisten und Deutschen außerhalb der Garnisonen des Gegners, die so genannten Beutewaffen. Die Partisanenabteilung und der Brigadestab beobachteten ständig die Garnisonen des Gegners, so beobachtete die Pervomajskaja-Brigade die Garnisonen in Kareliči, Šuchoviči, Valevka, Gorodišče, Novoel'naja, Molčad' und alle kleinen Garnisonen an der Bahnstrecke Lida - Baranoviči. Sobald wir Nachrichten hatten, daß eine Gruppe von Deutschen mit Polizisten aus ihrer Garnison auszog, meist um Lebensmittel zu beschaffen, wurden Partisanenabteilungen und manchmal auch eine ganze Brigade alarmiert und bewegten sich im Eilmarsch der gegnerischen Gruppierung entgegen, um ihr nicht nur die Lebensmittelbeschaffung zu vereiteln, sondern auch um im Gefecht Waffen zu erbeuten.

Wenn der Gegner lange Zeit seine Befestigungen nicht verließ, erfuhren wir über unsere Agenten die Parole, und eine Elitegruppe der Abteilung drang in die Stadt ein, beseitigte die Wachposten und entwaffnete Polizisten und "Selbstverteidiger" (siehe: Kampfhandlungen der Abteilungen).

Jeder Partisan hatte ein Gewehr Modell 1891, aber das galt als die schlechteste Waffe, ein jeder wollte sich einen Zehnlader oder eine MPi beschaffen. Besonders ging es den Partisanen um persönliche Waffen, um sich in kritischen Lagen eine $\mathrm{Ku}$ gel in den Kopf jagen zu können. Jeder Partisan strebte danach, 150-200 Patronen mitzuhaben, und trug trotz des beträchtlichen Gewichts diesen ganzen Vorrat mit sich.

Bei der Bevölkerung beschafft: Gewehre, Maschinenpistolen, Patronen, _ Stück persönliche Waffen. Beim Gegner erbeutet: 7 schwere und 22 leichte MGs, 3 Granatwerfer, 370 Gewehre, MPs und Pistolen, über $30000 \mathrm{~Pa}$ tronen.

\section{Der medizinische Dienst}

Seit Anfang Juni 1943 leitete der Brigadearzt Korpušin den medizinischen und Sanitätsdienst der Brigade. Die Brigade hatte ein Brigadelazarett, das über vollständiges chirurgisches und gynäkologisches Instrumentarium verfügte. Der Brigadechirurg war der Arzt Pupko, die zweite Ärztin des Lazaretts Gorbeleva, außerdem waren im Lazarett drei Krankenschwestern mit abgeschlossener medizinischer Fachschulbildung tätig. Die Pervomajskaja-Abteilung: die Ärztin Alkova. Die Suvorov-Abteilung: der Arzt Lubrajaneckij, die Abteilung "Groznyj“: der Arzt Zablodskij, die Abteilung „Oktjabr"“: der Feldscher Dolbik, die Kotovskij-Abteilung: der Arzt Bindel'. Jede Kompanie der Abteilungen hatte eine Krankenschwester. Die Ärzte und die Krankenschwestern hielten sich meist mit den Kampfgruppen im betreffen- 
den Rajon auf; sie betreuten die Partisanen, außerdem führten sie die hygienische Untersuchung des Rajons durch und behandelten örtliche Bewohner. Erforderlichenfalls fuhren ein Brigadearzt und ein Chirurg in die Rajons. Im Brigadelazarett wurden Operationen bis hin zur Laparotomie ausgeführt. Während der Blockade hielten sich die Ärzte und die Krankenschwestern in den Abteilungen auf. Die Verwundeten im Brigadelazarett mit dem Chirurgen und einer Krankenschwester befanden sich, gut getarnt, auf einer kleinen Insel und erlitten keine Verluste. Der Chirurg Gen. Dr. Pupko behandelte die chirurgischen Patienten der Kosakensonderabteilung, der Komsomol-Abteilung, der Zukov-Brigade, der Abteilung Nr. 106, der Kalinin-Abteilung. Außerdem fuhr er in die Čkalov-, die Dzeržinskij-, die Parchomenko-, die 1. Baranoviči-, die Suvorov-Brigade, die Brigade „25 Jahre BSSR “ und zu Partisanenfamilien. Die Gynäkologin Dr. Gorbeleva leistete denselben Abteilungen die entsprechende Hilfe. Im Januar 1944, nach der Aufgliederung der Brigade, trat der Arzt Pupko an die Spitze des medizinischen und Sanitätsdienstes. Die Pervomajskaja-Abteilung hatte zwei Ärzte: Dr. Alkova und Dr. Bindel'. In der Ždanov-Abteilung war der Arzt Kačajkin, in der Abteilung „Oktjabr“ der Feldscher Dolbik tätig. Jede Abteilung hatte ein Lazarett mit drei Stationen: einer chirurgischen, einer für die innere Medizin und einer für Infektionskranke. Jede Abteilung verfügte über eine Badeanlage und einen Quarantäneraum. Von den 220 chirurgischen und internistischen Kranken, die in den Lazaretten der Brigade und der Abteilungen behandelt wurden, starben nur drei. Alle 34 Typhuskranken wurden gesund gepflegt. In den Abteilungen trat kein Fleckentyphus auf, alle Kranken hatten sich außerhalb des Lagers angesteckt. Der einzige Diphtheriekranke wurde mittels Diphtherieserums geheilt. Der einzige Scharlachfall nahm ein gutes Ende. Von den 60 Malariakranken des Jahres 1943 hatten nach der Behandlung mit Chinin, Akrichin oder Prochinin 1944 nur fünf Patienten Rückfälle. Folgende Operationen wurden vorgenommen: zwei Laporatomien, eine Pleurotomie, zwei Beinamputationen, eine Armamputation. Die Gesamtzahl der durchgeführten Operationen beträgt 97, nur ein Fall hatte einen letalen Ausgang (Verwundung der Bauchhöhle, Darmbeschädigung, der Eingriff konnte erst 20 Stunden nach der Verwundung erfolgen). Bei nur drei Operationen wurde die Vollnarkose mit Äther, bei allen übrigen die Lokalanästhesie mit Novokain vorgenommen. Das Instrumentarium und die Medikamente der Brigade stammten aus deutschen Lazaretten und Apotheken, meist wurden sie bei Gefechten erbeutet, zum Teil über zivile Verbindungsleute in Dörfern und Städten beschafft. Seit Februar 1944 erhält die Brigade zusätzlich Medikamente und Verbandzeug aus den Gütern, die Flugzeuge vom „Festland“ mit Fallschirmen abwerfen. Im selben Zeitraum wurden 11 Verwundete und Invaliden der Brigade auf das „Festland“ abtransportiert.

\section{Die Taktik der Partisanen}

Die Hauptaufgabe, die das Brigadekommando der Abteilung stellte, war das Sprengwesen. Eisenbahnzüge des Gegners zu sprengen, sie nicht bis zur Frontlinie fahren zu lassen: Das ist die Hauptaufgabe der Partisanenabteilungen. Die zweite der Abteilung gestellte Aufgabe war die Vernichtung von Brücken und der Kampf gegen die Garnisonen des Gegners. Die Führung der Partisanenabteilungen, die Partei- und Komsomolorganisationen konzentrierten ihre ganze Aufmerksamkeit darauf, Sprengstoff zu beschaffen, Sprengtrupps zu organisieren und sie zu Spreng- 
aktionen zu entsenden. Die Abteilungen führten ununterbrochene Aufklärungsarbeit zur Beschaffung von Sprengstoff durch. Etwa die Hälfte des aktiven Teils der Abteilung befaßte sich mit dieser Frage. Sobald ein Partisan sagte, er wisse, wo ein Geschoß liege, wurde ihm sofort eine Gruppe von Partisanen beigegeben, und sie begaben sich zum betreffenden Ort. Ein Sprengsatz muß 12-18 kg TNT enthalten, mit weniger galt die Sprengladung als ineffektiv. TNT wurde auch in den Garnisonen des Gegners beschaffen. In der Stadt Baranoviči z. B. bestand ein Artillerielager, und in einem Teil des Lagers lagen alte Geschosse und Fliegerbomben herum. Mit den Partisanenabteilungen in Verbindung stehende Halbwüchsige von 12 bis 14 Jahren erhielten den Auftrag, Geschosse im Lager zu stehlen und den Partisanenabteilungen zu übergeben. Gruppen von Partisanen kamen zu den Arsenalen, um Sprengstoff zu beschaffen. Hatte man ihn, so mußte man eine scharfe Mine montieren, weil die Züge Ende 1943 und 1944 nachts nicht verkehrten, und es war praktisch unmöglich, einen Zug mit einem vereinfachten Zünder mittels einer Schnur zu sprengen. Zudem hatten die Deutschen an allen Eisenbahnstrecken Befestigungen gebaut, so daß die dort aufgestellten schweren Maschinengewehre und Granatwerfer alle Zugänge zur Eisenbahn und zu den Gleisen selbst unter Beschuß halten konnten. Frühmorgens wurden die Strecken mit einem Hund abgegangen, die geringsten Anzeichen eines Gleisschadens genau geprüft.

Ein 7-12 Mann starker Sprengtrupp, der zur Eisenbahn entsandt wurde, hatte eine feste Zusammensetzung und seine bevorzugten Punkte bei der Diversionsarbeit an der Bahn. Besonders günstig für die Sprengung eines gegnerischen Zuges waren Unwetter, bei denen der Regen alle Spuren der Sprengmeister wegspülte. Der Verlust eines Sprengsatzes an der Bahn ist ein großes Mißgeschick für die Abteilung, und solche Fälle wurden streng untersucht. Sehr oft erreichte der Trupp die Bahn, bereitete alles für die Detonation vor, der Zug aber kam nicht. Man mußte also bisweilen zwei- bis dreimal zur Eisenbahn gehen, um einen Erfolg zu erzielen. Resultate waren der Beharrlichkeit zu verdanken. Bei einem Mißerfolg holte der Sprengtrupp den Sprengsatz heraus und entfernte sich von der Bahn, um sich in Sicherheit $\mathrm{zu}$ bringen und in der darauf folgenden Nacht seinen Versuch zu wiederholen. $[\ldots]^{28}$

\section{Die Kampftätigkeit der Pervomajskaja-Partisanenbrigade}

Die von den Sprengmeistern der Abteilung „Oktjabr“" geleiteten Sprengtrupps der Abteilungen erreichten Anfang Juni 1943 die Bahnstrecke Lida - Baranoviči. Seit dieser Zeit folgten praktisch eine Explosion auf die andere an der Eisenbahn. Jeder Trupp hatte seinen Bahnabschnitt, an dem er die Gleise verminte und die Telefonverbindung zerstörte.

Für die Frühjahrs- und Sommerzeit hatten die Trupps den Auftrag, mindestens 45 Züge des Gegners zu sprengen, und die Abteilungen der Pervomajskaja-Partisanenbrigade erfüllten diesen Auftrag. Die Chausseen von Baranoviči, Novogrudok und Stolbcy waren außer Betrieb, weil die Partisanen der Pervomajskaja-Brigade und anderer Abteilungen alle Brücken an diesen Straßen zerstört und darüber hinaus an den Straßen dort, wo sie durch den Wald führten, Baumsperren anlegt hatten. Deshalb mußte der Verkehr auf den übrig gebliebenen Chausseen, insbesondere auf

28 Gekürzt: Aktion Sprengung von Gleisanlagen am 13. Februar 1943. 
der Chaussee Novoel'naja - Novogrudok, abgewickelt werden. Am 12. Juni 1943 legte eine Kompanie der Abteilung "Groznyj" einen Hinterhalt an dieser Chaussee an. Der Kompanie wurde aus der Abteilung „Oktjabr" eine Gruppe mit einer Panzerfaust beigegeben. Um $8.15 \mathrm{Uhr}$ fuhr über die Chaussee eine Kfz-Kolonne mit Truppen und Deckung durch Panzerwagen. Ergebnis: ein Panzerwagen mit der Panzerfaust angeschossen und ein Kraftfahrzeug verbrannt. Die deutsche Kfz-Kolonne blieb stehen, die Deutschen versuchten, die Kompanie einzukreisen, aber die Partisanen zerstreuten sich ohne Verluste im Wald. Zwischen Novoel'naja und Novogrudok war im Juni und Juli 1943 eine Schmalspurbahn in Betrieb; [...] eine Lokomotive wurde an dieser Bahn zerstört, das Gleis teilweise abmontiert und von den Partisanen der Pervomajskaja-Brigade weggeschafft.

Im Juni 1943 nahm der Partisan der Pervomajskaja-Abteilung, Gen. Rassjukevič, über den „Selbstverteidiger“ A. I. Patuk Verbindung mit der Sicherung der Stadt Novogrudok auf. Am 13. Juni teilte dieser die Parole mit. Eine Gruppe von Partisanen der Pervomajskaja-Abteilung unter Führung des Politruks K. Levašov und Ostap Rassjukevičs drang in die Stadt Novogrudok ein, nahm die Posten fest, führte sie nach außerhalb der Stadt, ließ sie dort bewachen, kehrte nach Novogrudok zurück und besetzte das Wachgebäude, wo die Partisanen ein leichtes MG, 12 Gewehre, 2 Revolver, 6 Gewehre mit Patronen und 1500 Patronen erbeuteten. Außerdem nahmen sie alle schlafenden Wachen fest und beförderten sie zum Abteilungsstab. Insgesamt wurden 22 Personen gefangengenommen.

Infolge der aktiven Operationen der Partisanen der Pervomajskaja-Brigade an der Bahnstrecke Lida - Baranoviči verstärkten die Okkupanten ihre Garnisonen in Gorodišče, Novogrudok, Kareliči und an allen Gleisbunkern der Eisenbahn. Sie versuchten, die Brigade in ihrem Operationen einzukreisen und zu vernichten. Nachts zogen die Truppen aus den Garnisonen von Novogrudok, Kareliči, Gorodišče und Dvorec aus und rückten über mehrere Straßen dicht an das Quartier der Abteilungen heran. Das Brigadekommando hatte genaue Angaben über die Vorhaben und Operationen des Gegners und erteilte den Befehl, die Abteilungen zu den Hauptstützpunkten in der Pušča zurückzuführen. Im Operationsraum blieben Aufklärungsgruppen aus jeder Abteilung und die Sprengtrupps mit Sprengstoff. Nach einer Rast verließ die Brigade die Pušča und marschierte am 14. Juli 1943 in vollem Bestand in den Operationsraum. Sie übernachtete bei den Gehöften von Zanemon. Am Abend wurde bekannt, daß das ukrainische 57. Bataillon, das sich in Gorodišče befunden hatte, am Tage eingetroffen war, Velikaja Sloboda besetzte und so den Ausgang aus der Pušča versperrte. Es wurde beschlossen, zusammen mit der Kosakensonderabteilung das 57. Bataillon aus Velikaja Sloboda zu vertreiben. Zur Erarbeitung eines Operationsplans wurde für $10 \mathrm{Uhr}$ des 15. Juli eine Beratung angesetzt. Als sich aber die Abteilungskommandeure dem Stab der Kosakenabteilung näherten, wurde vom anderen Nemanufer ein Trommelfeuer aus Gewehren, MPs und Granatwerfern eröffnet. Die Brigade bezog die Verteidigungsstellung längs des Neman, und während des ganzen 15. Juli konnten die Deutschen den Übergang über den Neman nicht erzwingen und in die Pušča eindringen. Bei der Übersetzstelle über den Neman bei Dobryč schickten die Deutschen mehrere Panzerwagen vor, so daß die Verteidigung der Kosakenabteilung unter Trommelfeuer lag. Zur Vernichtung der Panzerwagen wurde aus der Abteilung „Oktjabr"“ eine Gruppe mit einer Panzerfaust vorgeschickt. Zwei Panzerwagen wurden angeschossen, die 
übrigen von den Deutschen hinter eine Anhöhe zurückgefahren. Am Abend stellte die Aufklärung fest, daß der Gegner die Kräfte in der Ortschaft Naliboki und den anliegenden Ortschaften sammelte.

Hätte der Gegner die Straße Naliboki - Kroman' - Zanemon genommen, so wäre die Gefahr einer Einkreisung entstanden. Das Brigadekommando beschloß, nachts die Abteilungen hinter den Kroman'-See zurückzuführen, wo die Abteilung „Groznyj“ den Auftrag erhielt, eine Verteidigungslinie längs des Kroman'-Sees aufzubauen, sich einzugraben und die Deutschen nicht zur Straße nach Budy durchzulassen, wo sich das Brigadelager befand. Der Abteilungskommandeur Oberleutnant Kirin führte den Befehl des Brigadekommandeurs nicht aus und ließ seine Abteilung in den Gehöften beim Kroman'-See Rast machen. Obwohl an der Chaussee vor den Gehöften eine Kompanie der Žukov-Brigade an der verbrannten Brücke im Hinterhalt lag, wurden die Gehöfte am Morgen von den Deutschen eingekreist, und nur dank der Wachsamkeit der Wachposten wurde die Abteilung noch rechtzeitig alarmiert. Sie drängte die Deutschen zurück und durchbrach die Einkreisung, wobei nur ein Partisan fiel. Die Deutschen verfolgten die Abteilung nicht bis zum Kroman'-See, vielmehr stellten sie die Chaussee schnell wieder her und gingen in Richtung Zanemon vor. Beim Verlassen von Zanemon hatte die Pervomajskaja-Brigade als Hilfe für die Kosakenabteilung die Suvorov-Abteilung dagelassen, unter der Bedingung, daß die Abteilung, falls die Deutschen am Kroman'-See auftauchten, rechtzeitig darüber benachrichtigt werde. Aber die vom Abteilungskommandeur Kirin entsandten Verbindungsleute wurden von den Deutschen irregeführt und mußten Umwege machen und im Moor umherirren, ehe sie die Suvorov-Abteilung fanden. Deshalb erhielt der Kommandeur der Suvorov-Abteilung Levakov die Mitteilung nicht, daß die Deutschen seinen Waldabschnitt eingekreist hatten. Die Suvorov-Abteilung schlug alle Attacken des Gegners, der bei den Gehöften von Zanemon über den Neman übersetzen wollte, zurück, wurde jedoch überraschend von den Deutschen an der rechten Flanke angegriffen. Die Abteilungsführung mußte die Abteilung von der Verteidigungsstellung zurücknehmen, die Pferde dalassen und die Abteilung durchs Moor zum Quartier der Brigade bringen. Der Waldabschnitt Dobryč-Naliboki-Kroman'-See-Zanemon war der erste Kessel, den die deutschen Truppen säubern wollten.

Wir hatten keine Angaben der Aufklärung, weil die Verbindung mit den Rajons unterbrochen war. Der Gegner aber setzte die Chaussee Naliboki - Kroman' Ščrscy wieder instand, ließ seine Kolonnen über sie marschieren, versuchte jedoch nicht, tiefer in den Wald einzudringen. Das führte die Brigade irre.

Um 23 Uhr des 22. Juli 1943 passierten die Deutschen die Kanäle Želty - Neman und Šubino - Neman, beseitigten unsere Posten und beschossen uns aus Granatwerfern und Maschinengewehren. In dem Wald, in dem sich die Abteilungen der Pervomajskaja-Brigade aufhielten, befanden sich auch die Lager der Abteilung Zorin und der Abteilung Bel'skij. Das Lager war von Moor umgeben, wegen der Regenfälle stand das Wasser darin brusthoch. Die Annahme, daß die Deutschen diese Sümpfe nicht würden passieren können, erwies sich als Irrtum. Betrunkene Deutsche in speziellen Schutzanzügen zogen in Reihen durch das Moor. Das Brigadekommando mußte seine Abteilungen auf die Insel zurückführen. Dort wurden die Abteilungen in Gruppen in der Stärke von mindestens einem Zug aufgegliedert. Die Gruppen erhielten ihre speziellen Wegekarten, sie sollten die Einkreisung durchbre- 
chen und sich in den Operationsräumen sammeln, wo die Razzia zu dieser Zeit bereits zu Ende war. Die gehbehinderten Kranken und Verwundeten blieben an einem versteckten Ort unter der Aufsicht des Arztes Pupko; dorthin führte sie der zur Brigade gehörende Besitzer eines Gehöftes. Alle Gruppen konnten wohlbehalten aus der Umzingelung ausbrechen, einige von ihnen, die keine Rast im Walde machten, passierten rasch die Wassergrenze Bereza - Neman und verließen ohne Probleme den blockierten Naliboki-Wald in der Nähe der Gehöfte Žuravel'niki. Die Gruppen, die Rast machten, wurden erneut umzingelt, und mehrere Tage lang wanderten hungrige Partisanen durchs Moor, bis zum Gürtel im Wasser, von den Deutschen verfolgt, aber auch sie konnten aus der Einkreisung ausbrechen und den Operationsraum der Brigade erreichen.

Während der Razzia erlitt die Brigade folgende Verluste: 5 Personen getötet, $4 \mathrm{im}$ Neman versunken, 3 verwundet, 12 wurden von den Deutschen gefangen genommen bzw. sind zu den Deutschen übergelaufen - es handelte sich hierbei um die in der Stadt Novogrudok gefangen genommenen „Selbstverteidiger“. Die Abteilung „Oktjabr'“ befand sich während der Razzia bei den Gehöften Žuravel'niki, genauer, es befand sich dort nur der Abteilungsstab und der Versorgungszug. Alle Sprengtrupps dagegen, wie auch die anderer Abteilungen, führten ihren Auftrag aus, Militärzüge zu sprengen. Die Deutschen schrieben in ihren Zeitungen, daß die Partisanen vernichtet und in großer Zahl gefangen genommen worden seien, sie verbreiteten auch Flugblätter dieses Inhalts. Als die Brigade in den ihr zugeteilten Rajons auftauchte, war die Bevölkerung erstaunt, viele kamen aus kilometerweit entfernten Orten her, um mit eigenen Augen zu sehen, daß die Partisanen am Leben und wohlauf waren.

In der Brigade wurde für die Disziplin der Kämpfer und Kommandeure gesorgt, die vereinzelten Fälle des Marodierens wurden schonungslos ausgemerzt, die Marodeure erschossen; das Saufen und grobes Verhalten gingen merklich zurück. Man traf Maßnahmen gegen die heimlichen Branntweinbrenner. Täglich wurde unter den Partisanen und örtlichen Bewohnern politische Arbeit geleistet sowie viel dazu getan, Berichte des Sowjetischen Informbüros und illegale Zeitungen der Rajonparteikomitees zu verbreiten.

\section{Diversionsakte in den Städten}

In der Stadt Baranoviči war die Suvorov-Partisanenabteilung aktiv, die auf den Rajon Novomyšski oder auf den Südwesten des Rajons Gorodišči gestützt war. In Baranoviči wurde eine antifaschistische Gruppe organisiert, die bis zu 50 Mitglieder zählte, außerdem gab es in der Abteilung Partisanen, die Baranoviči gut kannten und unter den Deutschen in der Stadt gearbeitet hatten. Aus diesen Partisanen wurden mehrere 2-3 Mann starke Gruppen gebildet, deren Aufgabe die Diversionsarbeit in Baranoviči und an der Eisenbahn war.

Am 21. Oktober 1943 verübte eine Gruppe von Partisanen aus der Suvorov-Abteilung einen Anschlag im Treibstofflager, in dem eine englische Mine mit Uhrwerkzünder und dazu sie verstärkende zusätzliche TNT-Sprengkörper gelegt wurden. Bei der Detonation verbrannten 5 Tanks mit 250 Tonnen Petroleum und 2 Tanks mit 100 Tonnen Benzin.

Am 9. November 1943 steckte eine Gruppe von Partisanen der Suvorov-Abteilung eine Elektrowerkstatt in der Kaljaev-Straße von Baranoviči in Brand; auch dort 
wurde eine englische Mine mit Uhrwerkzünder und einem zusätzlichen TNTSprengkörper gelegt. Am 30. November 1943 sprengte eine Gruppe von Partisanen der Suvorov-Abteilung mittels einer englischen Mine und eines zusätzlichen TNTSprengkörpers eine Großgarage in Baranoviči. Das Gebäude der Garage und die gesamte Ausrüstung, $5 \mathrm{Kraftfahrzeuge} \mathrm{und} 25$ Fässer Benzin, verbrannten.

Am 31. Januar drangen die Partisanen der Suvorov-Abteilung Anatolij Krištofik und Michail Nikitin am Abend in die Wohnung des stellvertretenden Bürgermeisters von Baranoviči ein, fesselten ihn und beförderten ihn lebend zum Brigadestab. Anfang Februar 1944 tauchte bei der Suvorov-Abteilung ein ROA-Offizier auf. Um zu prüfen, wozu dieser Offizier zu uns gekommen war, gaben wir ihm einen Koffer mit TNT und einer Verzögerungsmine mit. Der Offizier ging zum Zentralbahnhof von Baranoviči, in dem sich das Lazarett und die Kantine befanden, aß in der Kantine, ließ den Koffer stehen und verschwand. Ergebnis der Detonation waren 70 getötete und über 400 verwundete Hitlerleute.

Eine Gruppe von Partisanen der Pervomajskaja-Abteilung unter Führung des Kompaniechefs Rassjukevič drang in der Nacht zum 25. April 1944 nach einem 40-km-Marsch zu Pferde in die Stadt Novogrudok ein, beseitigte, da sie die Parole kannte, die Wachposten im SD-Gebäude und nahm 5 SS-Leute gefangen; der Rest flüchtete. Trotz des Alarms in der Stadt erbeuteten die Partisanen 1 schweres MG, 3 leichte MGs, 18 Gewehre, 2500 Patronen mit MG-Gurten und Trommelmagazinen und kehrten ohne Verluste in die Abteilung zurück.

Am 27. Mai unternahm eine 33 Mann starke Gruppe von Partisanen der Pervomajskaja-Abteilung unter Führung des Kompaniechefs Ostap Rassjukevič folgende Kampfoperation: Der Sprengtrupp der Pervomajskaja-Abteilung erfüllte unweit der Garnison des Bunkers, ein paar Kilometer von der Ortschaft Dvorec entfernt, den Auftrag, Militärzüge zu sprengen. Unter Vermittlung einer Frau, die den Bunker mit Milch versorgte, stellte der Sprengtrupp Kontakte mit dem russischen Teil des Bahnschutzes her, und die Russen erklärten sich bereit, zu den Partisanen überzugehen. Zur vereinbarten Zeit kreisten die Partisanen den Bunker ein und warteten auf das Signal zum Angriff. Im Bunker hätten 5 Wachen, die sich zum Übergang bereit erklärt hatten, wie vereinbart, dasein, die deutschen Wachen überwältigen und zu den Partisanen schleppen sollen, worauf die Partisanen mit ihnen zusammen in den Bunker hätten eindringen und die Deutschen töten sollen. Aller Wahrscheinlichkeit nach errieten die Deutschen die Absicht, denn in dieser Nacht wurden die Wachen durch Leute ersetzt, auf die die Deutschen eher vertrauen konnten. Zur festgesetzten Zeit kam das Signal nicht. Die Wachen sahen, daß sie entlarvt waren, gingen das Risiko ein, den Bunker zu verlassen, entwaffneten die Wachposten und wollten einen Deutschen ersticken, dann beschlossen sie, ihn lebend gefangen zu nehmen. Der von einem Schlag mit einer Flasche benommene Deutsche brach in Geschrei aus, beim Versuch, ihn zum Schweigen zu bringen, wurde ihm der Mund zerrissen. Beim Bunker begannen Panik und Schießerei, die Partisanen eilten zu Hilfe, das Gefecht im Bunker dauerte anderthalb Stunden, bis Verstärkung herbeikam. Die Partisanen erbeuteten ein schweres MG, 2 Gewehre, mehrere Patronengurte, nahmen 5 ukrainische Wachen, die zu uns übergehen wollten, mit und kehrten ohne Verluste zum Quartier der Abteilung zurück. 


\section{Der Schienenkrieg}

Dank den Anstrengungen des konspirativen Oblastzentrums unter Führung von Gen. Platon wurden im Naliboki-Wald mehrere versteckte Flugplätze angelegt, um Güter vom „Festland“ entgegenzunehmen. Von Gen. Platon kam die Direktive, den gesamten Bestand der Brigade auf den Schienenkrieg vorzubereiten. Vom Vereinigten Rajonzentrum Lida erhielten wir TNT und alle notwendigen Materialien für ein "Konzert", wie wir solche Operationen nannten. Die Brigade befand sich zu dieser Zeit in unmittelbarer Nähe der Bahn Lida - Baranoviči bei der Strecke Novoel'naja - Dvorec - Baranoviči. Die Brigade erhielt 688 TNT-Sprengkörper und spezielle TNT-Kugeln, hinzu kamen bis zu 700 Sprengkörper aus eigenen Vorräten. Bei der dreitägigen speziellen Unterweisung aller Partisanen im Sprengwesen wurde darauf geachtet, diese Vorbereitung auf den Schienenkrieg geheim zu halten. Nach einem im voraus aufgestellten Plan erhielten die Abteilungen Sprengstoff: die Abteilung „Oktjabr'“ für 100 Detonationen, die sie im Raum der Station Neman und der Station Ecuki vornehmen sollte; die Pervomajskaja-Abteilung Sprengstoff für 150 Detonationen bei den Stationen Ecuki und Novoel'naja; die Abteilung "Groznyj" für 150 Detonationen im Raum der Stationen Novoel'naja und Dvorec; die KotovskijAbteilung für 150 Detonationen im Raum der Station Dvorec und des Haltepunktes Mordiči; die Suvorov-Abteilung Sprengstoff für 155 Detonationen am Abschnitt vom Haltepunkt Mordiči bis zur Station Baranoviči.

Als Ablenkungsmanöver wurde eine Elitegruppe von Partisanen der Abteilung "Groznyj“ mit einer 45-mm-Kanone zur Station Novoel'naja vorgeschickt. Die Partisanen sollten die Wachposten des Lagers bei der Station Novoel'naja überwältigen und das Lager niederbrennen, darauf Feuer aus der Kanone eröffnen, um einen Partisanenangriff auf die Station Novoel'naja vorzutäuschen. Als den Partisanenabteilungen der Pervomajskaja-Brigade die Aufgabe gestellt wurde, den Schienenkrieg zu führen, rückten sie im vollen Bestand an die Ausgangslinie vor, wo jeder Kämpfer seine Teilgefechtsaufgabe erhielt. Die Operation sollte Punkt 3 Uhr früh am 21. September 1943 beginnen. Am Abschnitt der Abteilung "Groznyj“, an dem sich der Brigadekommandeur befand, bemerkten die Deutschen die heranrükkenden Partisanen und eröffneten Feuer aus Maschinengewehren und Minenwerfern. Trotz des Feuers des Gegners setzten die Partisanen ihre Arbeit fort und beendeten sie vorfristig. Um 2.50 Uhr wurde am Abschnitt der Abteilung "Groznyj“ Befehl erteilt, mit der Sprengung der Gleise zu beginnen, und wenige Minuten darauf folgten ununterbrochene Detonationen an der gesamten Strecke von der Station Neman bis Baranoviči. Trotz des pausenlosen gegnerischen Feuers von den Bunkern aus erreichten die Kontrolltrupps die Bahn und prüften die Ergebnisse der Detonationen. Die vorgefundenen TNT-Sprengkörper wurden zur Explosion gebracht. Die Abteilung „Oktjabr"“ stieß bei der Station Ecuki auf einen starken Hinterhalt und mußte weichen. Die Aufgabe, die Gleise zu sprengen, erfüllte die Abteilung in der Nacht zum 22. September. Während der Operation hatte die Brigade keine Verluste. Für abermalige Operationen an den Eisenbahnen zur Sprengung der Gleisanlagen erhielt die Brigade 405 TNT-Sprengkörper; die Abteilungen der Pervomajskaja-Brigade brachten sie an denselben Bahnabschnitten selbständig zur Explosion.

Der Schienenkrieg der Abteilung beeindruckte die örtlichen Bewohner in höchstem 
Maße, sie kamen aus den Häusern und luden die Partisanen nach der Operation ein, sich nach getaner Arbeit zu stärken. Die Bevölkerung glaubte nicht sofort, daß es sich um eine Partisanenaktion handelte, vielmehr dachten die Bewohner, daß Luftlandetruppen der Roten Armee abgesetzt worden seien und Artilleriefeuer eröffnet hätten.

Auf die Okkupanten und ihre Helfershelfer machte der Schienenkrieg einen deprimierenden Eindruck. Um den Gegner an der planmäßigen Wiederherstellung der Gleise zu hindern, schickte jede Abteilung der Pervomajskaja-Brigade täglich eine Gruppe von Scharfschützen vor. In der Morgendämmerung fanden sie günstige Stellungen in unmittelbarer Nähe der Gleise, dort, wo sie beschädigt waren. Beim Erscheinen der Instandsetzungstrupps eröffneten die Scharfschützen das Feuer auf den Bahnschutz und vereitelten so die Versuche der Deutschen, die Bahn möglichst schnell wieder instand zu setzen. Im Ergebnis war die Bahnstrecke Lida - Baranoviči nach dem ersten „Konzert“ über einen Monat lang außer Betrieb.

Im Juni 1944 ging vom Bevollmächtigten des Oblastzentrums Gen. Dubov die Verfügung über eine weitere Operation des Schienenkrieges ein. Zu dieser Zeit lag die Pervomajskaja-Brigade in der Pušča, weil sich im Operationsraum der Brigade Weißkosaken befanden. Deshalb bestand keine Möglichkeit, die Eisenbahn über den eigenen Rajon zu erreichen. Zur Erfüllung der Aufgabe, den Schienenkrieg zu entfalten, erhielten wir 700 TNT-Sprengkörper und -Kugeln und dazu 300 Zündkapseln. Die Brigade sammelte in den Abteilungen alle noch vorhandenen alten Vorräte zusammen und war somit im Stande, 560 Detonationen auszulösen. Zur Erfüllung der gestellten Aufgabe wurde der Kavallerieteil der Brigade gesammelt, er setzte sich in Richtung Kroman'-See - Dorf Bor in Bewegung, durchwatete die Furt über die Berezina und bewegte sich in Richtung auf Nikolaev, die Gehöfte Žuravel'niki und in den Raum der Stationen Neman und Ecuki. In der Nacht zum 25. Juni wurde die erste Operation zur Sprengung der Gleise, in der Nacht zum 26. eine zweite und zum 27. eine dritte ebensolche Operation durchgeführt.

Hierbei wurden 574 Gleise gesprengt. Während der Operation wurde ein Partisan schwer verwundet. Insgesamt sprengte die Brigade 1677 Gleise, die Anlagen, die beim Entgleisen der Züge gesprengt wurden, nicht mitgerechnet.

Der Partisan Ivan Ivanovič Dubovik aus der Abteilung "Oktjabr" befand sich in einem Gehöft beim Dorf Gezgaly, wo er mit Erlaubnis des Abteilungskommandeurs seine Frau aufsuchte. Am 31. Oktober 1943 kreisten ihn über 50 Hitlerleute ein und forderten ihn auf, sich lebend zu ergeben. Darauf eröffnete Dubovik Feuer aus seinem Karabiner. Die Deutschen bewarfen ihn mit Handgranaten, aber Dubovik fing sie im Flug auf und warf sie aus dem Fenster zurück. Auf diese Weise warf er 6 deutsche Granaten gegen die Deutschen.

\section{Hilfe des "Großen Festlandes"}

Beim Abschied aus Moskau führten die Sprengtrupps der Abteilung „Oktjabr"“ ein Funkgerät mit, das der Gruppe Il'inič beigegeben war. Da sie aber über die Frontlinie bis zu ihrem Bestimmungsort zu Fuß gingen, wurde das Funkgerät auf Beschluß des PIK der BSSR im Ausbildungszentrum zurückgelassen, und wir erhielten das Versprechen, daß es uns mit einem Flugzeug geliefert werde. Bis Mai 1943 hatten wir keine Möglichkeit, Verbindung mit dem Stab der Partisanenbewegung aufzunehmen, selbst nachdem wir Gruppen von Verbindungsleuten in die Moore 
bei Pinsk ausgeschickt hatten. Erst der von uns aus der Lipičanskaja-Pušča ausgeschickte Danovič fand im Mai 1943 das Funkgerät von Platon in dem NalibokiWald, und dorthin übermittelte die Brigade später alle Nachrichten. Neben den Materialien, die wir über das Oblastzentrum zur Durchführung von „Konzerten“ an der Eisenbahn erhielten, bekamen wir auch Patronen, TNT und Medikamente. Aber diese Hilfe war sehr gering, im Grunde keine nennenswerte Unterstützung für uns. So erhielten wir eine Kiste TNT oder eine Patronenkiste für je 7 Abteilungen. Nur in letzter Zeit erhielt die Brigade eine einmalige Lieferung von 5000 Patronen. An Waffen erhielten wir in dieser ganzen Zeit nur 4 MGs. Sehr bedeutend war die Hilfe beim Transport der schwer Verwundeten zum „Festland“, denn sie waren eine große Bürde für die Abteilungen. Als diese Kranken abtransportiert worden waren, atmeten alle erleichtert auf. Insgesamt wurden 14 Personen zum „Festland“ befördert. Die regelmäßige Verbindung mit dem „Festland“ war für uns von enormer Bedeutung. Mit dem Eintreffen von Vertretern des Stabes der Partisanenbewegung nahm die Arbeit in den Partisanenabteilungen einen ganz anderen Verlauf. Vor der Organisation der Brigade und der Ankunft von Vertretern des Oblastzentrums arbeitete man von Fall zu Fall, später aber ging die Arbeit ausschließlich nach Plan. Jedermann war bestrebt, bis Monatsende möglichst viel Züge zum Entgleisen gebracht oder Gefechte geführt zu haben.

\section{Die Lebens- und Wohnverhältnisse der Brigade}

Die Pervomajskaja-Brigade war in den Ortschaften des Novomyšskj- und des Rajons Kareliči untergebracht. Abends setzte der Brigadekommandeur meist fest, in welche Ortschaften die Abteilungen am nächsten Tag verlegt werden sollten. Hierbei wurde immer das Zusammenwirken der Abteilungen für den Fall eines gegnerischen Überraschungsangriffs berücksichtigt. Zwei Abteilungen lagen stets in unmittelbarer Nähe voneinander. Je nach der zahlenmäßigen Stärke der Truppen in den Garnisonen des Gegners hielten sich die Abteilungen 2-3 Tage in ein und derselben Ortschaft auf. Das Lazarett, die Kranken und Verwundeten befanden sich im Naliboki-Wald, wohin die Abteilungen nur im äußersten Fall fuhren. Mit der Verpflegung stand es gut, die Kämpfer verteilten sich je nach der Größe der Ortschaft auf die Häuser und wurden vom Hausbesitzer verpflegt; eine Ausnahme bildeten nur Fleisch und manchmal Brot. Mehl bekamen die Abteilungen von ihren Partisanenmühlen, denn die Deutschen und die Polizei wagten sich in die Rajons nicht hinaus. Den in den Rajons lebenden Familien der Polizisten wurde überflüssiger Roggen abgenommen und zu den Mühlen befördert, wo die Getreidebesitzer das Mahlen mit Mehl bezahlten. Das Vieh wurde den Polizistenfamilien und reichen Besitzern von 2-4 Kühen weggenommen. Bis Ende 1943 ernährten sich die Abteilungen hauptsächlich von Schweinefleisch, erst seit Ende 1943 aßen sie auch Schafsund Rindfleisch. Unter allen Bedingungen war das Essen bei den Partisanen nicht rationiert. Der große Fleischverbrauch wirkte sich auf die Gesundheit einiger Partisanen aus. Für jeden Partisanen gab es einen eisernen Bestand. Die Verwundeten hatten ihre besondere Kost. [... $]^{29}$

F. 3500, op. 4, d. 250, 11. 89-121.

${ }^{29}$ Gekürzt: Arbeit der Komsomolorganisationen der Pervomajskaja-Brigade. 